INTERNATIONAL MONETARY FUND
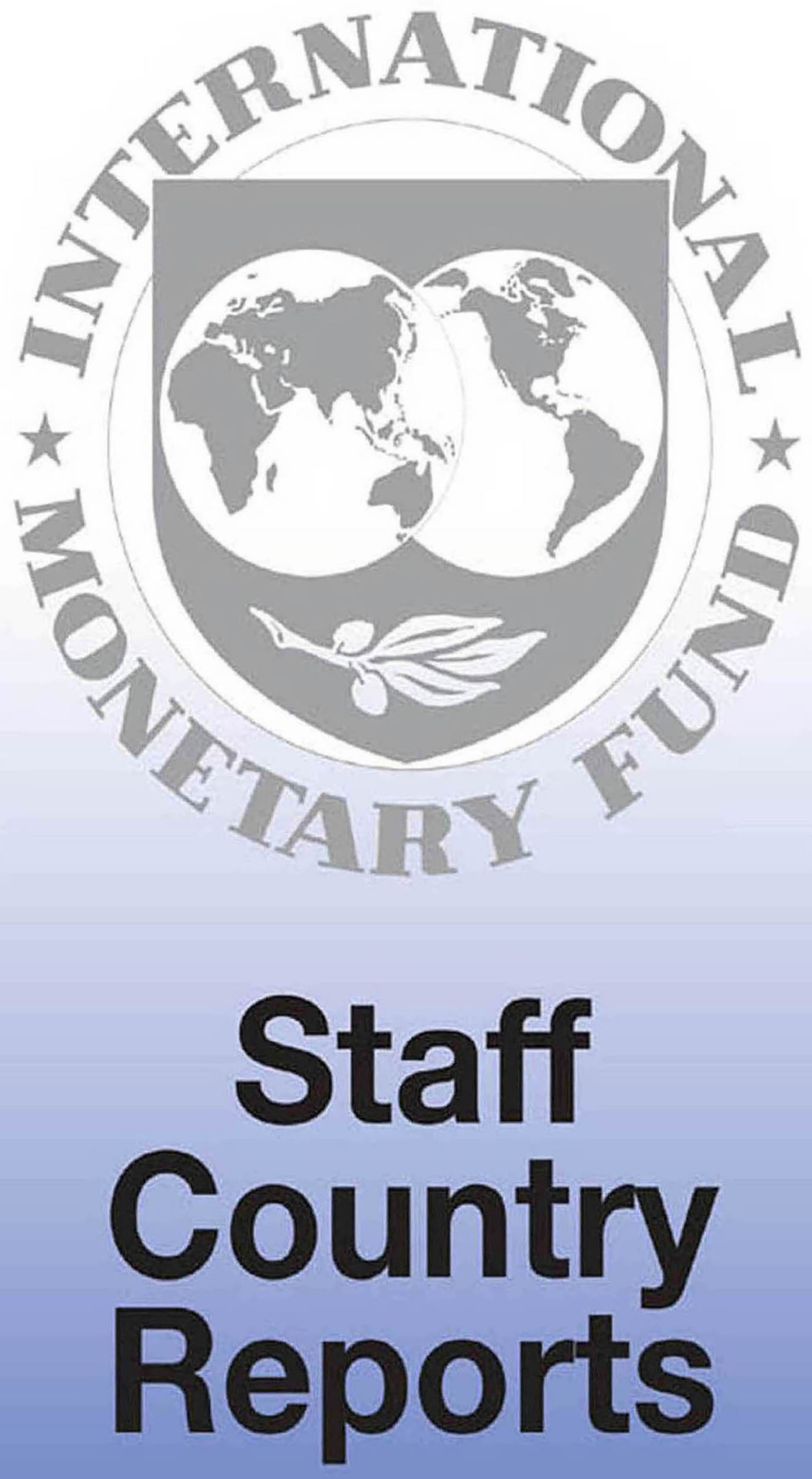


\section{Portugal: Selected Issues Paper}

This selected issues paper on Portugal was prepared by a staff team of the International Monetary Fund as background documentation for the periodic consultation with the member country. It is based on the information available at the time it was completed on December 26, 2012. The views expressed in this document are those of the staff team and do not necessarily reflect the views of the government of Portugal or the Executive Board of the IMF.

The policy of publication of staff reports and other documents by the IMF allows for the deletion of market-sensitive information.

Copies of this report are available to the public from

International Monetary Fund • Publication Services

$70019^{\text {th }}$ Street, N.W. • Washington, D.C. 20431

Telephone: (202) 623-7430 • Telefax: (202) 623-7201

E-mail: publications@imf.org Internet: http://www.imf.org

\section{International Monetary Fund \\ Washington, D.C.}




\section{INTERNATIONAL MONETARY FUND}

\section{PORTUGAL}

\section{Selected Issues}

Prepared by Manuela Goretti, Huidan Lin, Stephane Roudet, Marcos Souto, Ivanna Vladkova Hollar (all EUR), Andrea Lemgruber, Mauricio Soto (both FAD), and Alvaro Piris (SPR)

Approved by European Department

December 26, 2012

Contents

Page

I. How Fast Can Portugal Grow?

A. Introduction

B. Stylized Facts on Portugal's Growth and Convergence...

C. Taking Stock-Where Does Portugal Stand in 2012?

D. Prospect for Medium- to Long-Term Growth: Potential Gains from Structural Reforms

E. Conclusion

References

II. Portugal's Competitiveness

A. How Did Competitiveness Get Out of Line? ..........................................................

B. Crisis and External Adjustment …………………….......................................

C. Episodes of Internal Devaluation ....................................................................

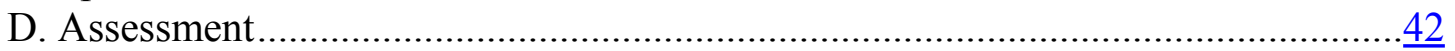

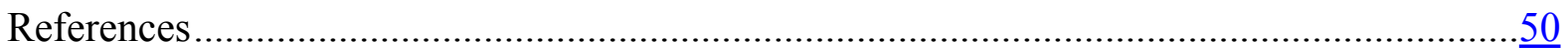

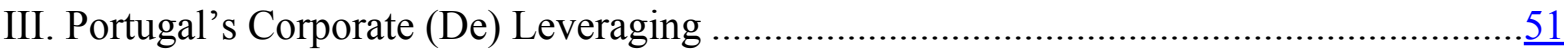

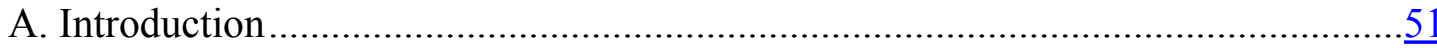

B. Diagnostics of Corporate Vulnerabilities and Risks in Portugal ............................

C. Macro-Financial Implications of Corporate Deleveraging …………………….....56

D. Key Lessons and Policy Recommendations for Portugal .........................................

Appendix I. Portuguese Firms' Leveraging Process in the Run-up to the Crisis .....................67

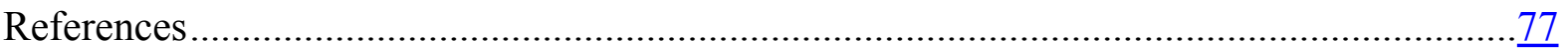


IV. Growth-Friendly, Equitable, and Sustainable Fiscal Reform in Portugal ..........................79

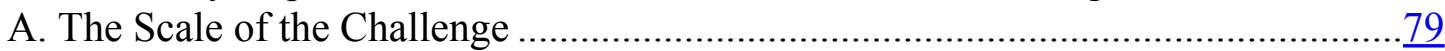

B. Towards A More Efficient and Better Targeted Expenditure Profile ...................... 82

C. Designing a Growth-Oriented Tax Policy.............................................................

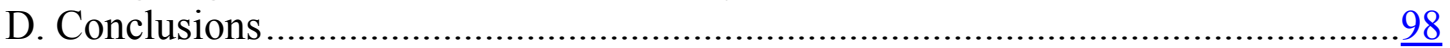

Appendix I. General Government Fiscal Accounts ............................................................99

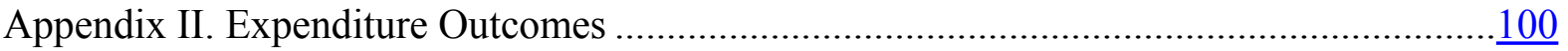

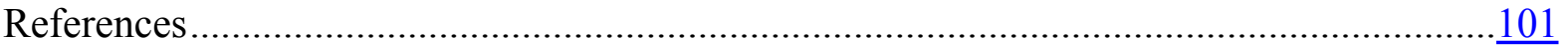

Tables

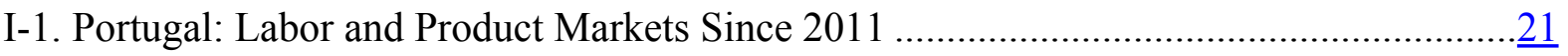

I-2. Selected Studies on the Impact of Labor and Product Market Reforms ...........................22

II-1 External Adjustment Episodes Under Rigid Nominal Exchange Rates ............................ 45

III-1. Portugal: Leverage of Nonfinancial Corporations, 1997-2011 …............................... 70

Figures

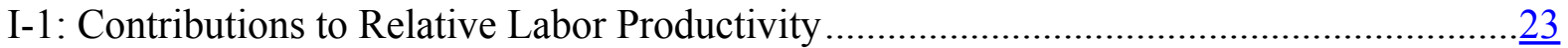

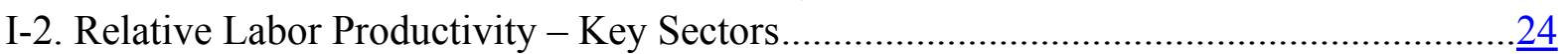

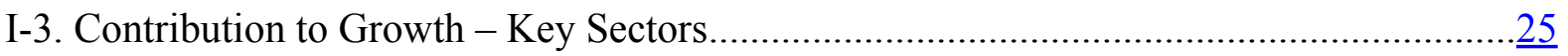

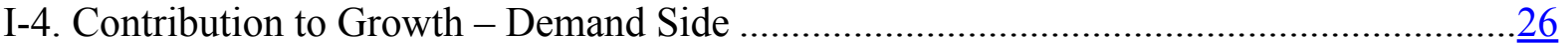

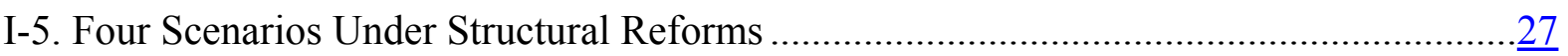

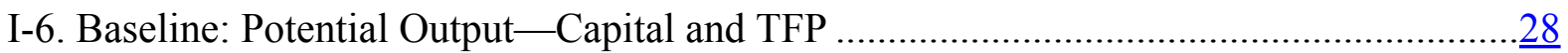

II-1A. Internal Devaluation Episodes: Sustained Declines in Relative Prices ......................... 46

II-1B. Internal Devaluation: Limited Relative Price Adjustment........................................47

II-2. Cost- and Price-Competitiveness: Alternative REER Measure......................................

II-3. Cumulative Current Account Adjustment …………...............................................

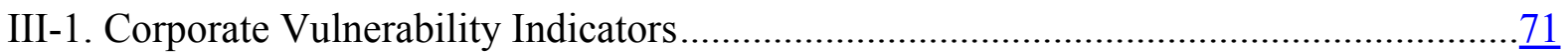

III-2. Evolution of Firms' Capacity to Repay Indicators, 1991-2011 …...............................

III-3. Corporate Vulnerability Indicators By Firm Size, 2011 ......................................... $\frac{73}{74}$

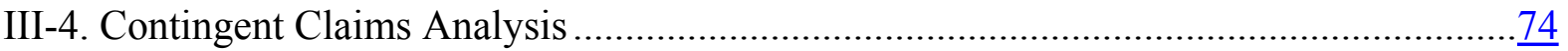

III-5. Corporate Balance Sheet Adjustment in Past Crisis Episodes .....................................

III-6. Macro-Economic Developments in Past Crisis Episodes .............................................

\section{Boxes}

I-1. Growth Accounting and Best-Practice Production Frontier Frameworks ........................... $\underline{6}$

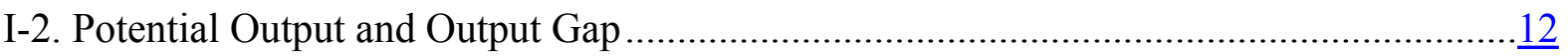

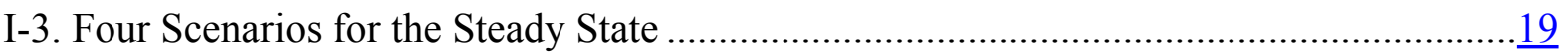

III-1. Bank and Corporate Deleveraging ........................................................................ 


\section{LIST OF ACRONYMS}

ACE

AGR

AMC

AT

BdP

CBS

CCA

CGQ

CNT

DD

EBITDA

FAC

IAPMEI

ICR

IFS

IIP

INE

INF

MAN

MIN

NFC

NPL

N-TRD

OTH

PD

REC

RET

ROA

SME

SS

TRD

TRS

UTL

WEO

WRT
Allowance for Corporate Equity

Agriculture

Asset Management Company

Tax Administration

Banco de Portugal

Central Balance Sheet (Database)

Contingent Claims Analysis

Corporate Governance Quality (Index)

Construction

Distance to Default

Earning before Interest, Taxes, Depreciation, and Amortization

Food and Accommodation

Instituto de Apoio às Pequenas e Médias Empresas (Portugal)

Interest Coverage Ratio

IMF International Financial Statistics

International Investment Position

Instituto Nacional de Estatistica (Portugal)

Media and Information

Manufacturing

Mining

Non-Financial Corporation

Non-Performing Loan

Non-tradable sector

Other

Probability of Default

Real Estate and Construction

Real Estate

Return on Assets

Small and Medium Enterprise

Social Security

Tradable sector

Transportation

Utilities

IMF World Economic Outlook

Wholesale and Retail Trade 


\section{How Fast Can Portugal Grow? ${ }^{1}$}

\section{A. Introduction}

1. Higher growth is a matter of urgency in Portugal. The economy is in deep recession, and the crisis has opened up a large output gap, with severe consequences for employment and government revenue. While a cyclical recovery would help alleviate these problems, ensuring sustained high growth is critical to raise incomes to peer levels and facilitate a return to sustainable public finances.

2. This paper aims at assessing Portugal's potential growth performance. While the focus is on the medium- and long-term, the analysis also offers insights on how deep the output gap is-something important for near-term policy considerations as well as growth perspectives. It also highlights ways in which policies and reforms can-if implemented now-promote growth over the longer haul.

\section{The assessment is conducted under an augmented growth-accounting} framework and makes use of a variant of the best-practice frontier approach to compare Portugal's growth performance to peers'. Section B reviews stylized facts about growth and convergence over the past forty years, with a particular focus on developments since the early 90s, when Portugal's relative growth performance started deteriorating. Section $\mathrm{C}$ takes stock of the current situation of Portugal in the cycle and relative to peers. Building up on this historical perspective, the forward-looking analysis (Section D) discusses scenarios for medium- and long-term growth, taking into account the potential impact of structural reforms.

\section{The analysis suggests that achieving a 2-percent growth rate over the long} term-consistent with moderate convergence growth-is a realistic objective. Based on relatively conservative assumptions for investment, this requires boosting TFP growth to about 1 percent a year. While this implies a significant improvement over the zero-TFP growth experienced since the early 90 s, it can be achieved through effective implementation of wide-raging reforms aimed at reducing wage and profit mark-ups and enhancing the business environment. The challenge is that reaching the 2-percent growth mark in the medium-term implies both a rapid turnaround in underlying TFP growth and a recovery (even if modest) in investment, despite strong headwinds from public and private sector deleveraging.

\footnotetext{
${ }^{1}$ Prepared by Huidan Lin and Stéphane Roudet. Upaasna Gupta provided excellent research assistance. We are grateful to the staffs from Banco de Portugal, the Ministry of Economy and Employment, and the Ministry of Finance for their helpful comments. The usual disclaimer applies.
} 


\section{B. Stylized Facts on Portugal's Growth and Convergence}

This section reviews Portugal's growth and convergence performance over the past forty years. It makes a distinction between the following two phases: (i) solid growth and convergence (mid 70s to early 90s); and (ii) increasingly anemic growth and relative income decline (since the early 90s). It also outlines a set of explanations for the weaker performance during the latter period.

\section{From Solid to Dismal Growth}

\section{In spite of significant economic difficulties, Portugal's growth was generally strong from the mid 70s to early $90 \mathrm{~s}$.}

- In the wake of the 1974 revolution, Portugal had to deal with a particularly difficult economic and institutional environment. This period, which began on the heels of the first oil shock, was marked by a revolution and increased government intervention, including nationalization of a large part of the production system, price and wage controls, and a non-market-based agrarian reform. Policies turned more market friendly after 1975 , and the economy benefited from an IMF-supported program to address external imbalances. This allowed GDP growth to average about $3 \frac{1}{2}$ percent over 1974-79, supported by a rapid expansion of the labor force and capital accumulation, and in spite of declining TFP (Box I-1).

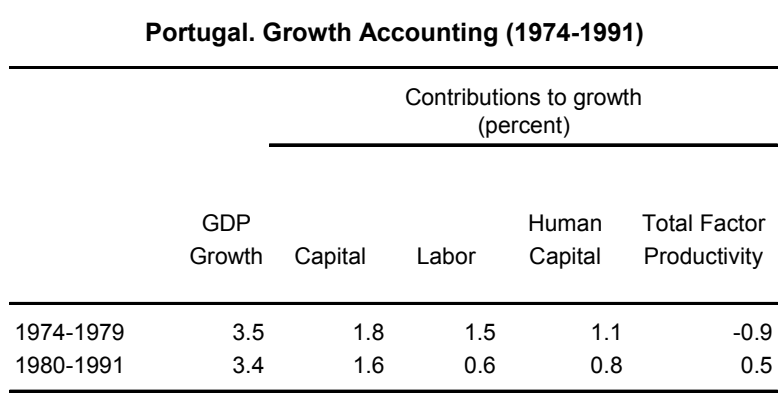

Sources: Des Neves (1995); and IMF staff calculations.

- $\quad$ The 80 s were marked by a second IMF-supported stabilization program (1983-85) and the entry into the European Economic Community in 1986. After that, the economy benefited from further opening-up and liberalization and deepening of European integration. Real GDP growth also averaged about $3 \frac{1}{2}$ percent over this period, supported by TFP growth of about $1 / 2$ percent per year.

6. Over this period, the country experienced some labor productivity convergence. Output per (full-time) employee grew by close to $2 \frac{1}{2}$ percent per year on average over 1974 91, compared to annual average growth rates of about $1 \frac{1}{4}$ percent in the US and 2 percent in the EU's best performing countries (EU-9). ${ }^{2}$ Consequently, the large convergence setback

\footnotetext{
${ }^{2}$ This includes a group of 9 EU member countries: Austria, Belgium, Denmark, Finland, France, Germany, Netherlands, Sweden, and UK.
} 


\section{Box I-1. Growth Accounting and Best-Practice Production Frontier Frameworks}

The paper uses an augmented growth-accounting framework to study production factors' contributions to growth and the best-practice production frontier approach to assess convergence in a cross-country context.

The growth accounting framework is based on the following traditional Cobb-Douglas production function augmented with human capital (Mankiw et al, 1992) and capacity utilization rates

$$
\ln (Y)=\alpha \ln (K \times C U R)+(1-\alpha) \ln (W A P \times L P \times(1-U) \times H o u r \times h)+\varepsilon
$$

where $Y$ denotes output, $\alpha$ is the capital share for the sample period (about 37 percent), $\mathrm{K}$ is the capital stock, CUR stands for the capacity utilization rate, WAP is the working age population, $L P$ the labor participation rate, $u$ the unemployment rate, Hour is a conversion factor to full-time employment, and $h$ denotes human capital per labor. Total factor productivity $(\varepsilon)$ is derived as the residual.

Following Hall and Jones (1999), the growth of human capital, dln(h), is assumed to follow a piecewiselinear function of schooling, where the slope of each linear piece is based on Psacharopoulos' (1994) survey of return-to-schooling. A 13.4-percent rate of return is assumed for the first four years of education; 10.1 percent for the following four years - corresponding to world average; and education beyond the eighth year is assumed to yield OECD-type returns (6.8 percent).

Capacity utilization fluctuates along the business cycles, capturing the impact of demand shocks on the flow of services provided by a given capital stock. Therefore, including capacity utilization rates helps isolate the permanent change in productivity from the impact of cyclical downturns. This is particularly useful for analysis during short time spans, such as during the current crisis.

Due to data availability constraints for the longer time period, the evolution of TFP for the cross-country analysis is estimated using a simplified model without taking into account the capacity utilization: $\ln (Y)=\alpha \ln (K)+(1-\alpha) \ln (L \times h)+\varepsilon$.

Best-practice production frontiers are equivalent to curves that depict-for a given year and a given level of human capital - the highest possible level of labor productivity (Y/L) for varying stocks of capital per unit of labor $(\mathrm{K} / \mathrm{L})$. These are based on the idea that TFP can be divided into (i) technical efficiency-representing the knowledge ex ante as to how best combine factors of production; assumed to be common to all countries and increasing exogenously through time with the global pace of technological innovation; and (ii) allocative efficiency - representing how effectively factors are actually used in practice depending on country-specific circumstances. Lower efficiency in the use of capital and labor may arise from various sources, such as poor functioning of market institutions or a low level of human capital that prevents profitable use of the best available technologies.

Instead of estimating the best-practice frontiers econometrically, the paper uses the US TFP as the benchmark. Since the technical efficiency component is common to all countries, the differences in country-level TFP relative to the US are assumed to reflect primarily relative allocative efficiency. Production frontiers for different levels of relative efficiency are derived, where for a given level of capital per unit of labor, the vertical difference with the US (benchmark) frontier reflects the difference in labor productivity due to (i) human capital and (ii) allocative efficiency. Although the U.S. may not be the country with the best allocative efficiency at all points in time, it seems to be a reasonable approximation in view of its particularly high TFP and technological advancement. This approach also has the advantage of being easier to replicate; and results do not differ significantly than those proposed by other authors. ${ }^{1}$

\footnotetext{
${ }^{1}$ See for instance Tiffin (2006 and 2012) who estimates best-practice production frontiers stochastically, including to study growth prospects, respectively for Ukraine and the euro area periphery
} 
in the early 70 s was more than made up for over this period, with relative labor productivity peaking at its highest level (about 50 percent relative to EU countries) around 1990.

\section{However, convergence over 1974-91 was} mainly the result of the Portuguese economy rapidly becoming more capital intensive. Allocative efficiency-measured as relative TFP-remained virtually at the same level over the period, with the exception of a few sub-periods of ups and downs

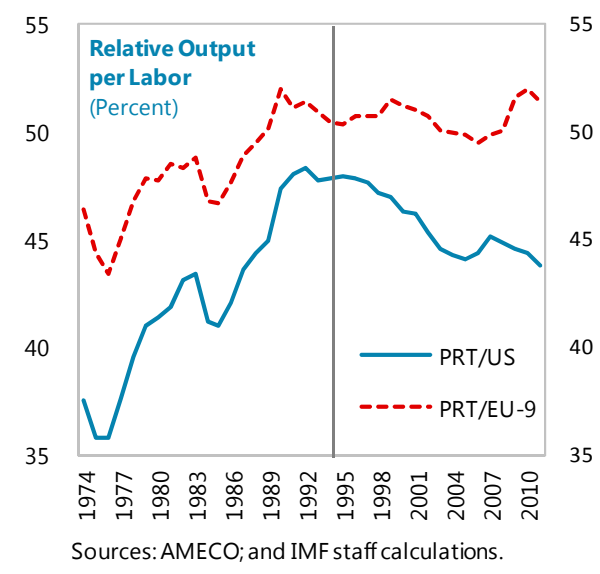
reflecting economic difficulties. Convergence in income levels was mainly driven by the accumulation of physical capital, with the relative stock of capital per employee growing strongly (see charts) as a result of strong growth of public and private sector investment growth. An increase in relative human capital also contributed to the convergence process (Figure I-1). ${ }^{3}$
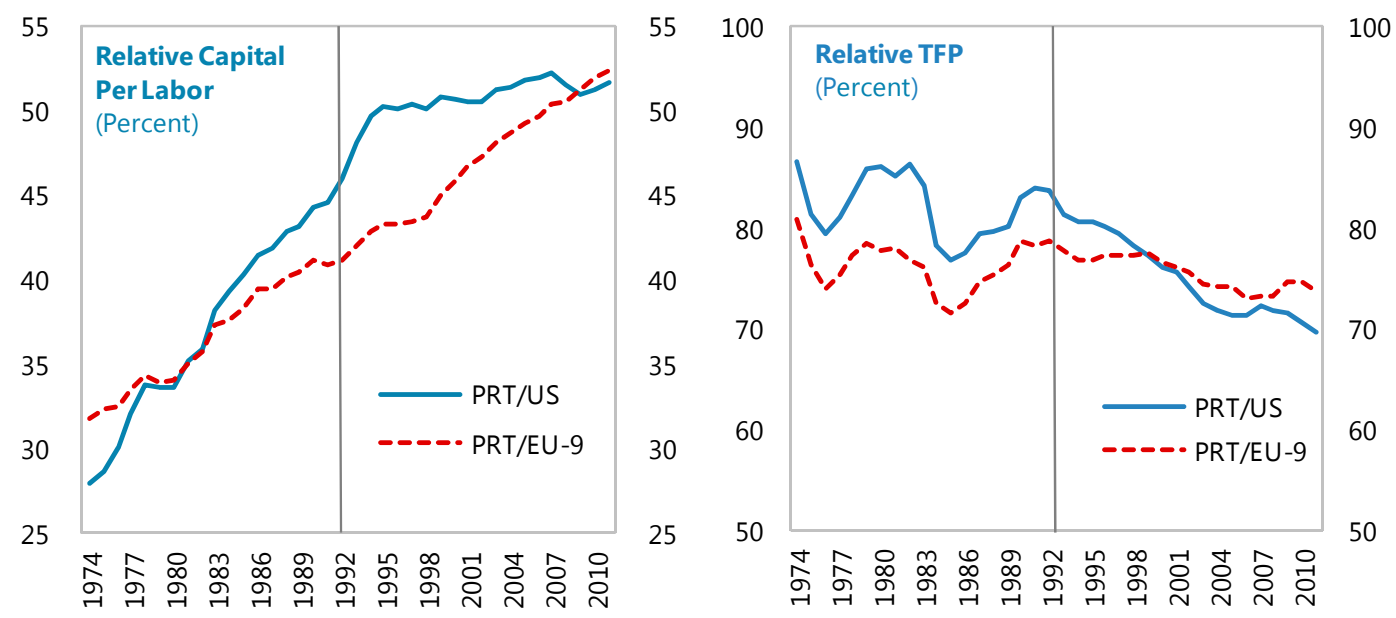

Sources: AMECO; and IMF staff calculations.

\section{Growth became increasingly weak from}

\section{the early 90s, marking the end of the}

convergence process. Since the early 90 s, labor productivity has remained broadly stable vis-à-vis that of the best performing EU countriesreflecting some convergence in the stock of capital per employee - while declining substantially with respect to the US'. This turnaround reflected mainly a decline in relative

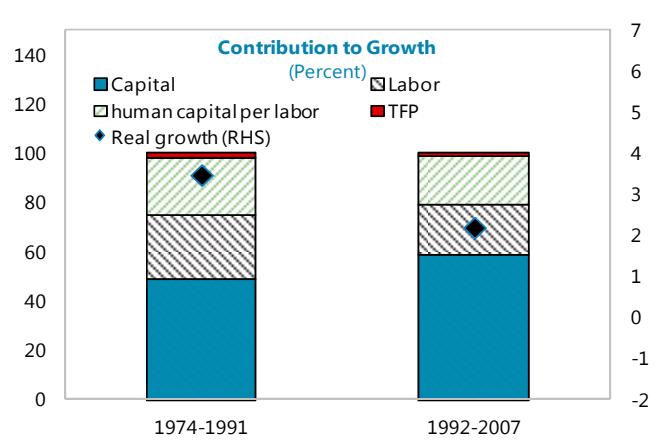

Sources: AMECO; Barro and Lee (2010); and IMF staff estimates.

\footnotetext{
${ }^{3}$ Taking into account the relative increase in the number of hours worked in Portugal—which can generate a bias in the TFP calculations if not accounted for-does not fundamentally affect these results.
} 
TFP. In particular, average real GDP growth gradually declined to only about $1 \frac{1}{2}$ over $2000-$ 07. The contributions of capital and labor both dropped, and TFP growth turned negative.

\section{Why Did the Economy Run Out of Steam Since the Early 90s?}

\section{The weaker growth performance and lack of convergence over the past two} decades can be explained by several self-reinforcing factors. In the face of shocks that brought both challenges and opportunities, weak institutions and failed policies prevented the economy from adapting quickly and maintaining strong productivity growth.

\section{A domestic demand boom was fueled by strong capital inflows in the run up to the} euro adoption. The new era of exchange rate stability in the run-up to the euro adoption in 1999 led to a strong surge in capital flows. This surge served to amplify the impact of Portugal's existing distortions - weak financial supervision and risk management, inflexible labor market, and lack of competition in non-tradable sectors - contributing to growing macroeconomic imbalances. With a financial sector mostly liberalized and increased bank competition, higher inflows quickly turned into lower funding costs for enterprises and

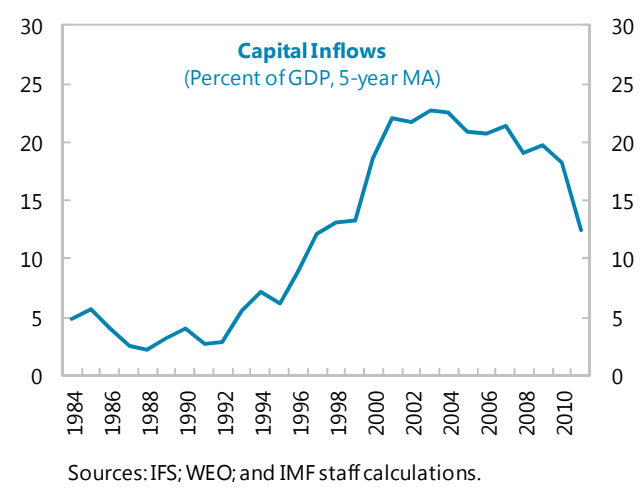
consumers (Almeida et al., 2009). In combination with a marked increase in official inflows (including in the form of EU structural funds), these developments led to a strong domestic demand growth - particularly directed toward non-tradable goods and services, a decrease in unemployment and rapid attendant increases in wage, unit labor costs, and inflation.

Consequently, the real effective exchange rate further appreciated-following a marked appreciation after EU membership — which, in turn, favored domestic demand over exports, leading to growing macroeconomic imbalances.

\section{With a low degree of competition} and high mark-ups in network industries, construction, real estate, and wholesale/retail trade, capital flows were increasingly directed towards these sectors, where productivity growth was lagging. There was also under-investment in machinery and equipment where returns are known to be higher. Excessive profit markups in non-tradables also weighed on tradable sector profitability directly through high

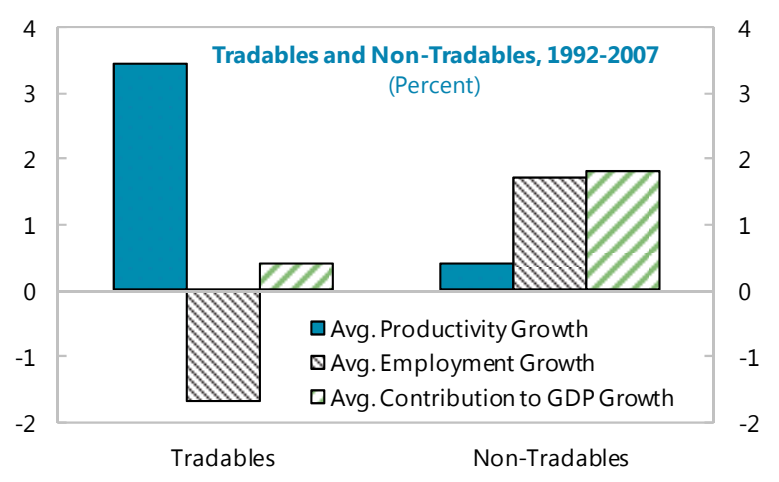

Sources: AMECO; and IMf staff calculations. intermediate input costs. In addition, the lack of labor market flexibility encouraged wage increases not sufficiently sensitive to the competitive requirements of the tradable sector. 
Portugal's uniquely strong labor protection may also have prevented the more productive firms from growing to their optimal size, thereby constraining output per capita (Braguinsky et al., 2011). Finally, the government ran a pro-cyclical fiscal policy over the period, which exacerbated the pressures on domestic demand. Expenditure was geared toward nonproductive investments, particularly in non-tradable sectors.

\section{Externally, further liberalization of world trade - notably China's entry into the} global supply chain and the gradual dismantling of the quotas under the Multi-Fiber Arrangement by end 2004—as well as the European Union's expansion into Eastern Europe meant that that Portugal had to face more intense competition, particularly in the manufacturing and agriculture sectors. This weighed on the country's competitive advantage but also meant that Portugal had to compete for foreign investment with the new EU members.

\section{Portugal's significant human capital gap prevented the country from moving up} the global value-added chain to tackle this increased competition and to benefit from new technologies. Despite its gradual modernization and relative expansion since the 1960s, the education system remained underdeveloped until the 2000s when it finally reached some of the developed world's best practices and trends. ${ }^{4}$ However, the secondary education graduation rates and the overall labor force education level remain low (see chart). And

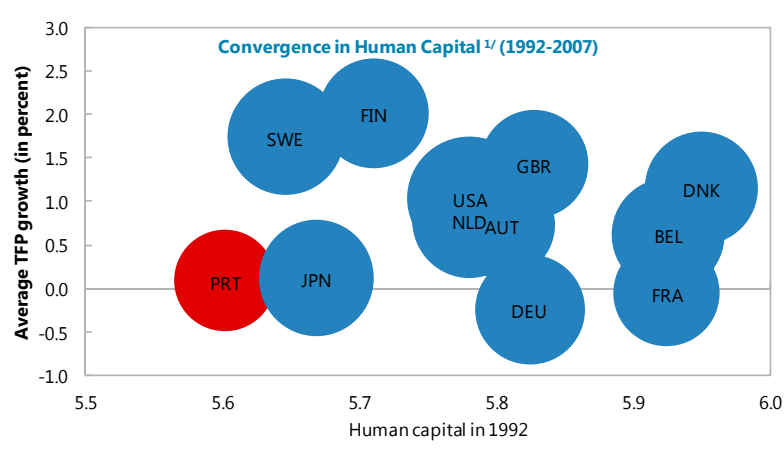

Sources: AMECO; Barro and Lee (2010); and IMF staffestimates.

1/ A larger ballloon denotes a higher level of human capital per labor, constructed based on Barro and Lee (2010). while the difference in stocks of human capital has been shown to explain a large part in difference in per-capita income level across countries, there is also evidence that the stock of human capital can influence the TFP convergence speed (see chart). The relatively low level of education may have hindered the adoption of the information and communications technologies (ICTs), especially during the 1995-2005 decade, when there was a global boom in the use of ICTs (see chart). ${ }^{5}$

\footnotetext{
${ }^{4}$ In particular, the new generation possesses education comparable to other advanced economies. According to the OECD's Programme for International Student Assessment (PISA) for 2009, the average Portuguese 15-years old student, when rated in terms of reading literacy, mathematics and science knowledge, is placed at the same level as those students from the United States, Sweden, Germany, Ireland, France, Denmark, United Kingdom, Hungary and Taiwan Province of China.
}

${ }^{5}$ This argument is also often cited as a reason for the difference in productivity growth between the U.S. and Europe during this period (Van Ark et al., 2008). 

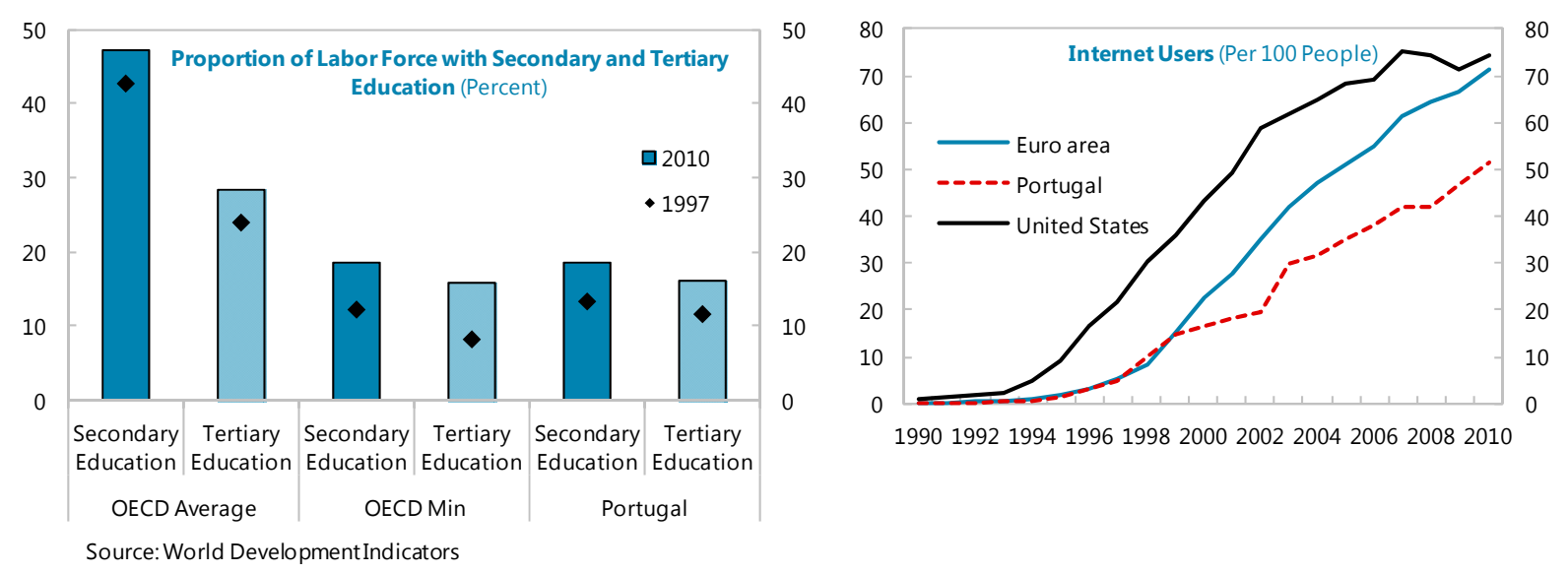

\section{The business climate was especially} weak, with high incidental costs of doing business reflecting, among other things, inefficient judiciary, bureaucratic red tape, and governance and business climate indicators ranking among the lowest compared to peers. This further discouraged investment in non-protected sectors.

Generally speaking, TFP convergence tends to be faster when market institutions are more developed (see chart).

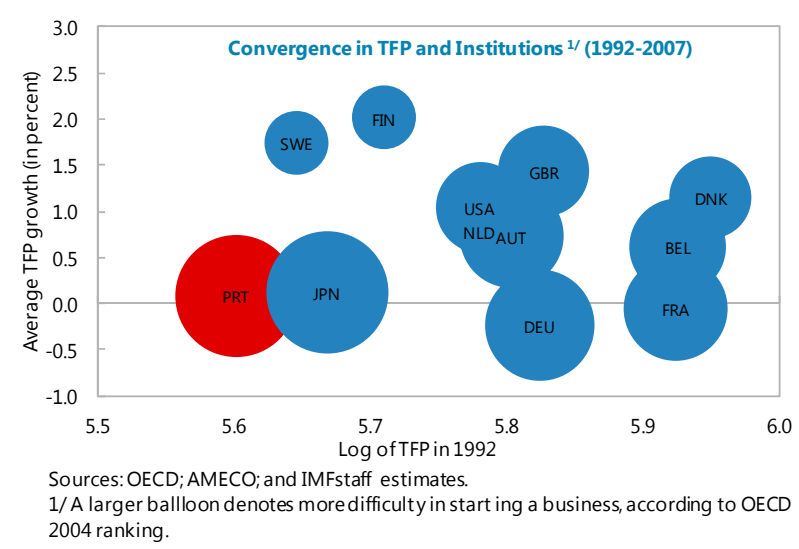

\section{Finally, an increasingly leveraged economy hindered investment and productivity} gains, contributing to the dismal growth performance. With a tax system favoring debt over equity financing, much of the capital inflows during the pre- and post-euro adoption period were in the form of debt, leading to a high corporate leverage. While capital inflows increasingly supported consumption, excess leverage may in turn have had a negative impact on investment, as over-indebted firms tend to pass up on new investment opportunities, particularly those with limited short-term benefits but higher long-term productivity gains. ${ }^{6}$ The negative relationship between leverage and investment is well established in the literature. ${ }^{7}$ In the case of Portugal, investment growth

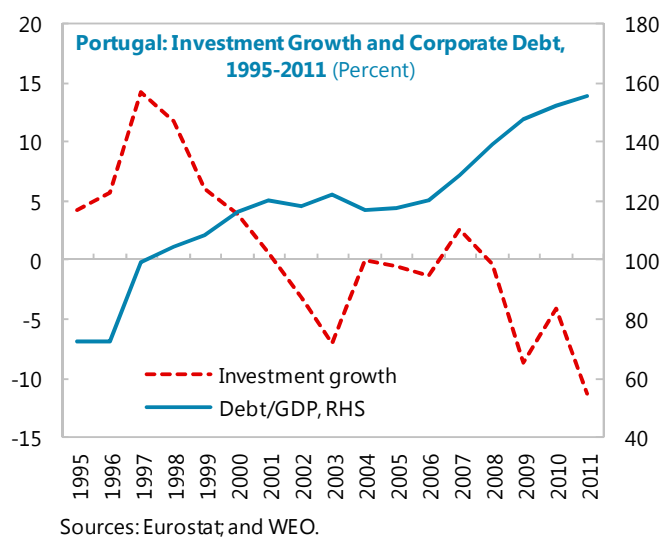

\footnotetext{
${ }^{6}$ This reflects for instance higher funding costs stemming for asymmetric information between firm managers and lenders, as well as fear of bankruptcy when leverage is high and investment opportunities riskier. Stein (2001) provides a comprehensive review of the modern finance literature on this topic.
}

${ }^{7}$ See Jaeger (2003) and Goretti and Souto (2012) for recent examples. 
peaked in 1997 and then gradually declined to turn negative, as leverage was increasing (see chart). Excess leverage may also have directly hindered productivity growth (Pal et al., 2012). ${ }^{8}$

\section{In contrast to Portugal, many other euro} area countries managed to reap the full benefits of monetary integration and the technological advances. Ireland, for example, experienced a remarkable performance over the past two decades (Amador et al., 2007). Modern economic institutions and a highly educated and flexible workforce allowed the country to orient inflows toward the most promising activities and benefit from an acceleration of TFP.

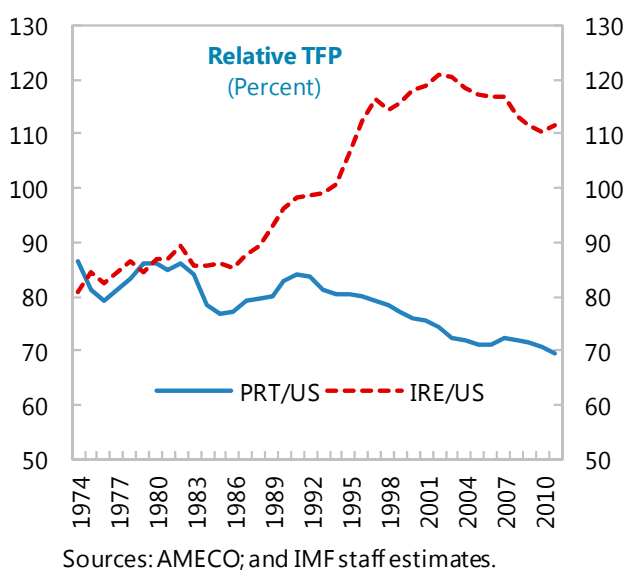

\section{Taking Stock-Where Does Portugal Stand in 2012?}

17. The financial crisis has opened a large output gap. Domestic demand collapsed during 2008-12 (with an average contribution to growth of -4 percent). At the same time, the unemployment rate rose from 8 percent in 2007 to some 16 percent in the third quarter of 2012. These developments partly reflect structural changes, as the economy rebalances toward tradables. And the deep contraction in non-tradables forces a difficult re-allocation of the labor force, with tradables not yet able to absorb these flows. The output gap is estimated to have reached some 4 percent in 2012, with a structural unemployment rate of close to 13 percent (Box I-2).

18. There is uncertainty as to how quickly the output gap can be closed, particularly in view of the strong headwinds to the cyclical recovery. The still large competitiveness gap is an immediate constraint. The ongoing public and private sector deleveragingnecessary to reduce the high debt burdens and thus pre-conditions for sustained future growth - also represents a strong impediment to output growth in the next few years.

19. But there are also reasons for optimism. External adjustment has taken place at a faster pace than expected, even in the absence of significant improvements in pricecompetitiveness indicators. As these materialize and economic activity in the euro area normalizes, the export sector is likely to provide some persistent support to growth. Moreover, private sector investment is estimated to have declined by about 35 percent cumulatively since the peak in 2007 , leading to a reduction in the capital stock of about

\footnotetext{
${ }^{8}$ Pal et al. (2012) estimate a threshold regression model on a sample of Central and Eastern European countries. The study confirms that TFP growth increases with leverage until the latter reaches a critical threshold beyond which leverage lowers TFP growth.
} 
1 percent. A further expansion of exports would soon hit capacity constraints providing impetus for a modest increase in investment in the medium-term.

\section{Box I-2. Potential Output and Output Gap}

Potential output is estimated under the augmented growth accounting framework presented in Box I-1, by stripping cyclical components out of the factor inputs and total factor productivity. ${ }^{1}$ The model is estimated for a sample period from 1987 through 2017 (based on IMF staff medium-term projections).

- Factor inputs. The structural unemployment rate is estimated by the European Commission. It is derived by estimating a Phillips curve with a Kalman filter technique where the NAIRU is treated as an unobserved variable. And the equilibrium labor market participation rate and equilibrium capacity utilization rate are derived through HP filter.

- Trend TFP. By construction, the TFP derived from the capacity utilization augmented growth model should not be affected by cyclical factors. ${ }^{2}$ It is further smoothed by HP filter to remove any remaining cyclical factors to be used for trend TFP.

- Potential output is the aggreate of these smoothed factor inputs.

The output gap is estimated to have reached some 4 percent in 2012, with a structural unemployment rate of close to 13 percent.
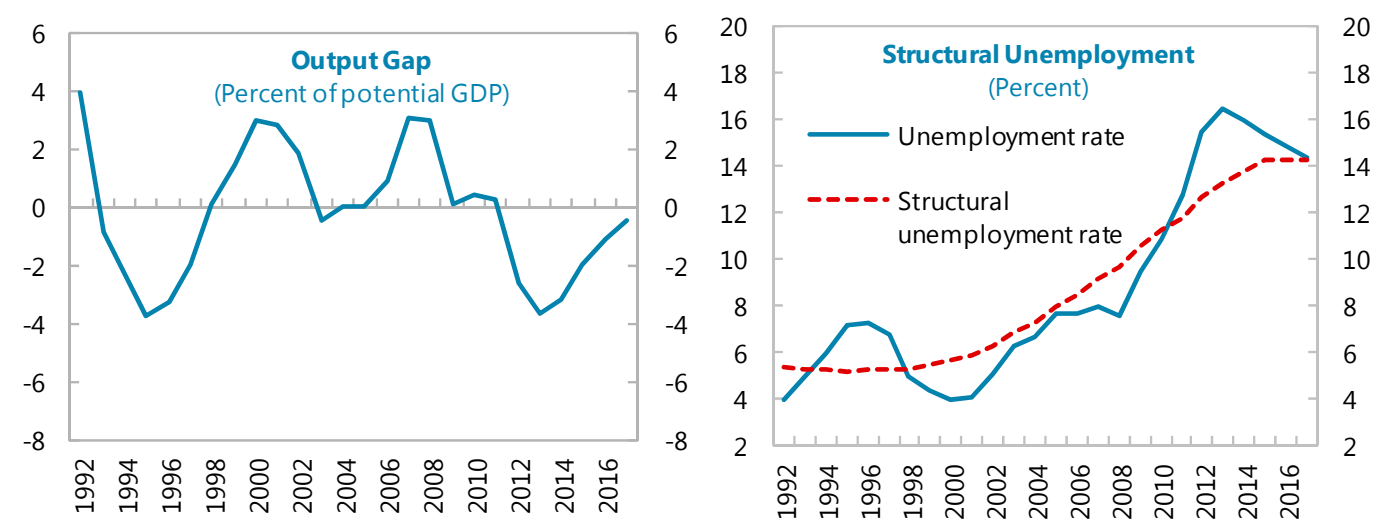

Sources: AMECO;INE; and IMf staffestimates.

\footnotetext{
${ }^{1}$ Compared to pure HP-filter, this method attends more to potential relevant economic information. However, the trend developments of most factors are derived using HP filter. This method thus potentially suffers from same shortcomings as the HP-filter, such as being slow in discovering structural breaks (which during a recession would overestimate potential GDP and the output gap) as well as the "end-point problem".

${ }^{2}$ Some caution is warranted when interpreting these results. Manufacturing capacity utilization may be more volatile than the whole economy capacity utilization. In this case, the TFP derived using only manufacturing capacity utilization may be overestimated. HP-filter series would then overestimate the trend TFP, leading to an overestimated negative gap.
} 
20. Beyond cyclical developments, Portugal's labor productivity gap compared to its peers is very large, making it more likely that a strong reform effort will indeed foster income convergence. Even after adjusting for capacity utilization - which dropped from some 82 percent to close to 75 percent during 2008-12, TFP declined by an annual 0.2 percent over the period. As a result, notwithstanding the convergence until the early 90s, Portugal is left with one of the largest gaps of per-capita income among EA countries:

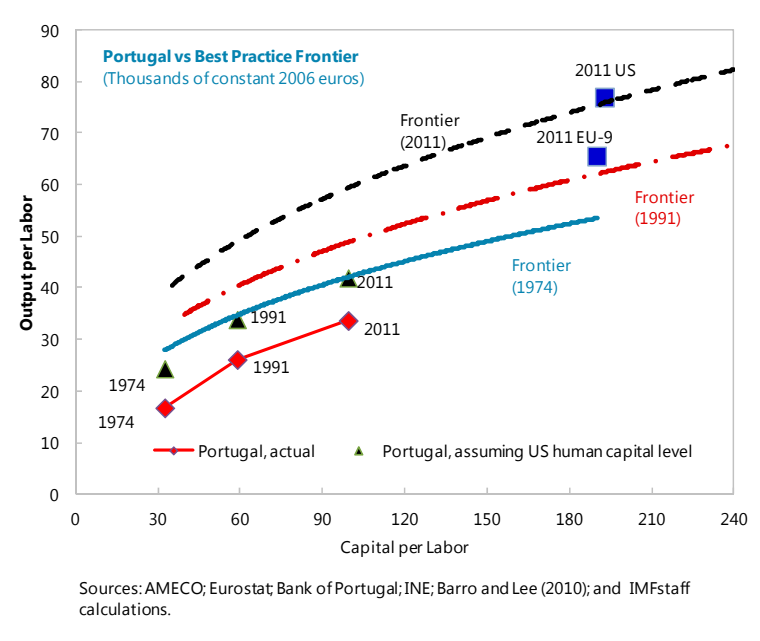

- $\quad$ Labor productivity in Portugal represents only 45 percent of the US's and about half of productivity in the richer EU countries.

- About one-third of the gap with the US is attributable to a gap in the stock of physical capital;

- One-third of this cross-country difference in labor productivity is explained directly by the difference in the stock of human capital;

- $\quad$ And the rest of the labor productivity gap (some 40 percent) reflecting allocative inefficiencies, in turn related to the human capital and structural policy gap.

These gaps vis-à-vis the peers and the lagging business environment should make it even easier to engineer a rapid catch up.

\section{Prospect for Medium- to Long-Term Growth: Potential Gains from Structural Reforms}

In response to the massive TFP shortfall and the need to resume convergence growth, the Portuguese authorities have embarked on an ambitious set of structural reforms. This section considers the effect these reforms can have on medium-and long-term growth.

\section{The Impact of Structural Reforms on Growth: Empirical Evidence}

\section{Portugal has launched a wide-ranging structural reform program aimed at boosting competitiveness and growth (Table I-1):}

- Labor market reforms. Steps are being taken to reduce severance payments and unemployment benefits, and rationalize automatic extension of collective bargaining 
agreements. These should increase labor mobility and help wages adapt to firm- or

sector-level conditions, with a positive bearing on employment and productivity.

- $\quad$ Product market reforms. Excessive product market regulation has contributed to high mark-ups and low output, investment, and employment. As noted earlier, high profit mark-ups in the non-tradable sector have impeded the competitiveness of the tradable sector. To address these problems, reforms to reduce the regulatory burden and improve competition are in train. Significant steps have already been taken, including to abolish the state's special rights in companies, revise the Competition Law, liberalize restricted professions, and reduce mark-ups in network industries, particularly in the electricity and telecommunications sectors.

- $\quad$ Improved business environment. Licensing procedures are being streamlined. Judicial reforms are also advancing, aimed at addressing slow judicial processes, weak court management, and the severe backlog of cases that have created serious obstacles to efficient economic activity. A new corporate insolvency framework should also facilitate private sector debt workouts. Over time, these reforms are expected to make Portugal a more attractive destination for investment and facilitate convergence in the allocative efficiency (see paragraph 6).

\section{Empirical evidence points to potentially significant long-term pay-offs from a} package of comprehensive structural reforms along the lines described above. Four key findings emerge from the recent empirical studies (Table I-2):

- In the long run, product and labor market reforms can enhance TFP, labor productivity, and employment rate (Barnes et al., 2011), and the overall potential GDP gain for the average OECD country could reach $4 \frac{1}{2}$ and 10 percent at 5- and 10year horizons, respectively (Bouis and Duval, 2011). Reforms aimed at deregulating product markets, especially network industries, could increase the probability of exiting a low-growth spell (Lusinyan and Muir, 2012).

- In the short run, the impact of reforms is mixed. While reforms could generate positive confidence, income and wealth effects via expected reform-driven changes in future incomes, households may perceive higher income insecurity in the wake of certain reforms, leading to higher precautionary savings and lower demand. In addition, some labor market reforms (e.g. of unemployment benefit and job protection) can even entail short-term losses in severely depressed economies (Bouis et al., 2012; Cacciatore et al., 2012).

- A broad reform package is more beneficial than individual reforms as the former can help minimize or even alleviate the transitional costs (Cacciatore et al., 2012). 
- $\quad$ Cross-country coordination of reforms could produce larger and more evenly distributed positive effects (Gomes et al., 2011; IMF, 2012).

23. Portugal-specific empirical studies confirm potentially sizable positive effects of structural reforms on GDP and productivity. In particular:

- $\quad$ Barnes et al. (2011) link together a range of empirical studies (mostly carried out by the OECD) under an accounting framework of reduced-form equations that explain individual sub-components of GDP per capita. The findings suggest that, out of the 35 percent income gap in 2009 between Portugal and the OECD average, some 7 and 9 points are due to gaps in labor and product market policies, respectively, with the rest is due to the gap in human capital. The results also point to potentially sizable positive effects from various structural reforms (see table).

\section{Long-term Effect of Structural Reforms on GDP Per Capita}

(Percent deviation from the baseline)

\begin{tabular}{|c|c|c|c|c|}
\hline \multicolumn{2}{|c|}{ Labor Market } & Product Market & \multicolumn{2}{|c|}{ Human Capital } \\
\hline $\begin{array}{c}\text { Average } \\
\text { Replacement } \\
\text { Rate }\end{array}$ & $\begin{array}{l}\text { Employment } \\
\text { Protection } \\
\text { Legislation }\end{array}$ & $\begin{array}{l}\text { Energy, Transport, } \\
\text { and Communications } \\
\text { Regulation Indicator }\end{array}$ & PISA Score & $\begin{array}{c}\text { Average Years } \\
\text { of Schooling }\end{array}$ \\
\hline$-10 \mathrm{ppt}$ & -1 point & -0.1 point & +10 points & +1 year \\
\hline 4.0 & 2.6 & 1.9 & 1.2 & 6.0 \\
\hline
\end{tabular}

Source: Barnes, et al. (2011) "The GDP impact of reform: A simple simulation framework". (OECD Economic Depeartment Working Paper No. 834.)

- Under a similar framework, Bouis and Duval (2011) find that, with a broad package of reforms implemented within a five-year time period, per capita GDP could be boosted by 6 percent in the first five years and 14 percent after 10 years.

- $\quad$ Finally, Gomes et al. (2011) simulate EAGLE (Euro Area and Global Economy model) - a large scale DSGE model—calibrated for Portugal. The results suggest that the real output could be close to 8 percent higher by lowering mark-ups by 15 percentage points in Portuguese labor and services markets.

\section{Four Long-Term Scenarios}

Four long-term growth scenarios are considered, assuming various degrees of impact of structural reforms. Reforms are assumed to have an impact through three main channels: (i) improving TFP growth; (ii) increasing labor participation and employment rates; and (iii) allowing for a more rapid improvement in the structural unemployment rate. The quantitative impact of reforms is calibrated so as to be broadly consistent with the studies mentioned above. 


\section{Key Assumptions}

\section{Investment and capital stock accumulation dynamics play an important role in} these four scenarios. On the one hand, the crisis has brought the investment ratio down to a level unseen since the mid-1980s. On the other hand, the debt overhang is now more acute, raising questions as to how the necessary investments can be financed, especially in view of the deleveraging process and related tight credit conditions. The simulations are based on the assumption of a gradual recovery in investment rate to about 20 percent by 2032 across all four scenarios. This is below the 20 -year average of $21 \frac{1 / 4}{4}$ percent and above the projected medium-term average of $16 \frac{1}{2}$ percent. In view of the current account projections (balanced by end of medium term), this implies a gradual increase in the saving rate to about 20 percent, compared to the 20 -year average of 16 percent. Keeping the investment ratio constant across scenarios implies self-reinforcing positive capital-accumulation-growth dynamics at play.

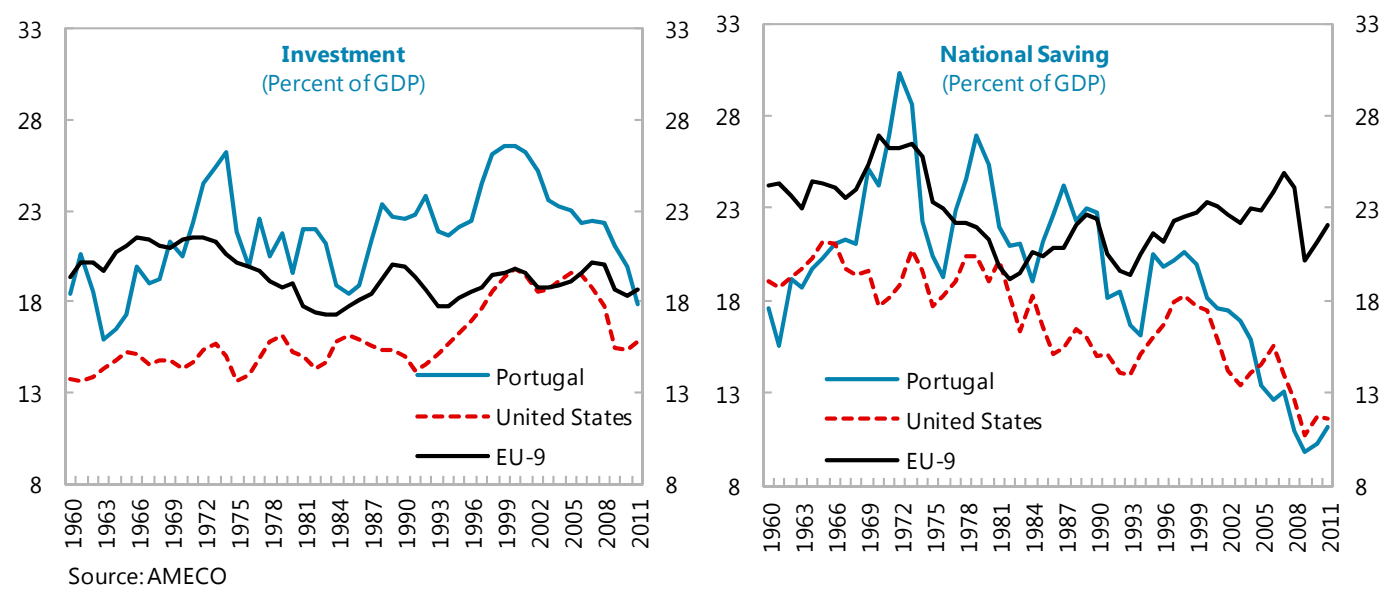

25. Working age population is assumed to decline over the long term, based on the Eurostat projection which reflects a possible scenario of trends in fertility, mortality, and migration. However, the projection does not assume that the recent pickup in the emigration will continue into the medium and long term. Therefore, in the less optimistic scenarios with worse growth prospects, the risk of higher emigration than currently envisaged is non-trivial, in particular that of younger and better educated Potuguese. Should this risk materialize, it would put downward pressure on growth. On the other hand, if the optimistic scenario becomes more likely, the country may attract more immigrants which would further enhance the growth.

\section{Human capital accumulation is assumed to contribute 0.4 percentage points to} growth annually, broadly in line with what has been experienced in the past two decades. This is yet another conservative assumption considering the still very large gap with other OECD economies. However, education reforms take several generations to make a significant difference for all age cohorts, because policies can only directly influence the length of education and PISA scores for the 15-24 age cohort (e.g., Barnes et al., 2011). In 
the case of Portugal, progress has been made in raising both the level and the quality of education, particularly in the younger cohort, but the investment in this area was made less efficiently than it should be (see charts). In view of this and in the context of severely constrained public finances, human capital reforms have to be phased in gradually and can only rely on increasing efficiency rather than additional budget allocations (Lemgruber and Soto, 2012).
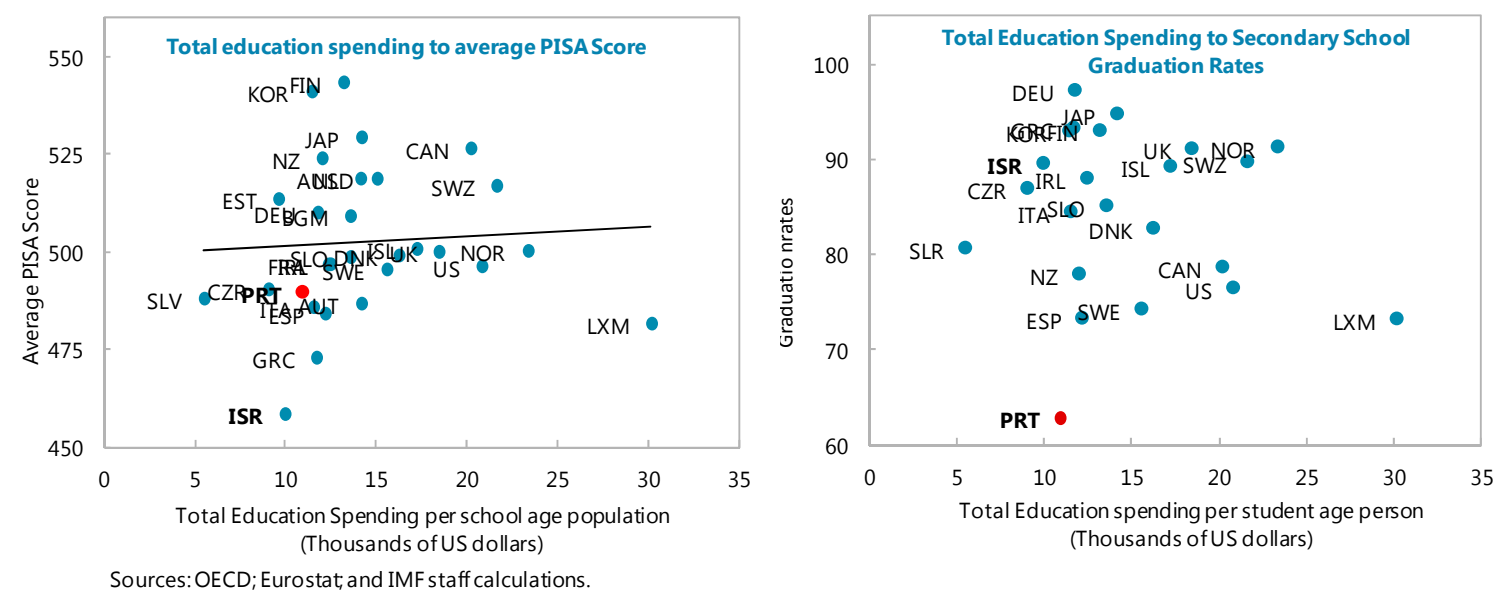

\section{Main Results}

27. The starting point of the simulation is a moderately pessimistic scenario in which reforms have a limited impact-TFP increases by $1 / 2$ percent a year, so at a slightly faster pace than since the early $90 \mathrm{~s}$, but there are no gains in allocative efficiency (Box I-3). In this case, real GDP growth averages 1.2 percent over the long term, with relative labor productivity remaining broadly stable compared to the US and falling back to its low levels in the 1980s. Should reforms be delayed or should actual implementation lag, long-run growth could also end up much lower. Assuming zero TFP growth (as experienced since the early $90 \mathrm{~s}$ ) in the pessimistic scenario would imply growth of about $1 / 2$ percent a year and a continuation of the relative decline compared to peers.

\section{But assuming a moderate impact of the ongoing structural reforms, a real} output growth of about 2 percent on average in the long run appears to be a reasonable conjecture. Staff's baseline scenario assumes that all the reforms planned under the program are fully implemented and bear fruits over the long term, although to a lesser extent than suggested by the literature reviewed above (Figure I-5).

- $\quad$ Reflecting the positive impact of structural reforms, TFP is assumed to grow at 1 percent in the long run. This is slightly higher than the projected 0.8 percent for the US (based on OECD projections-see Box I-3), but less than half that experienced by Portugal immediately after the EU accession (21/4 percent over 1986-92). In comparison, over 2000-07, Netherlands and Sweden experienced average TFP 
growth rates of 0.7 percent and 1.6 percent, respectively, after a comprehensive package of reforms in labor and product markets during 1980s-90s.

- $\quad$ Capital stock accumulation is projected to resume by the end of medium term-a somewhat conservative assumption, contributing 0.5 point to the annual growth, while the increase in labor participation and employment are assumed to offset the decline in working age population-leading to zero contribution from labor input.

- Human capital accumulates at the same rate as during 1999-2007, contributing 0.4 point to the annual growth.

- $\quad$ As a result, the cumulative increase of GDP per capita compared to the no-reform (or lack of impact thereof) scenario amounts to about 5 percent by 2022 , and

\begin{tabular}{|l|l|l|}
\hline \multicolumn{2}{|c|}{ Level of GDP per capita, relative to moderately pessimistic } \\
\hline & $\ln 2022$ & $\ln 2027$ \\
\hline Literature (average) & $6 \%$ & $14 \%$ \\
\hline Baseline & $5 \%$ & $8 \%$ \\
\hline Optimistic & $10 \%$ & $18 \%$ \\
\hline
\end{tabular}
8 percent by 2027 . This is much less than implied by the literature on average.

- $\quad$ Under the baseline, the labor productivity gap with the US narrows only very gradually over the long term (see chart below).

29. In a somewhat more optimistic scenario where the structural reforms unleash an even higher potential TFP growth, real output grows by some $23 / 4$ percent per year. The higher TFP growth (at $1 \frac{1}{2}$ percent on average) also encourages firms to hire more and invest more, especially in machinery and equipments, which as some empirical studies suggest leads to higher output growth (De Long and Summers, 1991). The labor productivity gap with the US narrows at a faster pace-

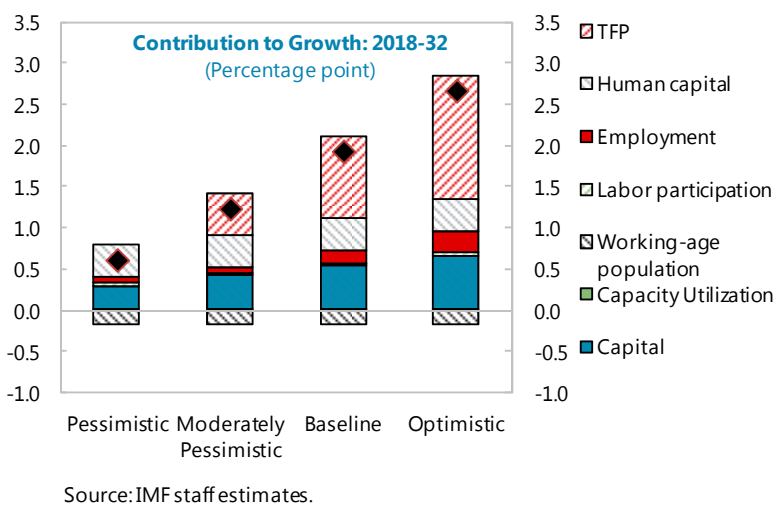
although, at this pace, it would still take some 15 years (by 2028) to bring Portugal's relative labor productivity to the level achieved in the early 1990s. Growth could even be higher under a less conservative assumptions regarding capital accumulation.
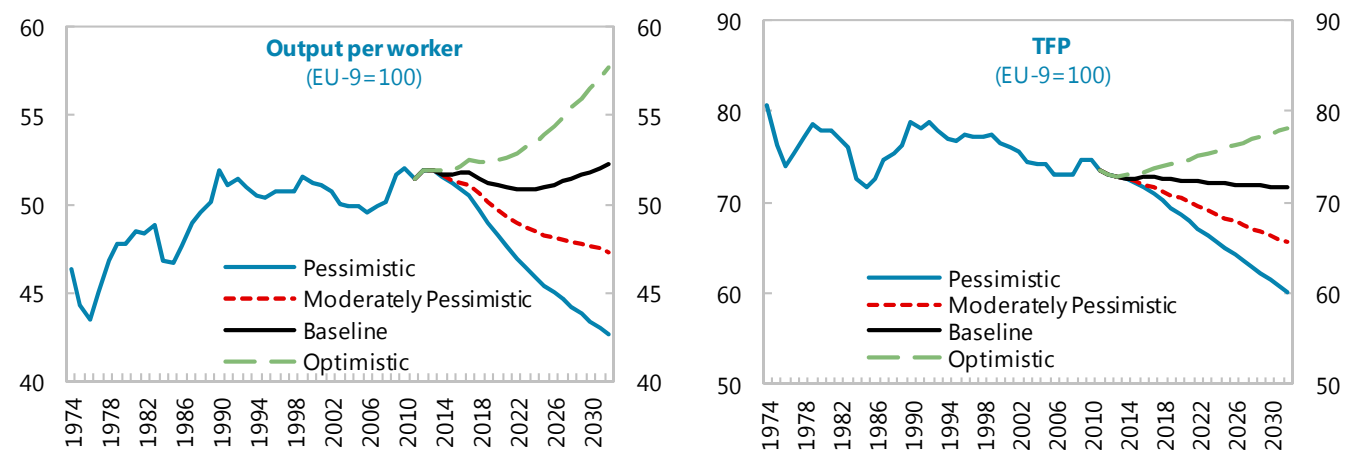

Sources: AMECO; and IMF staff estimates. 


\section{Box I-3. Four Scenarios for the Steady State}

\section{Key Common Assumptions}

- US long-term growth: The paper uses OECD projections of long-term real GDP growth (2.4 percent), investment-GDP ratio ( $16 \frac{1}{2}$ percent), and employment growth ( 0.9 percent).

- US technical progress: For a given initial capital stock, long-term growth projections imply TFP growth of about 0.8 percent per year. We assume (ad hoc) this can be split between 0.4 percentage point from technical progress and 0.4 point from improvement in allocative efficiency.

- $\quad$ Total and working age population in Portugal: Based on Eurostat projections and reflecting demographic trends, total population growth is flat, while working age population (age 15-64) declines by 0.3 percent per year on average in the long run.

- Human capital accumulation in US and Portugal: Human capital accumulates at the same pace as in the past 20 years, at 0.3 percent in the US and 0.6 percent in Portugal.

\section{Four Scenarios}

\section{Pessimistic Scenario}

- Reforms do not bear fruit (or reform implementation encounters major setback).

- TFP remains flat — not only aren't there efficiency gains, but Portugal does not enjoy the benefit of the global technical progress. Relative TFP vis-à-vis the US continues to decline at the same pace as experienced in the past 20 years.

- The average growth rate is 0.6 percent, based equally on physical and human capital accumulation.

\section{Moderately Pessimistic Scenario}

- Some positive spillover from the ongoing rebalancing of the economy towards net exports-led growth-or economy moving towards sectors with higher productivity growth-although, similar to the pessimistic scenario, it assumes no structural reforms.

- TFP grows faster at around $1 / 2$ percent a year - the relative efficiency continues to decline, although at a slower pace than what was experienced in the past 20 years.

- The downward trend in relative labor productivity is stopped by 2032.

- The contribution to the 1.2 percent average growth is equally shared by physical and human capital accumulations, and TFP growth.

\section{Baseline Scenario}

- This scenario incorporates the impact of the structural reforms currently taking place. It assumes that the ongoing reforms will be fully implemented within a 5-year time period.

- TFP grows faster at around 1 percent a year - the relative efficiency starts increasing, although at a slow pace. TFP growth contributes half to the growth of 1.9 percent, with the rest contribution shared by physical and human capital accumulation.

- Structural unemployment is to decline to 11-12 percent, supported by labor market reforms that reduce severance payments and unemployment benefits.

\section{Optimistic scenario}

- This scenario is even more optimistic regarding the impact of structural reforms-broadly consistent with the more optimistic views/estimates about the potential impact of reforms.

- TFP grows at around $1 \frac{1}{2}$ percent a year-the relative efficiency increases faster than in the baseline. TFP growth contributes more than half to the growth of 2.7 percent, with the remaining contribution due to physical and human capital accumulation.

- Structural unemployment is to decline to below 10 percent, supported by labor market reforms that reduce severance payments and unemployment benefits, as well as stronger TFP growth, which spurs more hiring by firms. 


\section{Medium-Term Growth Prospects}

30. While a 2-percent growth appears feasible in the long-term, reaching this mark in the medium-term implies a rapid turnaround in TFP growth and a modest recovery in investment. Taking into account a pickup in the capacity utilization and employment over the next 3-4 years, TFP growth would need to rapidly converge toward about 0.7 percent a year, and investment rates toward about 17 percent. This would imply investment growth of about 4 percent (Figure I-6); and in these circumstances, investment growth would still not be sufficient to generate a positive contribution of capital accumulation to growth. Under staff's baseline scenario, output would bottom out in 2014 and growth would gradually pick up to near 2 percentimplying an average growth of about

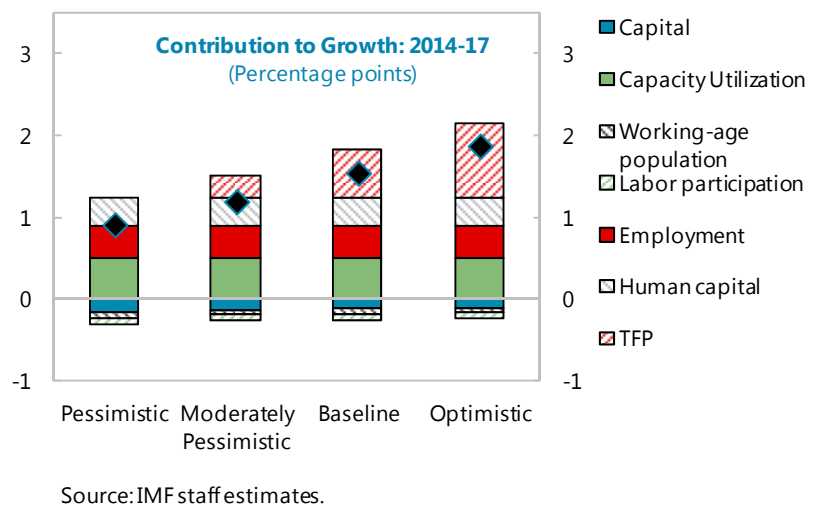
1.5 percent over 2014-17- and the output gap would be closed by 2017. Depending on confidence effects and the headwinds to growth from deleveraging in the public and private sectors, various scenarios can be envisaged for the TFP and investment growth implying average output growth rates of between 1 and 2 percent (see chart).

\section{E. Conclusion}

31. The paper aims to assess Portugal's potential growth performance over the medium- to long-term. The evaluation is underpinned by a backward-looking analysis of growth and convergence, and in particular of the massive TFP shortfall and lack of convergence experienced since the early 90 s. It outlines how the institutional set-up and policy response were inadequate to absorb the various shocks faced by the economy over this period and how the large human capital gap prevented the country from moving up the global value-added chain to tackle increased competition and benefit from new technologies.

\section{The forward-looking analysis, however, assumes that the authorities' ambitious} structural reform agenda delivers on its promise to address these institutional and policy gaps and boost TFP growth significantly. On this basis, achieving a 2-percent growth rate over the long-term - consistent with resumption of moderate convergence growth - appears to be a realistic objective. The challenge is that reaching the 2-percent growth mark in the medium-term implies both a rapid turnaround in underlying TFP growth and a recovery in investment. 
Table I-1. Portugal: Labor and Product Markets Since 2011

\section{Labor Market Reforms}

Introducing a higher degree of representation before allowing extension of collective agreements.

Multi-year tripartite agreement on minimum wage increases halted; minimum wage frozen (duration of program). Public sector salaries cut.

Unemployment benefit reform reduced the replacement rate, shortened duration, and reduced minimum benefits.

Reorientation of ALMP toward training programs and/or practical insertion courses.

Improving the quality of secondary education; strengthening vocational training.

Reduced severance pay: fully aligned under all types (fixed and open-ended) of new contracts; rate of accumulation (without losing accrued-to-date entitlements) lowered and aligned for existing contracts.

Labor Code revisions facilitating working time flexibility; reductions in holidays and annual leave days.

\section{Product Market Reforms}

New Competition Law approved by Parliament; specialized Competition Court established. A study of all major industry regulators is underway. Public Procurement Code has been revised. Removal of certain special rights of the state ("golden shares") in publicly held companies. Competition being fostered in regulated professions (new draft law in Parliament).

Transposition into national legislation of the EU Regulatory Framework for Electronic Communications. Mobile termination rates lowered. Adopted measures for increased competition in fixed market by improving the mobility of consumers. $4 \mathrm{G}$ spectrum auction launched under The spectrum auction has been launched under rules designed to facilitate market entry and increase competition.

Legislation phases out remaining regulated tariffs for electricity by January 2013. The transposition of the EU's Third Energy Package is close to completion. Rent-reducing measures will alleviate some of the still substantial pressures on end-user prices.

Legislation phases out remaining regulated tariffs for natural gas by January 2013. Early stages of work towards establishment of a pan-Iberian gas market.

Landmark Port Work reform near completion-with substantial effects on labor costs and efficiency in ports-and ambitious reform proposals for the port governance model are in train.

New legal frameworks for about half of the amendments required to comply with the EU Services Directive have been approved.

Judicial system reform: targets to resolve the backlog in courts, with good progress in clearing enforcement cases; rationalization of court system; adoption of legal framework for arbitration, strengthening out-of-court dispute mechanisms.

Housing Market: Landmark revisions to the urban rental legislation have been adopted. 
Table I-2. Selected Studies on the Impact of Labor and Product Market Reforms

\begin{tabular}{|c|c|c|}
\hline Study & Sample & Findings \\
\hline Allard et al, 2010 & G20, Europe & $\begin{array}{l}\text { Labor and service market reforms to fill half the gap with the } \\
\text { three best EU performers could yield } 1 / 2 \text { percentage points of } \\
\text { additional annual growth over the next } 5 \text { years, based on IMF } \\
\text { and EC studies. }\end{array}$ \\
\hline Annett, 2007 & $\begin{array}{l}14 \text { EU } \\
\text { countries, 1980- } \\
2003\end{array}$ & $\begin{array}{l}\text { Higher tax wedge and benefits affect labor supply negatively. } \\
\text { Benefits of wage moderation are higher in countries with more } \\
\text { liberal product and labor market regulations. }\end{array}$ \\
\hline Barnes et al, 2011 & OECD & $\begin{array}{l}9 \text { ppt increase in GDP per capita after } 10 \text { years due to the } \\
\text { change in product market regulation implemented by OECD } \\
\text { countries on average between 1998-2003.1/ }\end{array}$ \\
\hline $\begin{array}{l}\text { Bassanini and } \\
\text { Venn, } 2008\end{array}$ & OECD, 1982-2003 & $\begin{array}{l}\text { Strict employment protection depresses productivity growth in } \\
\text { industries where this is binding }\end{array}$ \\
\hline Bayoumi et al, 2004 & Euro area and US & $\begin{array}{l}8.6 \mathrm{ppt} \mathrm{level} \mathrm{increase} \mathrm{in} \mathrm{GDP} \mathrm{in} \mathrm{the} \mathrm{long} \mathrm{run} \mathrm{by} \mathrm{reducing} \mathrm{the} \\
\text { price mark-up in the euro area to US levels. }\end{array}$ \\
\hline $\begin{array}{l}\text { Berger and } \\
\text { Danninger, } 2007\end{array}$ & OECD, 1990-2004 & $\begin{array}{l}\text { Comprehensive and large-scale labor and product market } \\
\text { reforms can lead to additional employment growth of } 1- \\
1.3 \text { percentage points annually. }\end{array}$ \\
\hline $\begin{array}{l}\text { Cincera and } \\
\text { Galgau, } 2005\end{array}$ & 9 EU countries & $\begin{array}{l}0.6 \mathrm{ppt} \text { increase in labor productivity and } 2.7 \mathrm{ppt} \text { increase in } \\
\text { employment growth from reforms to increase the firm entry rate. }\end{array}$ \\
\hline $\begin{array}{l}\text { European } \\
\text { Commission, } 2010\end{array}$ & EU & $\begin{array}{l}0.3 \mathrm{ppt} \text { increase in potential output in the long-run from a } 1 \% \\
\text { tax shift from labor to VAT. }\end{array}$ \\
\hline $\begin{array}{l}\text { Everaert and } \\
\text { Schule, } 2006\end{array}$ & EU countries & $\begin{array}{l}\text { Product and labor market reforms have sizeable steady state } \\
\text { effects, well above } 10 \text { percentage points of GDP for some } \\
\text { countries, depending on pre-reform rigidities. }\end{array}$ \\
\hline $\begin{array}{l}\text { Goldman } \\
\text { Sachs, } 2012\end{array}$ & $\begin{array}{l}183 \text { countries, euro } \\
\text { area }\end{array}$ & $\begin{array}{l}\text { Product market reforms could boost potential growth } \\
\text { substantially, by up to } 1.7 \text { percent annually in euro area } \\
\text { periphery countries. }\end{array}$ \\
\hline Gomes et al, 2011 & Euro area & $\begin{array}{l}\text { Benefits from implementing reforms are large and cross-country } \\
\text { coordination adds extra benefits by limiting the deterioration in } \\
\text { relative prices that occur if reforms are implemented unilaterally. }\end{array}$ \\
\hline $\begin{array}{l}\text { OECD, } 2012 \text { (Bouis } \\
\text { and Duval, 2011) }\end{array}$ & OECD, Euro area & $\begin{array}{l}\text { A comprehensive country-specific reform package could yield an } \\
\text { overall gain in potential GDP of more than } 10 \text { percent of GDP for } \\
\text { most euro area countries over a } 10 \text {-year period. }\end{array}$ \\
\hline
\end{tabular}

\begin{tabular}{|c|c|c|}
\hline Ostry et al, 2009 & $\begin{array}{l}91 \text { developed and } \\
\text { emerging countries, }\end{array}$ & $\begin{array}{l}\text { Structural reforms boost income growth, but growth effects } \\
\text { depend on reform sequencing. }\end{array}$ \\
\hline $\begin{array}{l}\text { Pérez and } \\
\text { Yao, } 2012\end{array}$ & $\begin{array}{l}20 \text { OECD } \\
\text { countries, } 1985- \\
2008\end{array}$ & $\begin{array}{l}\text { A policy package combining services deregulation, a reduction in } \\
\text { tax wedges and replacement rates could reduce unemployment } \\
\text { rates by } 3 / 4-51 / 2 \text { percentage points, depending on country initial } \\
\text { conditions. }\end{array}$ \\
\hline Salgado, 2002 & 20 OECD & $\begin{array}{l}0.2-0.3 \text { ppt increase in TFP growth in the long run, weak results } \\
\text { in the short run from product market reforms implemented } \\
\text { over } 1985-95 .\end{array}$ \\
\hline $\begin{array}{l}\text { Tang and } \\
\text { Verweij, } 2004\end{array}$ & EU & $\begin{array}{l}1 \text { ppt level increase in GDP from a } 25 \% \text { reduction in } \\
\text { administrative burdens. }\end{array}$ \\
\hline $\begin{array}{l}\text { The World } \\
\text { Bank, } 2012\end{array}$ & $\begin{array}{l}\text { OECD, EU } \\
\text { members, and } \\
\text { accession countries }\end{array}$ & $\begin{array}{l}\text { Strict employment protection, high labor tax, and minimum } \\
\text { wages are associated with lower participation and higher } \\
\text { unemployment rates. }\end{array}$ \\
\hline
\end{tabular}


Figure I-1: Contributions to Relative Labor Productivity 1/
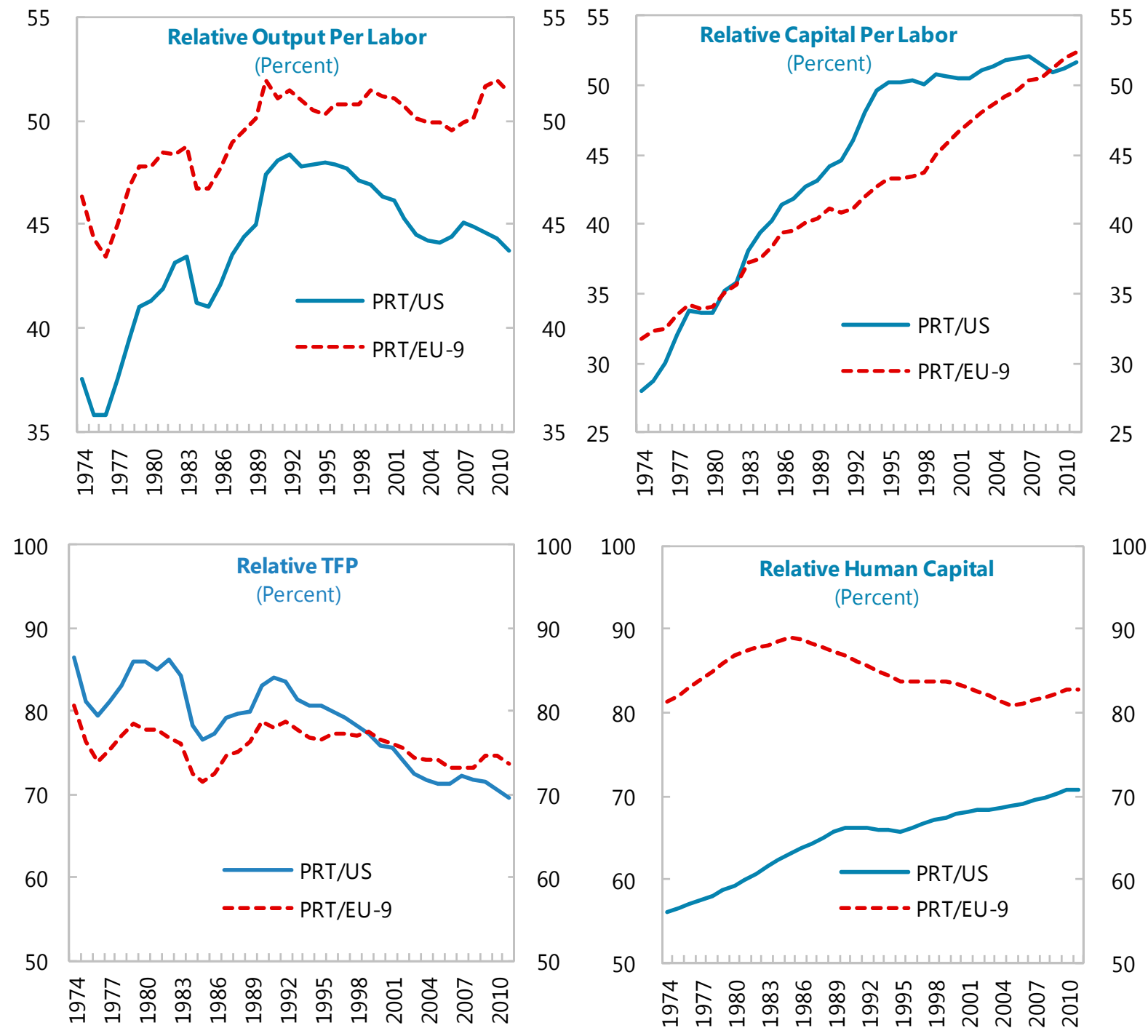

Sources: AMECO; Eurostat; Bank of Portugal; INE; Barro and Lee (2010); and IMF staff calculations.

1/ EU-9 includes a group of 9 EU member countries: Austria, Belgium, Denmark, Finland, France, Germany, Netherlands, Sweden and UK. 
Figure I-2. Relative Labor Productivity - Key Sectors ${ }^{1 /}$

(Average percent change)

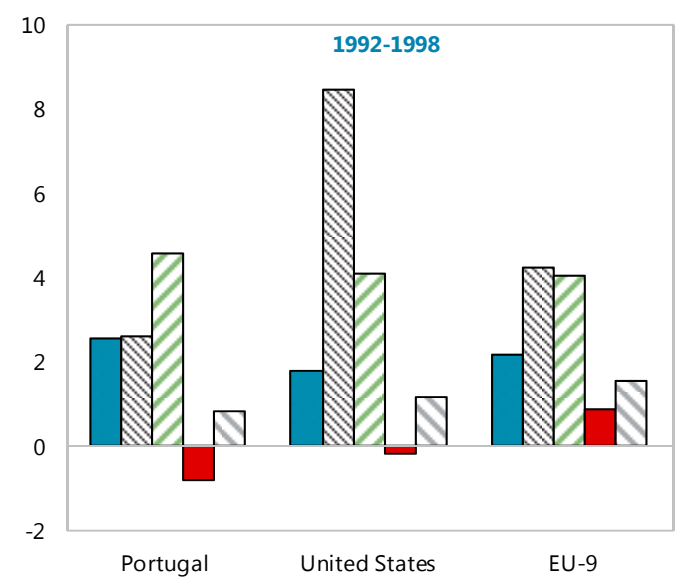

10 Whole economy

8

Agriculture, forestry and

6 fishery products

$\square$ Industry excluding building

4 and construction

$\square$ Building and construction

2

घServices

0

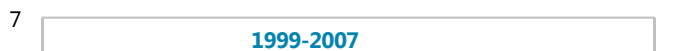

$\square$ Whole economy

5

Agriculture, forestry and

3 fishery products

घIndustry excluding

building and construction

$-1 \quad \square$ Building and construction

-3 a Services

EU-9

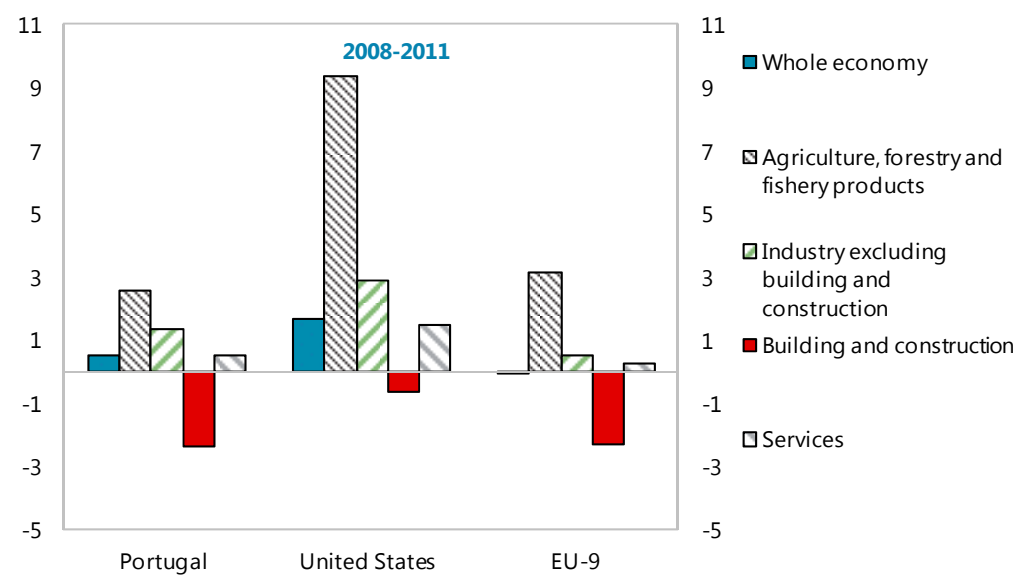

Sources: AMECO; and IMF staff calculations.

$1 /$ EU-9 includes a group of 9 EU member countries: Austria, Belgium, Denmark, Finland,

France, Germany, Netherlands, Sweden and UK.

\section{(C)International Monetary Fund. Not for Redistribution}


Figure I-3. Contribution to Growth - Key Sectors 1/

(average percent change)

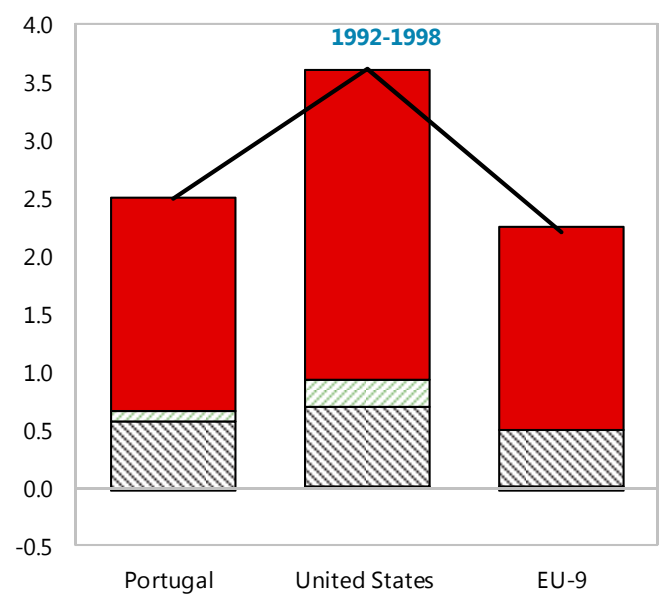

4.0

$3.5 \square$ Services

$3.0 \quad$ Building and

2.5 construction

$2.0 \$$ Industry excluding

building and

1.5 construction

$\square$ Agriculture,

1.0 forestry and

0.5 Gross value added

0.0

$-0.5$

3.0

3.0

2.5

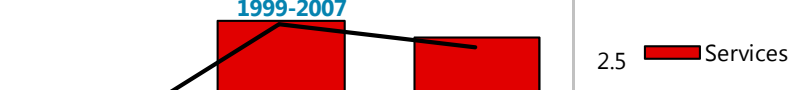

20

1.5

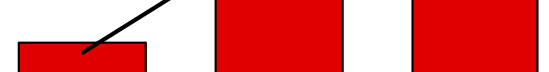

$2.0 \square$ Building and

construction

1.5

1.5 Industry excluding

building and

construction

$\square$ Agriculture, forestry

0.5 and fishery products

.5

0.0
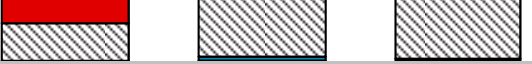

0.0

Gross value added

$-0.5$

Portugal United States EU-9

$-0.5$

1.0

0.5

0.5

0.0

$-0.5$

$-1.0$

$-1.5$

$-2.0$
1.0

$\square$ Services

0.5

Building and construction

$\$$ Industry excluding

-0.5 building and construction

$\square$ Agriculture, forestry

-1.0 and fishery products

Gross value added

$-1.5$

$-2.0$

Sources: AMECO; and IMF staff calculations.

1/ EU-9 includes a group of 9 EU member countries: Austria, Belgium, Denmark, Finland,

France, Germany, Netherlands, Sweden and UK.

\section{(C)International Monetary Fund. Not for Redistribution}


Figure I-4. Contribution to Growth - Demand Side ${ }^{1 /}$

(Percentage points)
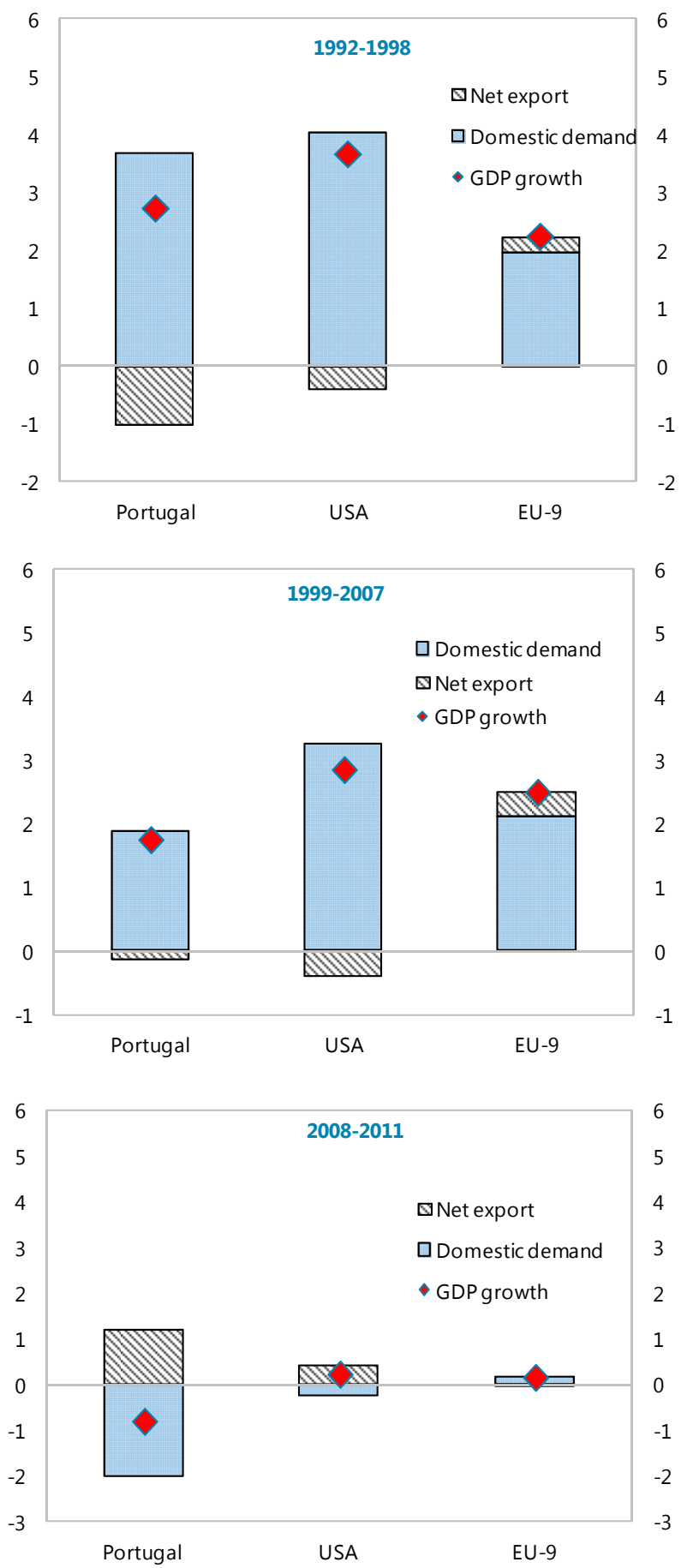

Sources: AMECO; Eurostat; Bank of Portugal; INE; Barro and Lee (2010); and IMF staff calculations.

1/ EU-9 includes a group of 9 EU member countries: Austria, Belgium, Denmark, Finlar France, Germany, Netherlands, Sweden and UK.

\section{(C)International Monetary Fund. Not for Redistribution}


Figure I-5. Four Scenarios Under Structural Reforms
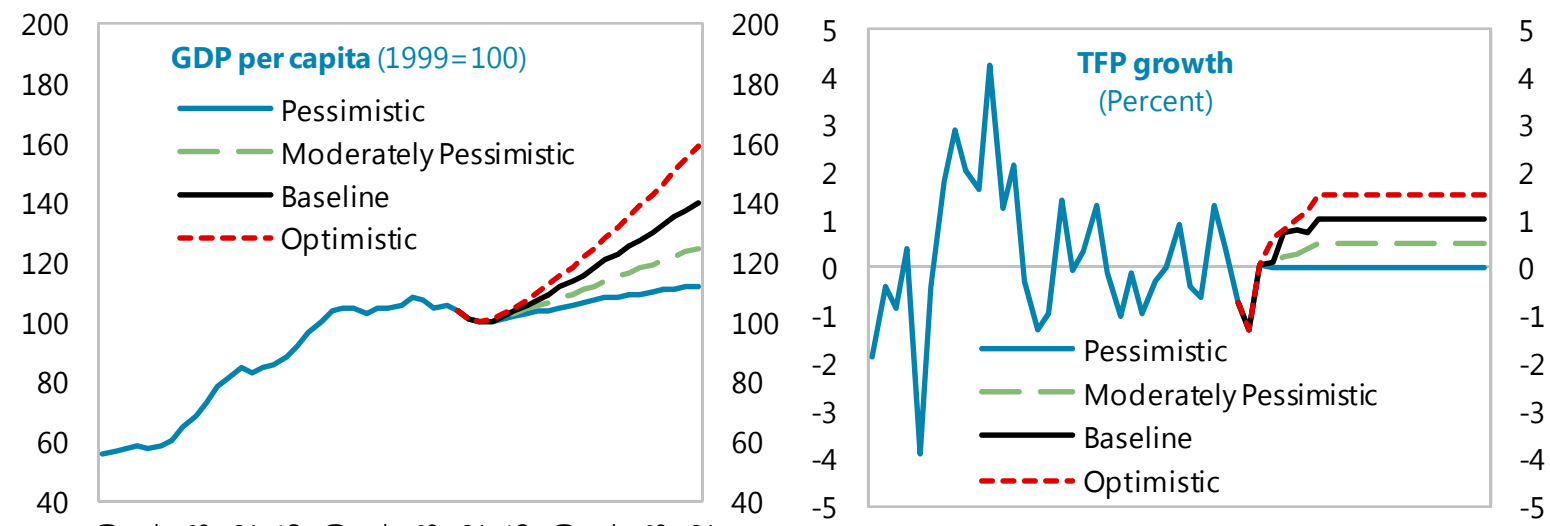

○

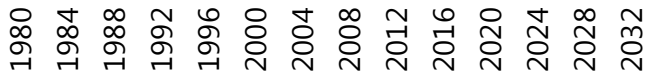

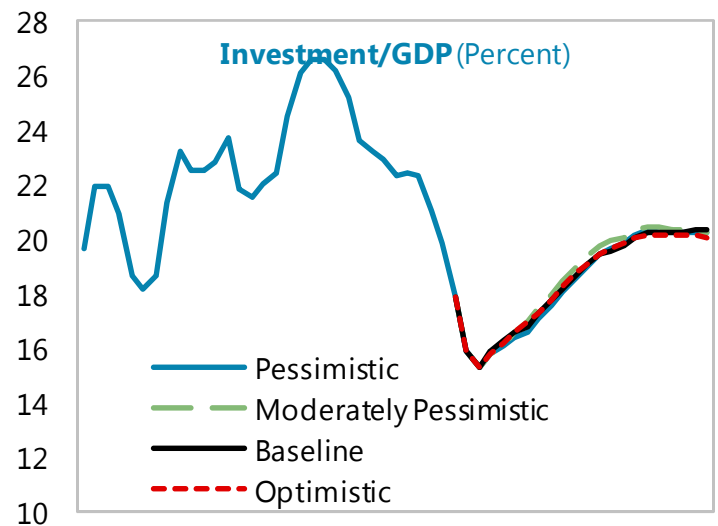

○
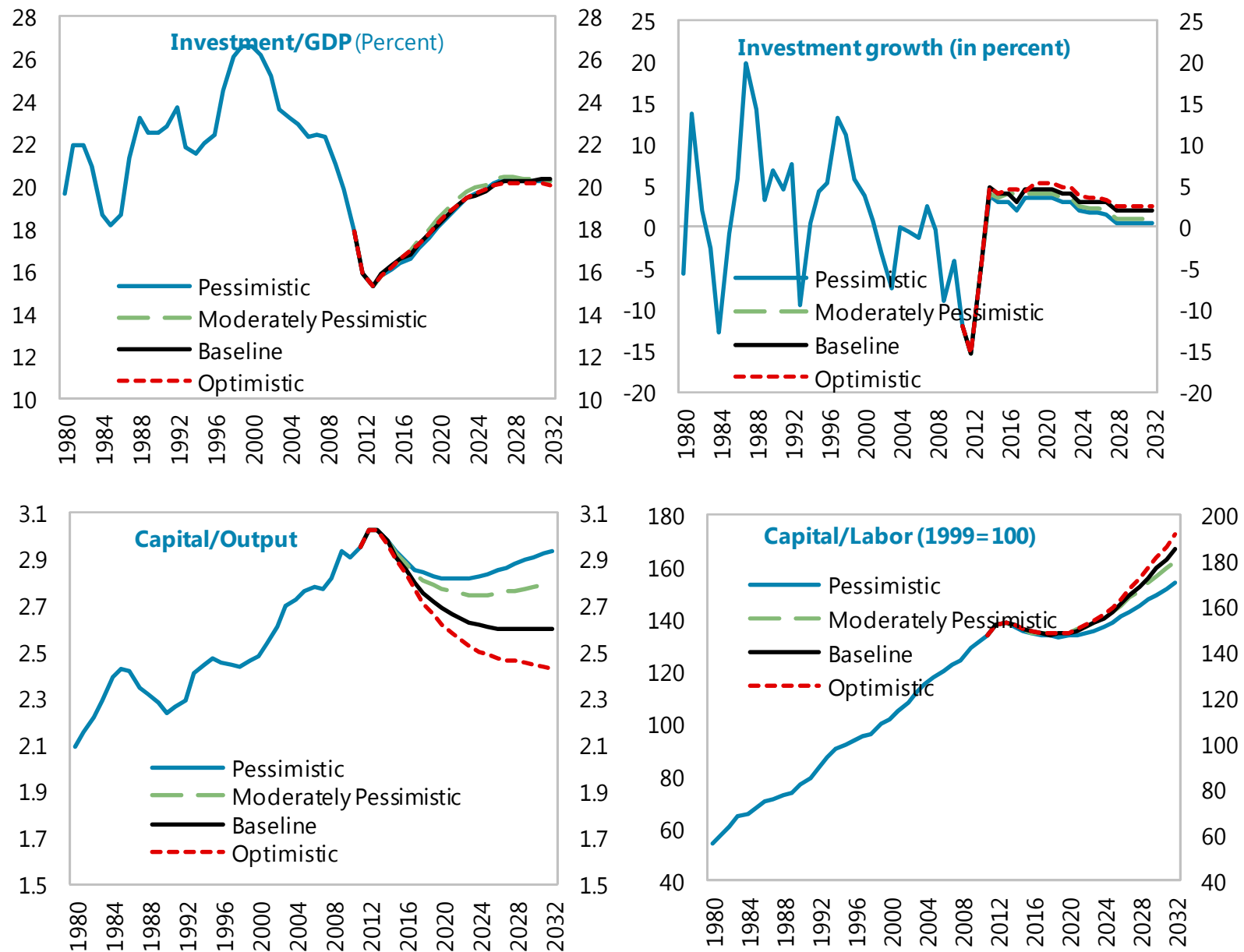

○

Sources: AMECO; Eurostat; Bank of Portugal; INE; and IMF staff calculations, projections and estimation. 
Figure I-6. Baseline: Potential Output-Capital and TFP

Growth of the capital stock is determined by gross investment (from NA) and depreciation -- projected to gradually return to historical averages of 6 percent.

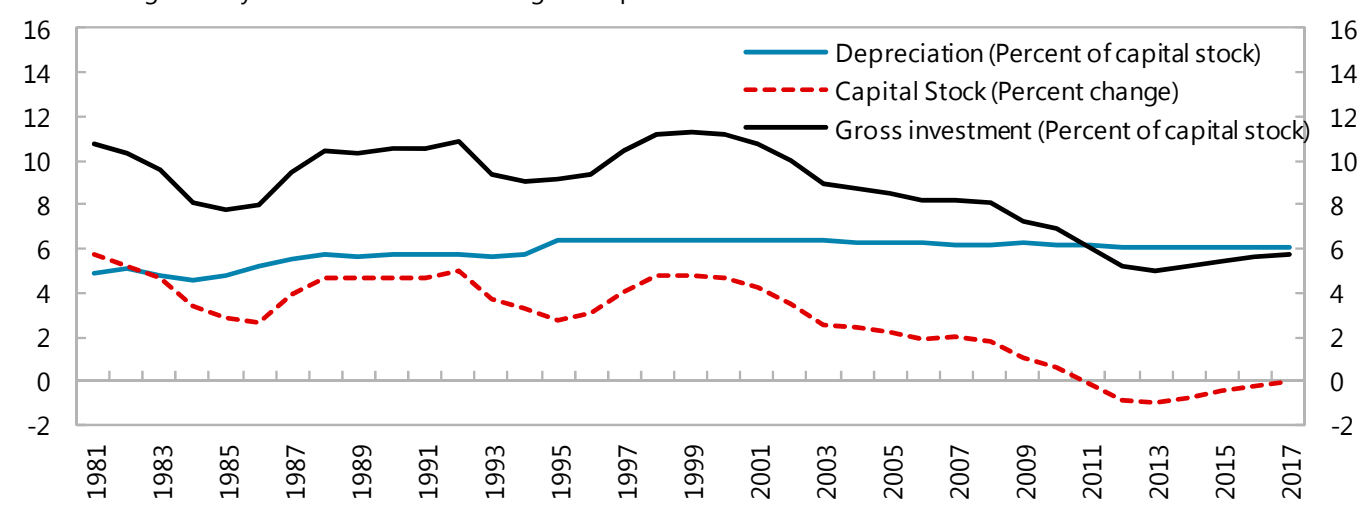

Historical TFP is proxied by smoothed Solow residuals from a human capital and capacity utilization augmented framework.

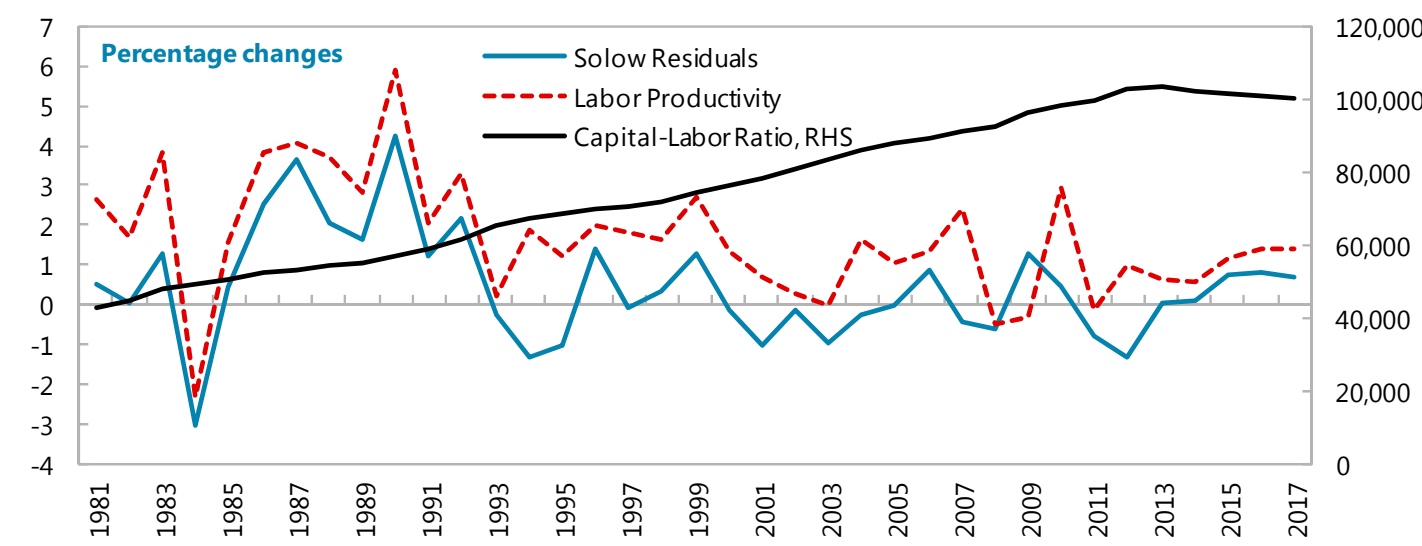

In the baseline scenario, potential GDP is expected to remain low, at around 1 percent, owing to weak TFP growth and lower WAP growth.

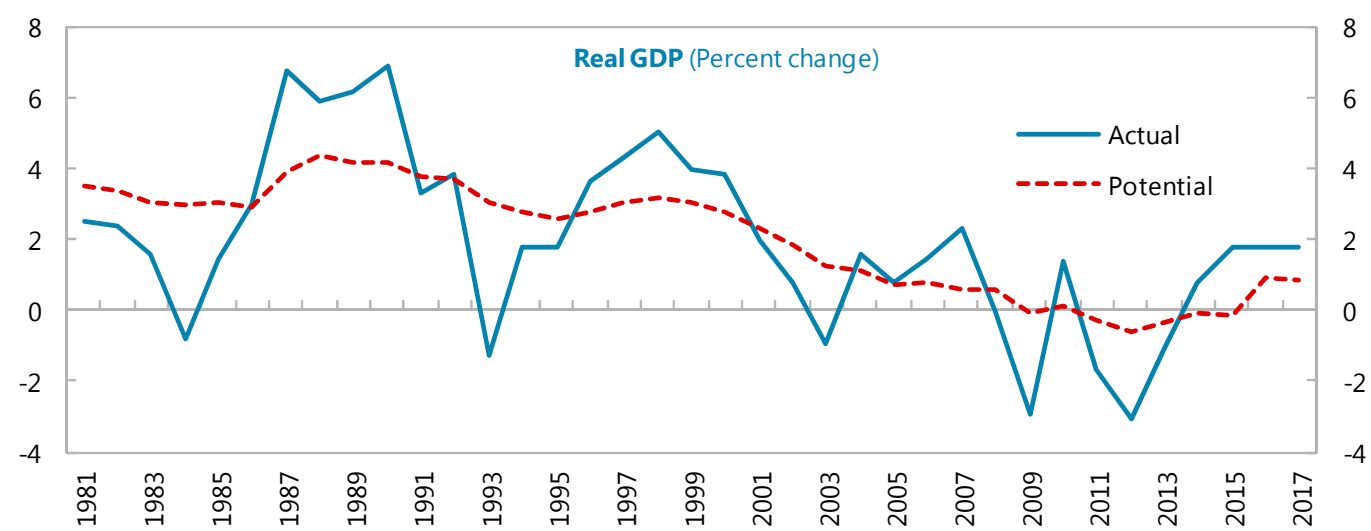

Sources: Ameco; Eurostat; INE; and IMF staff estimates, calculations and projections.

\section{CInternational Monetary Fund. Not for Redistribution}




\section{REFERENCES}

Allard, C., L. Everaert, with A. Annett, A. Chopra, J. Escolano, D. Hardy, M. Mülheisen, and B. Yontcheva, "Lifting Euro Area Growth: Priorities for Structural Reforms and Governance," IMF Staff Position Note No. 10/19 (2010).

Almeida, V., G. Castro, and R.M. Félix, 2009, "The Portuguese economy in the European context: structure, shocks and policy," in The Portuguese Economy in the Context of Economic, Financial and Monetary Integration, Banco de Portugal, 2009.

Amador, J. and C., Coimbra, "Characteristics of the Portuguese Economic Growth: What Has Been Missing?” Banco de Portugal, Working Paper 8, 2007.

Annett, A., "Lessons from Successful Labor Market Reformers in Europe," IMF Policy Discussion Paper No. 07/1 (Washington: International Monetary Fund).

van Ark, B., M. O’Mahony, and M.P.Timmer, 2008, "The Productivity Gap between Europe and the United States: Trends and Causes," Journal of Economic Perspectives, Volume 22, Number 1, Winter 2008, pp. 25-44.

Barnes, S., R. Bouis, P.Briard, S. Dougherty, and M. Eris, 2011, “The GDP Impact of Reform: A Simple Simulation Framework," OECD Economic Department Working Papers No. 834.

Barro, R. and J-W. Lee, 2010, "A New Data Set of Educational Attainment in the World, 1950-2010", NBER Working Paper No. 15902.

Bassanini, A. and R. Duval, 2006, "Employment Patterns in OECD Countries: Reassessing the Role of Policies and Institutions," OECD Social, Employment and Migration Working Papers No. 35.

Bassinini, A. and D. Venn, 2008, "The Impact of Labour Market Policies on Productivity in OECD Countries," International Productivity Monitor, Vol. 17, pp. 3-15.

Bayoumi, T., D. Laxton, and P. Pesenti, 2004, "Benefits and Spillovers of Greater Competition in Europe: A Macroeconomic Assessment," ECB Working Paper 341.

Berger, H. and S. Danninger, 2007, "The Employment Effects of Labor and Product Market Deregulation and Their Implications for Structural Reform," IMF Staff Papers, Vol. 54, pp. 591-619.

Bouis, R., O. Causa, R. Bouis, L. Demmou, R. Duval, A. Zdzienicka, 2012, “The Short-Term Effects of Structural Reforms: An Empirical analysis," OECD Economics Department Working Papers, No. 949. 
Bouis, R. and R. Duval, 2011, "Raising Potential Growth After the Crisis: A Quantitative Assessment of the Potential Gains from Various Structural Reforms in the OECD Area and Beyond," OECD Economic Department Working Papers No. 835.

Braguinsky, S, L.G. Branstetter, and A. Regateiro, 2011, “The Incredible Shrinking Portuguese Firm,” NBER Working Paper 17265.

Cacciatore, M., R. Duval and G. Fiori, 2012, "Short-Term Gain or Pain? A DSGE ModelBased Analysis of the Short-Term Effects of Structural Reforms in Labour and Product Markets," OECD Economics Department Working Papers, No. 948.

Cincera, M., and O. Galgau, 2005, "Impact of market entry and exit on EU productivity and growth performance," European Economy, European Commission, Directorate General Economic and Financial Affairs, Economic Papers N. 222, February.

Everaert, L. and W. Schule, 2006, "Structural Reforms in the Euro Area: Economic Impact and Role of Synchronization across Markets and Countries," IMF Working Paper No. 06/137.

Goldman Sachs, 2012, "Our 2011 GES: A Sharper Signal for Growth," Goldman Sachs Global Economics, Commodities and Strategy Research.

Gomes, S., P. Jacquinot, M. Mohr, and M. Pisani, 2011, "Structural Reforms and Macroeconomic Performance in the Euro Area Countries, A Model-Based Assessment," ECB Working Paper No. 1323 (Frankfurt, European Central Bank).

Goretti, M. and M. Souto, 2012, "Portugal's Corporate (De)Leveraging," in Portugal: Selected Issues, http://www.imf.org.

Lemgruber, A. and M. Soto, 2012, "Designing a Growth-Friendly, Equitable, and Sustainable Fiscal Reform in Portugal," in Portugal: Selected Issues, http://www.imf.org.

Hall, R.E. and C.I. Jones, 1999, "Why Do Some Countries Produce so Much More Output per Worker than Others?" The Quarterly Journal of Economics, February 1999, Vol. 114 , Issue 1, pp. 83-116.

Lusinyan, L. and D. Muir, 2012, "Structural Reforms in Italy: Overview and Macroeconomic Impact," in Italy: Selected Issues, IMF Staff Country Report No. 12/168.

IMF, 2012, "Fostering Growth in Europe Now," Staff Discussion Note, SDN/12/07.

Jaeger, A., 2003, "Corporate Balance Sheet Restructuring and Investment in the Euro Area," IMF Working Paper No. 03/117. 
de Long, J.B. and L.H. Summers, 1991, "Equipment Investment and Economic Growth," The Quarterly Journal of Economics, Vol. 106, Issue 2, pp. 445-502.

Mankiw, N.G., D. Romer, and D.N.Weil, 1992, "A Contribution to the Empirics of Economic Growth," The Quarterly Journal of Economics, Vol. 107, Issue 2, pp. 40737.

de Mello, L. and P. C. Padoan, 2010, "Promoting Potential Growth: The Role of Structural Reform," OECD Economics Department Working Papers, No. 793.

das Neves J.L.C., 1996, "Portuguese Postwar Growth: A Global Approach," in Economic Growth in Europe Since 1945, N. Crfats and G. Toniolo (ed), Cambridge University Press, 1996.

OECD, 2012, "Medium and Long-term Scenarios for Global Growhth and Imbalances," OECD Economic Outlook, Volume 2012/1, Chapter 4.

OECD, Programme for International Student Assessment 2009 Database.

Ostry, J., A. Spilimbergo, and A. Prati, 2009, "Structural Reforms and EconomicPerformance in Advance and Developing Countries," IMF Occasional Paper (Washington: International Monetary Fund).

Pal, S, F. Coricelli, N. Driffield, and I. Roland, 2012, "When Does Leverage Productivity Growth? A Firm-level Analysis," Journal of International Money and Finance, 31 (6), pp. 1674-94.

Pérez, E., and Y. Yao, 2012, "Can Institutional Reform Reduce Job Destruction and Unemployment Duration? Yes It Can,” IMF Working Paper No. 12/54.

Psacharopoulos, George, "Returns to Investment in Education: A Global Update," World Development, XXII (1994), pp. 1325-43.

Salgado, R., 2002, "Impact of Structural Reforms on Productivity Growth in Industrial Countries," IMF Working Paper 02/10.

Stein, J., 2001, “Agency, Information and Corporate Investment," in Handbook of the Economics of Finance, Edited by G.M. Constantinides, M. Harris and R. Stulz, (C) 2003 Elsevier Science B.V.

Tang P. and G. Verweij, 2004, "Reducing the Administrative Burden in the European Union," CPB Memorandum 93, CPB Netherlands Bureau for Economic Policy Analysis.

Tiffin, A., 2006, “Ukraine: The Cost of Weak Institutions," IMF Working Paper No. 06/167. 
Tiffin, A., forthcoming, "Potential Growth Prospects in Euro-area Program Countries," IMF Working Paper.

World Bank, 2012, "Golden Growth—Restoring the Luster of the European Economic Model," (Washington). 


\section{Portugal's Competitiveness ${ }^{1}$}

Portugal's loss of external competitiveness in the run-up to Euro adoption is well documented. ${ }^{2}$ Falling interest rates led to rising investment and consumption that was not matched by productivity growth, with wages and prices rising more rapidly than in trading partners, resulting in sharply deteriorating external balances, and poor growth and employment outcomes. Since the crisis, there has been a strong turnaround in trade and current account balances with little apparent relative price change to date. This raises questions about the sustainability of the adjustment-might recent progress be reversed when the economy begins to recover? This paper assesses the evidence and considers crosscountry experience with adjustment under fixed exchange rate regimes to address this question.

\section{A. How Did Competitiveness Get Out of Line?}

1. From the mid-1990s, Portugal's exchange rate was stabilized in the run-up to the adoption of the euro in 1999. Compared with the decade up to 1994, during 1995-98 the standard deviation of the monthly exchange rate versus the Deutsche Mark fell by half. This exchange rate-based stabilization process allowed inflation to converge to that in the country of the anchor currency in the ERM, Germany-hence, average annual consumer price inflation in Portugal fell from about 11 percent in 1985-94 to 21/2 percent in 1995-99. The process of nominal convergence also facilitated steep declines in interest rates, as euro adoption bolstered commitment to permanently low inflation. This in turn led to a rise in investment and growth, and a fall in private saving.
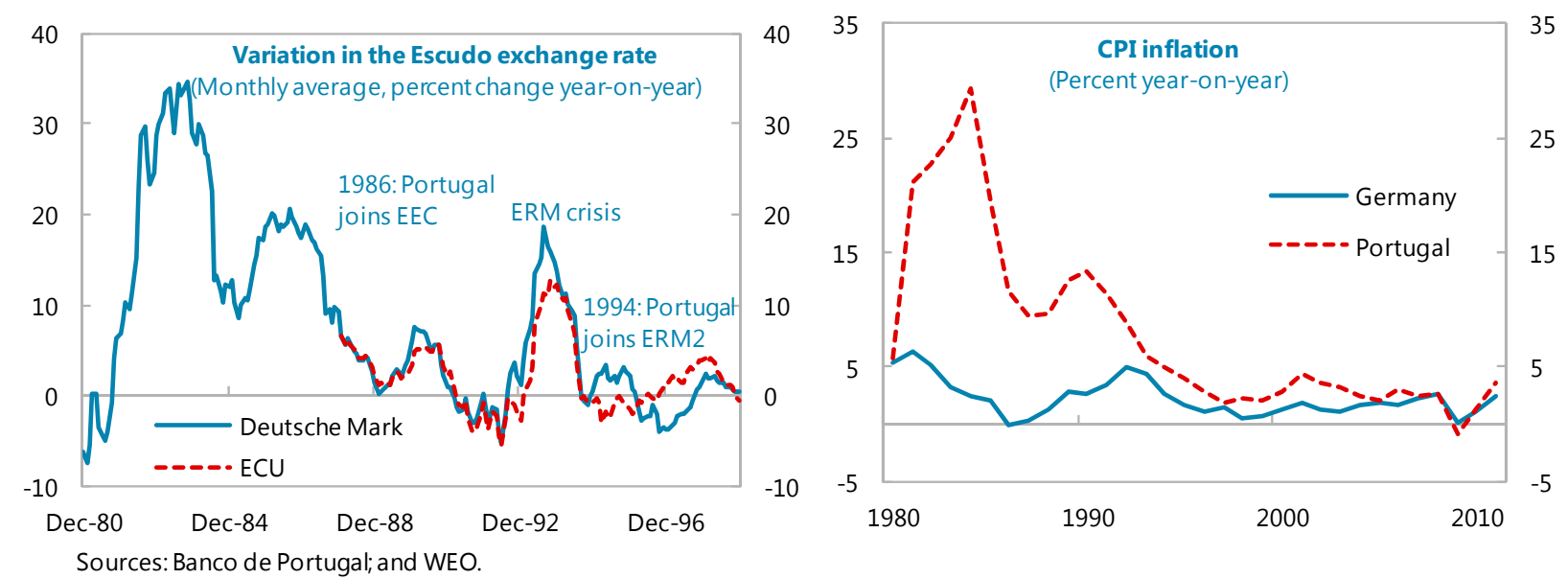

\footnotetext{
${ }^{1}$ Prepared by Ivanna Vladkova Hollar and Alvaro Piris.

${ }^{2}$ See, for example, Amador, Cabral and Opromolla (2009), Blanchard (2007), or Bennet et al (2008).
} 
2. In tandem, competitiveness was declining. After a large devaluation of the escudo in the early-to-mid 1980s associated with an external crisis, there was a period of relatively strong economic growth and external balances up to 1992. Consumer price-based measures of the real effective exchange rate (REER) showed a sharp real appreciation from 1988 through 1992, possibly reflecting a correction of the previous undervaluation, as well as productivity gains and real convergence with European partners. From 1995, REER measures showed a further steady appreciation through to peaks in 2008/09, of about 17 percent on cost (unit labor cost (ULC)-based REER), and 9-12 percent on price-based (GDP deflator and CPI) measures. This latter period was however also one of generally low growth and worsening external balances. One of the ways in which erosion of competitiveness was evident is the faster increase in average compensation in Portugal (3.7 percent per year between 1995 and 2011) compared with average CPI inflation ( 2.5 percent). Nor was this faster increase supported by labor productivity gains, which were anemic throughout this period.
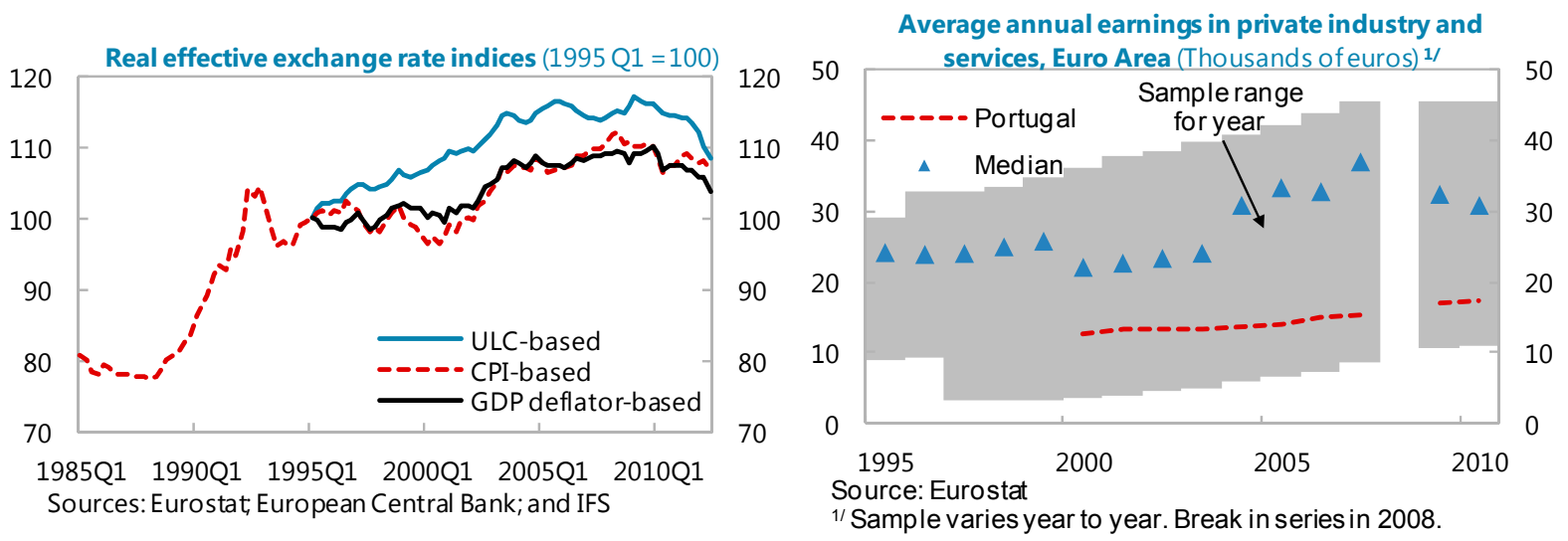

3. Interest rates also declined markedly in the run-up to joining the euro area, with nominal yields on 10-year sovereign debt falling from 19 percent in 1990 to 5 percent in 1999 . The real interest rate fell by 5 percentage points to under $1 \frac{1}{2}$ percent over the same period. Real bank lending rates fell even more sharply, by 9 percentage points.

\section{Put simply, as nominal convergence set in, Portugal's external position began to}

deteriorate. The current account position, which had remained in broad balance after the external crisis of the 1980s, eventually reached deficits in excess of 10 percent of GDP in the late $1990 \mathrm{~s}$, and $12^{1} \frac{1}{2}$ percent of GDP in 2008 . The deterioration reflected worsening trade balances, but also the drying up of remittance flows, an important source of external financing for the economy from the 1960s through the late 1980s. Trade deficits were now financed principally through debt, with relatively little net FDI, and the deterioration in the international investment position led to income account deficits adding to deficits on the current account. 

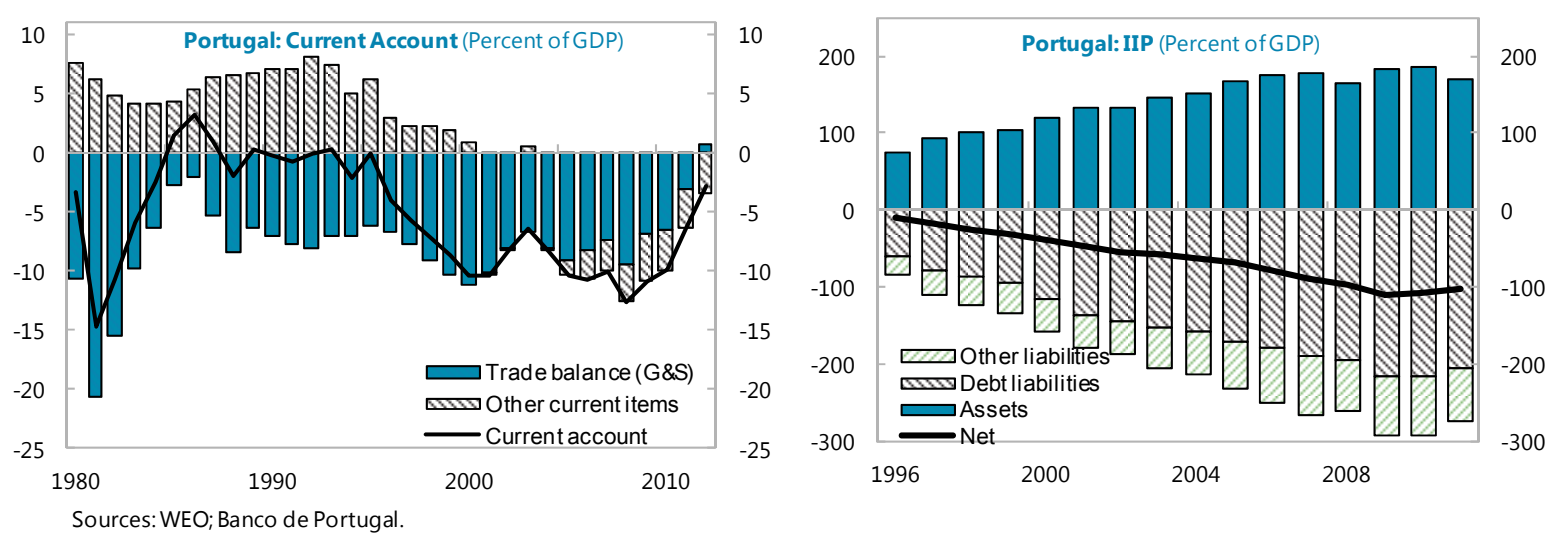

5. From an investment-savings perspective, the late 1990s saw a pronounced increase in investment and a fall in private savings. Investment rose markedly

between 1994 and 2000 - from 24 to $281 / 2$ percent of GDP while private savings fell 7 percentage points to $171 / 2$ percent of GDP. Initially, this was rationalized as reflecting fundamental structural changes - notably access to the European single market and the pay-off from greatly reduced variability in inflation. At the time, it was believed that permanently lower inflation and nominal interest rates

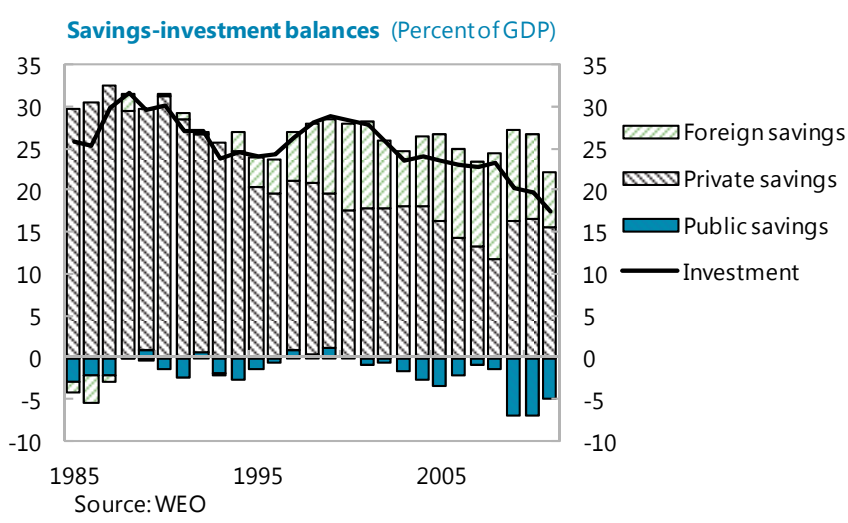
also provided scope for higher debt burden than in the past, allowing for the increase in investment to be accommodated.

\section{Productivity growth, however, was disappointing, and by 2001 GDP growth was}

slowing markedly. Investment was concentrated in non-tradable sectors, where average productivity growth was low (Lin and Roudet, 2012). Negative shocks from the entry of China and Eastern European competitors in Portugal's external markets may also have played a role in worsening outcomes. With little being done to maintain competitiveness and fiscal policy remaining on an expansionary footing (with the exception of a short-lived interval in the mid-2000s), the current account deficit continued to widen to a peak of 12.5 percent of GDP in 2008. The competitiveness challenge during this period is also apparent in a trend decline in export market shares from their peak in 1996 (Amador et al, 2009). Export 
performance was poor, with export growth averaging around 5 percent per year from 19992007, compared with partner country demand of at least a point higher.

\section{The large current account deficits were readily financed by indulgent financial}

markets. With returns on real sector investments disappointing, FDI inflows declined and deficits were financed with debt creating inflows. By 2005, FDI liabilities accounted for about 15 percent of total external liabilities, while portfolio debt and other investment liabilities accounted for three quarters of the total. The economic record up to the global crisis in 2008 was one of low growth, slowly rising prices and wages, stagnant or rising unemployment and deteriorating external balances.

8. After 2001, growth was sluggish. In this environment, rising unemployment should theoretically have led to falling real wages, eventually feeding through to lower export prices and restoring competitiveness. However, as noted, the steady rise in unemployment was not accompanied by labor cost adjustments, with real compensation remaining stable from 2000 onward. Policy contributed to this outcome, with real increases in public wages and minimum wages and pensions as policymakers sought to bolster demand and address longstanding social pressures under weak financing constraints. The decline in competitiveness ensured that rising trade deficits went in tandem with rising unemployment up to the global crisis in 2008.
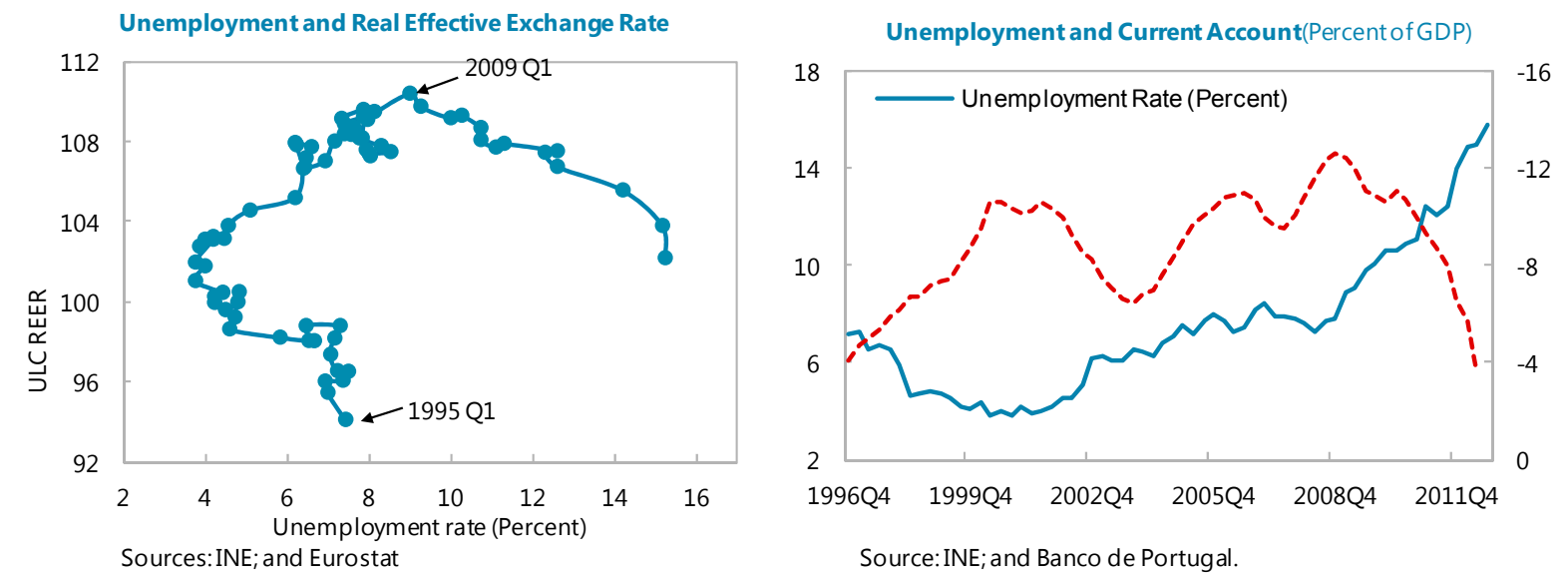

\section{B. Crisis and External Adjustment}

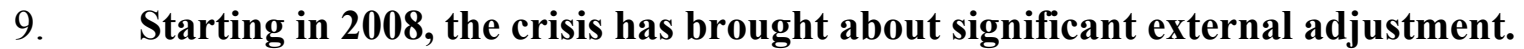

The current account deficit has already declined by 10 percentage points of GDP from its peak, largely due to an improvement in the trade balance. Adjustment has been driven by a "sudden stop" in external financing for the highly indebted private and public sectors, and has been comparable to the 1980s crisis episode, where adjustment was supported by nominal devaluation. Households and firms have increased savings to pay off debt, thereby 
depressing consumption, investment, and imports. Similarly, a significant fiscal consolidation has been underway leading to improvement in the current account.
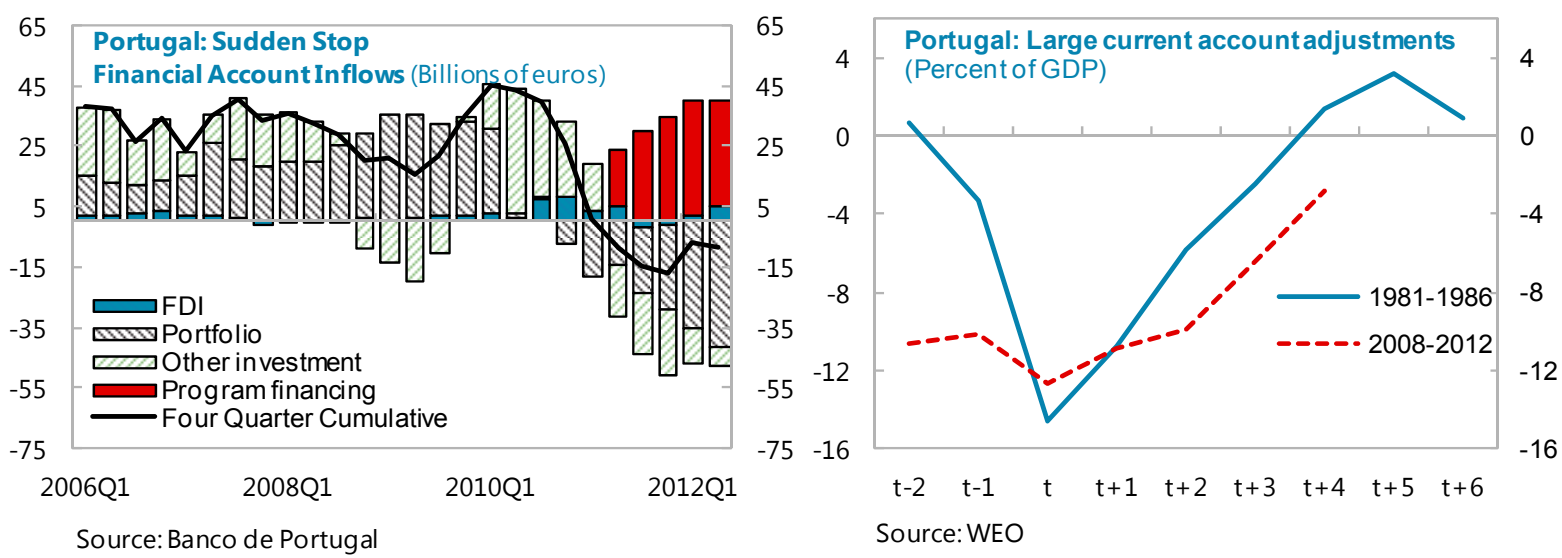

\section{There is some similarity in the pace and composition of current account}

adjustment in Portugal, Ireland and Spain. All the periphery countries have undergone significant current account corrections since 2008, except Italy, whose starting deficit was relatively low at 3 percent of GDP. The sharp turnaround in the Portuguese current account deficit has been underpinned by an improvement in the trade balance, and in particular by strong exports and, to a lesser degree, import compression. Of the total adjustment of 10 percentage points of GDP to date, half has come from exports, 40 percent from import compression, and the remainder from transfers and the income account. This is comparable to the adjustment in Spain, where exports also account for half of the total, and Ireland, where exports are rising more than twice as fast as imports as the economy returns to growth. Among the four euro area periphery countries with significant current account adjustment to date, only in Greece has import compression outweighed export growth, explaining 80 percent of the total adjustment.

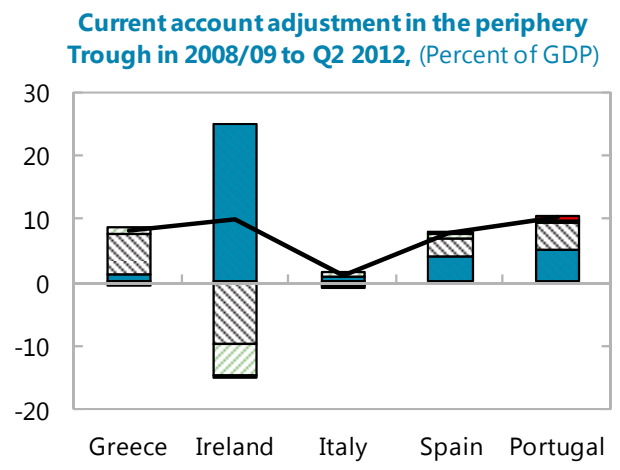

Source: Haver Analytics.
Portugal: Trade in Goods and Services, 12-month Balance, to Sept 2012 (Billions of euros)

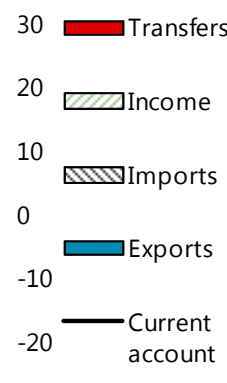

Source: Banco de Portugal. 


\section{The strong export performance of recent months in Portugal is all the more} impressive given the relatively weak demand conditions in many trading partners. Export volume growth from the trough in 2009 has been 22 percent, while import volumes have fallen by close to 7 percent. Two previous episodes of large reversals in the Portuguese trade deficit have also been export-led, with comparably much larger increases in export volume of around 50 percent in the first four years of adjustment. The first episode in the 1960s occurred in the context of much stronger global growth, and while global growth is similar now to that in the 1980s episode, demand in core European trade partners is weaker, and 1980s episode occurred in the context of a sizeable nominal depreciation.

\section{Portuguese exports have grown across a broad range of product categories, with} a marked diversification in export destinations. Within product categories, exports of fuels and lubricants have performed strongly—reflecting excess refining capacity and depressed domestic demand - growing by close to 160 percent in nominal terms from the trough. However, this still represents only 7 points of total nominal export growth of 42 percent over this period, with industrial goods and transport equipment contributing 60 percent of total growth. There has also been a steady diversification of export destinations, with the share of the total going to the European Union declining by

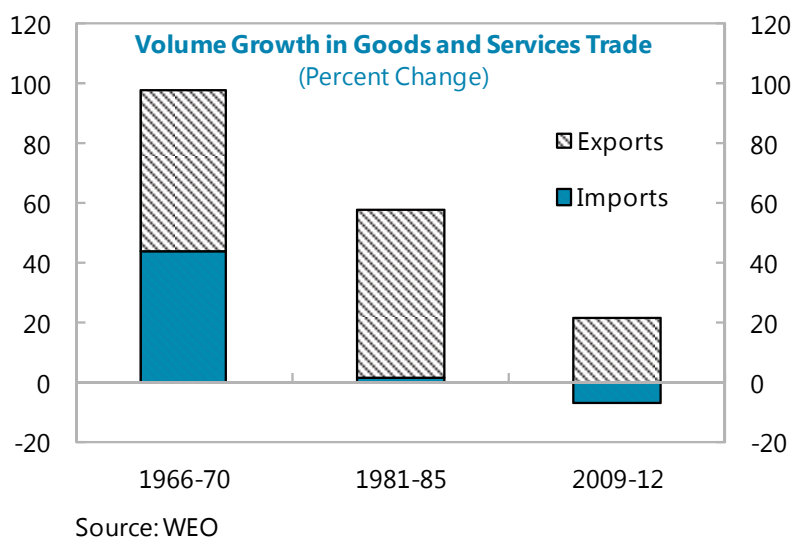
5 percentage points to about 70 percent.

Angola, China, the US, and Brazil have all grown in importance as export destinations, albeit from small bases. One component of growth arises from reaching a critical mass of transport equipment exports to justify direct shipment to China, rather than via Germany, and thus in large part replaces one destination with another without reflecting increased production of exportable goods. However, exports to Germany have held up even as those to China have grown.

\section{Relative price adjustment has been modest and has lagged behind the reversal in} the trade balance (see Table II-1). There have been some recent declines in unit labor cost, led by productivity growth through job shedding rather than wage reductions, particularly in tradable sectors. The pattern is similar across Europe, with "core" countries also seeing exports recover from the global crisis and then exceed 2008 levels, while they have shown little change in ULC-based REER measures. 


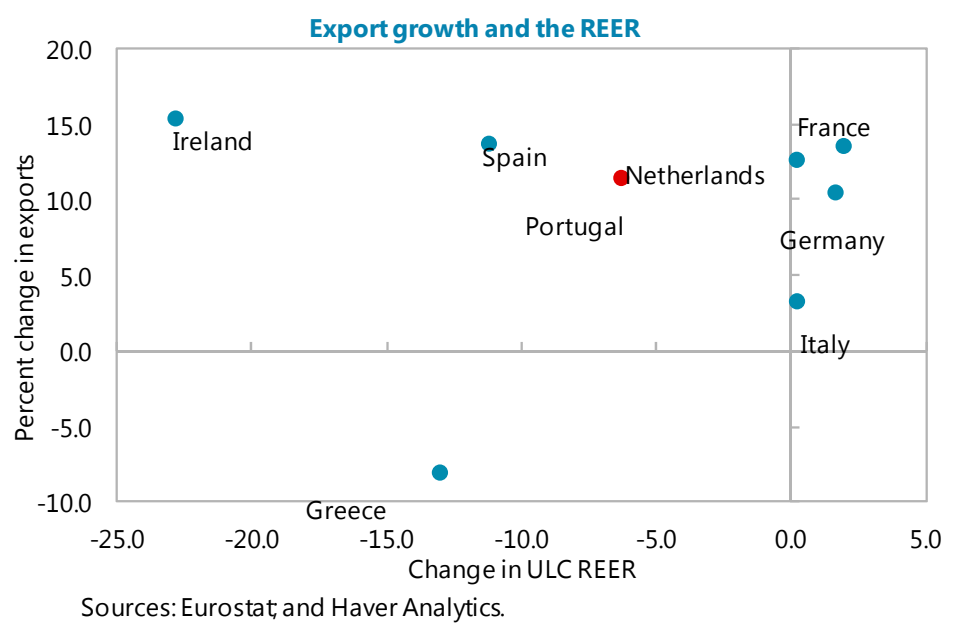

14. But is the adjustment permanent? In Portugal, the absence of a strong REER depreciation, the reliance on labor shedding, and the possible impact of economic recovery (rising demand for imports for investment and reversion to selling exportable goods in the internal market) raise questions about whether a durable adjustment is feasible. Reducing the highly negative IIP (-104 percent of GDP in 2011) will require a sustained, sizeable adjustment. In the absence of the exchange rate as a policy tool to adjust relative prices, this also raises questions about the costs of adjustment in lost output.

\section{Episodes of Internal Devaluation}

15. To explore these questions, ten "internal devaluations" are considered. These are episodes of significant current account adjustment, generally associated with structural reform, where nominal exchange rates were not used. They cover the cases in Denmark, Germany, and the Netherlands, where adjustment was not associated with a sudden stop in capital inflows, as well as in Hong Kong, the Baltics and the ongoing adjustments in Greece, Portugal, and Spain, where financial account pressures have been important in driving adjustment. The episodes cover the period from the beginning of the adjustment up to the time when the current account ceases to improve (a median duration of four years - see Table II-1 and Figures II-1-3). An important caveat is that while past adjustments were also "successful", in a sense that the adjustment has been permanent, the same is still not known of the episodes still underway, where cyclical recovery may undo some of the adjustment. Among the key stylized facts that emerge are: (1) current account adjustment occurred without large changes in the REER; (2) outright deflation has not been a feature of adjustment; and (3) growth costs have varied, depending on external demand and economic flexibility.

16. Large cumulative current account adjustments have been achieved with relatively small cumulative headline price-based REER changes: 
- $\quad$ The median peak-to-trough depreciation in the headline CPI-based real effective exchange rates in the ten cases is just under $2 \frac{1}{2}$ percent-with the notable exception of Hong Kong's 20 percent depreciation - against a median current account adjustment of 8 percent of GDP. In cumulative terms, over the full adjustment episodes, the CPI-based REER has generally appreciated, with a NEER appreciation working against a median underlying relative price decline of $2 \frac{1}{2}$ percent.

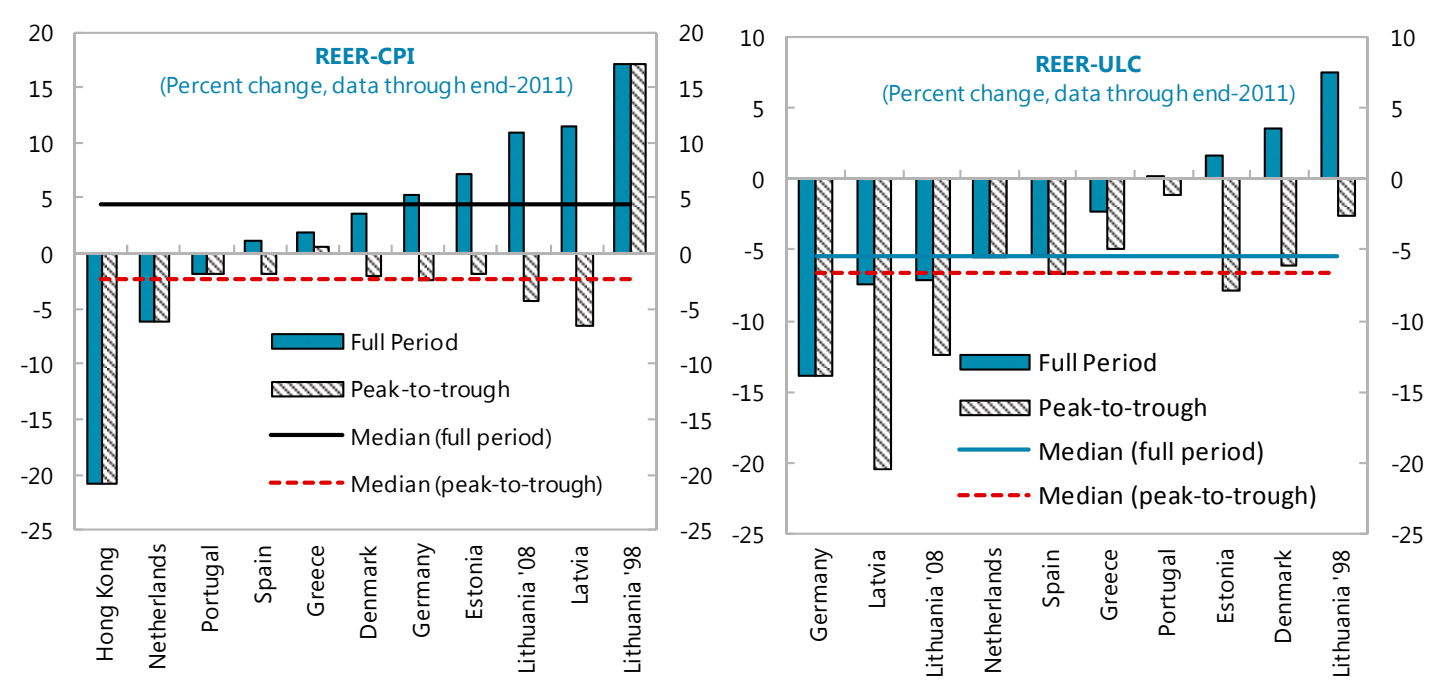

Source: European Commission, AMECO database; European Commission, Price and Competitiveness Project; IMF, INS database; IMF, WEO database; and Fund staff calculations.

- $\quad$ ULC-based REERs have depreciated more: the median cumulative depreciation was $5 \frac{1}{2}$ percent, with a median peak-totrough depreciation of $6 \frac{3}{4}$ percent, suggesting that it is relative ULCs that matter for external adjustment. However, it appears that most of the adjustment in relative ULCs was driven by labor shedding, as nominal wages rose, but unemployment increased markedly (text figure). Latvia and Greece are notable exceptions. ${ }^{3}$

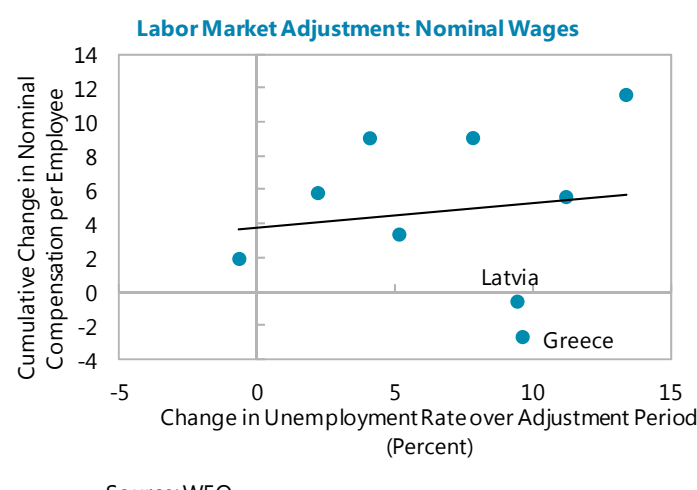

Source:WEO.

\footnotetext{
${ }^{3}$ There is limited (and heterogeneous) empirical evidence of the role of cost- vs. price-based real exchange rate measures in explaining external adjustment. For example, Chinn (2006) finds that for the U.S. the sensitivity of exports to the real exchange rate is 2.3 when using the CPI-deflated measure, and smaller (0.7) when specified by unit labor costs. Lafrance, et. al., (1998) shows that real effective exchange rate indices that are computed using unit labor costs explain movements in Canadian net exports and real output significantly better than those based on consumer price indices.
} 


\section{Relative price adjustment has generally been effected without the need for}

domestic deflation. With the notable exception of Hong Kong and Lithuania in the late 1990s, cumulative changes in consumer prices and the GDP deflator have been positive in all other cases. In the context of moderate external inflation, low domestic price growth rather than outright price declines has been enough to generate sufficient relative price adjustment.

\section{The growth cost of adjustment episodes varied significantly across countries, with the following factors seeming to be at play:}

- $\quad$ Strong external demand has been a key factor. Rapid export growth has supported GDP growth as domestic demand has adjusted. Median cumulative export growth over the adjustment period was over 35 percent in cases that registered a cumulative rise in output, in sharp contrast to those cases where output declines have been substantial (where cumulative export growth was 10 percent). A decomposition of the current account adjustment by main components highlights that episodes with lower growth cost are export-driven, in the context of robust external demand (Figure II-3).

- $\quad$ Low cost episodes are characterized by declines in the relative price component (RPI) of the REER over the adjustment episode. These also map to the successful past internal devaluations associated with structural reforms. A key factor in explaining this result may be that lower domestic inflation helped support real disposable incomes. For roughly the same median change in nominal wages (Table II-1, last two columns), efforts to contain domestic price growth have delivered still-positive real disposable income growth, which may have prevented the sharp decline in private consumption observed in cases where inflation containment has proved elusive. However, the paucity of meaningful and long-dated indicators of labor and product market flexibility limit what can be said on the role structural determinants in the cost of adjustment.

- $\quad$ The low cost adjustments, and particularly those not driven by reversals in external financing, were characterized by structural reform processes, generally aimed at liberalizing labor and product markets. While part of the result is therefore explained by the absence of a financing shock, lower output losses over the medium term may also be related to scope for RPI declines, as noted above, and easier reallocation of resources across the economy.

- $\quad$ Large adjustments with a high output cost are characterized by a shorter duration. This likely reflects important constraints in this specific set of case studiesadjustments necessitated by sudden stops in capital flows that do not allow for a more gradual adjustment, for example. 


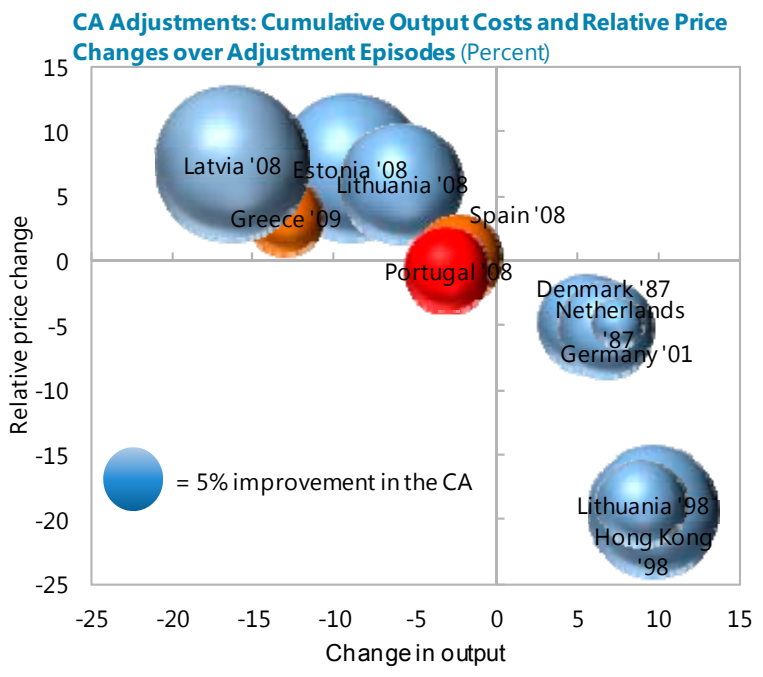

Sources: INS; and WEO.

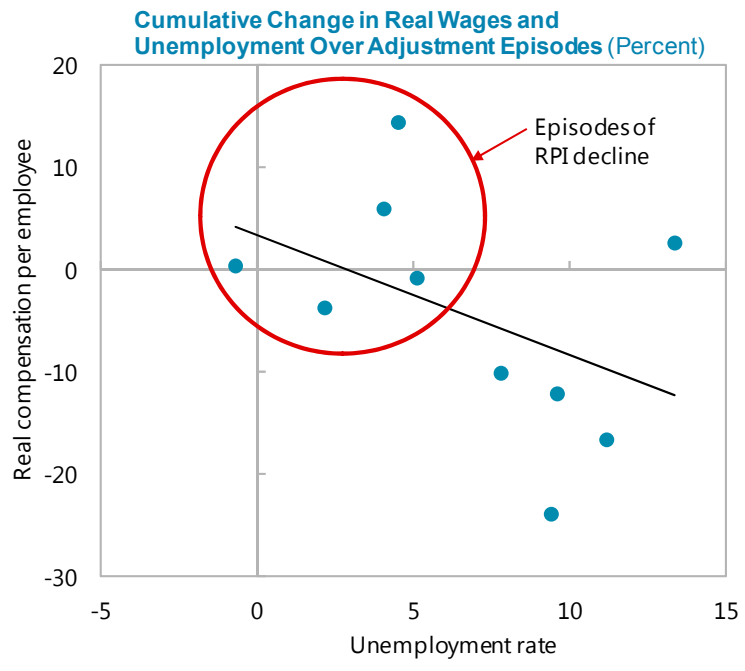

Sources:INS; WEO; AMECO; and IMF staff calculations.

\section{Assessment}

\section{The turnaround in Portugal's external balances in such a short time has been}

remarkable. To a degree, this has been brought about by the sharp curtailment in the availability of external financing since the global crisis began in 2008. After many years of low and readily available financing, the sudden stop has been an important factor behind the recession. Relative price changes, however, have lagged behind the large swing in the trade balance. With investment at low ebb and unemployment at record highs, the durability of the adjustment once the economy begins to recover can therefore be questioned. In this context, there are essentially two interpretations of the recent sharp turnaround in the external account:

- The more benign interpretation is that the rapid reversal in the external balances is a sign of a permanent adjustment, with a strong contribution from export growth. One of the factors that had been behind the widening of the current account deficit prior to 2008 was excess domestic demand. But in the wake of the global financial crisis, debt tolerance has dissipated and financing has become durably more expensive. Consequently, both consumption and investment are henceforth unlikely to revert to previous peaks. And with both private and public sector leverage still high, both sectors are likely to maintain higher levels of savings to pay down debt. In this context, large relative price adjustments may not be necessary for the current account adjustment to endure. There has already been some adjustment in competitiveness indicators, and all that is required for the adjustment to endure is a moderate recovery in external demand.

- A less benign interpretation of the recent current account correction, however, is that it largely reflects the presently weak domestic demand conditions. With investment 
and consumption subdued, not only has this meant lower import demand but also higher exports of tradable goods that would have otherwise been sold on the domestic market. A good example of the latter is the recent jump in exports of refined fuel - an almost perfectly tradable good - as domestic demand has slumped. With the relative price of tradable relative to nontradable goods not having adjusted all that much, as the economy recovers it will lead to higher imports, somewhat lesser exports and widening of the current account deficit.

\section{The implications of these two perspectives in terms of the likely path of wages,} prices and the real effective exchange rate are different. Under the more optimistic view, the changes in demand patterns induced by recession and (to some extent, permanently) higher financing costs underpin external adjustment. Large price and wage adjustments may not be needed, particularly if structural reform facilitates resource reallocation. The second view, in contrast, could imply a more prolonged, or a more acute, episode of wage and price adjustment (as for example in the Baltics). In this view, demand for tradables would pick up sharply with incipient economic recovery, running afresh into financing constraints generating new pressures on wages and prices.

\section{While it is still too soon to draw definitive conclusions, the evidence so far} appears more supportive of the first view. External financing constraints have been tight but have started to ease of late, particularly for the sovereign, with borrowing costs declining markedly in recent months. Larger corporates have also seen their access to external financing being gradually restored. Export growth has been broad-based across products and destinations, and has run ahead of partner country demand indicating market share gains from 2010 onward. While declining capacity utilization and profits since 2011 suggests firms may be substituting foreign for domestic demand rather than increasing production, by the same token there should be scope to maintain presence in foreign markets even as domestic demand recovers.

\section{Previous experiences with internal devaluation also suggest large real exchange} rate changes are not always necessary for permanent adjustment. As in several such successful cases, structural reforms in Portugal should bolster productivity growth over the longer run. There is some evidence that countries with relatively flexible prices-i.e. where RPI gains were possible - endured lower losses in employment and output. Favorable external demand conditions have been also been an important mitigant, an effect Portugal is mimicking, albeit partially, through diversification to relatively dynamic markets outside the euro area. Combined with lower domestic absorption of tradables, debt reduction efforts, and higher cost of external financing, these developments suggest that relatively slow gains in cost competitiveness could prove sufficient to achieve a durable external adjustment. 
23. Structural reforms have an important contribution to make in allowing the adjustment to endure. Reforms contributing to greater flexibility in price setting in product and labor markets could accelerate falls in costs and real exchange rate adjustment. They could also enable a more rapid resource reallocation and productivity rises mitigating the need for aggregate falls in declines and employment. This latter point could describe the structural reform-led adjustments of some of the lower-cost episodes discussed above, such as Germany or the Netherlands, where real compensation fell modestly or not at all. In those cases, real exchange adjustment was accumulated over time with wages and prices rising more slowly than in partner countries, and the product mix shifting towards tradable goods. 


\begin{tabular}{|c|c|c|c|c|c|c|c|c|c|c|c|c|c|c|}
\hline \multicolumn{15}{|c|}{$\begin{array}{l}\text { Table II-1 External Adjustment Episodes Under Rigid Nominal Exchange Rates } \\
\text { (Cumulative percent change unless otherwise indicated) }\end{array}$} \\
\hline & Denmark ' 87 & Estonia '08 & Germany '01 & Greece '09 & Hong Kong ' 98 & Latvia '08 & Lithuania '08 & Lithuania '98 & Netherlands ' 87 & Spain '08 & Portugal '08 & $\begin{array}{c}\text { Median - All } \\
\text { episodes }\end{array}$ & $\begin{array}{l}\text { Median - With } \\
\text { RPI declines }\end{array}$ & $\begin{array}{c}\text { Median - } \\
\text { Without RPI } \\
\text { declines }\end{array}$ \\
\hline Headline Growth & 5.6 & -9.1 & 6.8 & -13.1 & 9.7 & -16.4 & -5.9 & 9.0 & 7.5 & -2.3 & -3.0 & 1.7 & $\begin{array}{ll}7 & 7.5\end{array}$ & -9.1 \\
\hline Public Consumption & 6.9 & 3.9 & 2.7 & -11.9 & 16.9 & -15.8 & -4.0 & -6.0 & 2.7 & 7.7 & 2.3 & 2.7 & 2.7 & -4.0 \\
\hline Private Consumption & 0.9 & -19.4 & 3.1 & -11.7 & 0.0 & -23.6 & -13.3 & 15.8 & 4.8 & -4.3 & -4.2 & -2.2 & 3.1 & -13.3 \\
\hline Investment & -31.5 & -39.2 & -6.3 & -48.5 & -18.3 & -38.7 & -36.3 & -0.4 & 18.7 & -28.8 & -27.9 & -30.1 & -6.3 & -38.7 \\
\hline Exports & 37.8 & 25.3 & 53.3 & -16.2 & 40.3 & 10.0 & 30.1 & 11.0 & 18.3 & 9.6 & 3.8 & 21.8 & 37.8 & 10.0 \\
\hline Imports & 14.5 & -3.0 & 35.7 & -34.3 & 28.5 & -19.9 & 4.4 & 8.0 & 17.0 & -14.7 & -10.6 & 6.2 & 17.0 & -14.7 \\
\hline Unemployment rate & 4.5 & 7.8 & 2.2 & 9.6 & 5.7 & 9.4 & 11.2 & 4.1 & -0.7 & 13.4 & 5.1 & 6.8 & 4.1 & 9.6 \\
\hline Private Consumption (share of GDP) & -2.3 & -6.4 & -2.1 & 1.1 & -6.1 & -6.3 & -5.3 & 3.6 & -1.3 & -1.3 & -0.8 & -2.2 & -2.1 & -5.3 \\
\hline Exports (share of GDP) & 8.1 & 27.3 & 13.6 & -0.9 & 40.3 & 13.4 & 21.4 & 0.9 & 3.7 & 3.8 & 2.3 & 10.8 & 8.1 & 13.4 \\
\hline Imports (share of GDP) & 2.0 & 5.8 & 8.3 & -10.0 & 26.5 & -2.9 & 7.5 & -0.5 & 3.0 & -5.3 & -3.3 & 2.5 & 3.0 & -2.9 \\
\hline Private Savings (percent of GDP) & 7.1 & 10.3 & 2.3 & 1.2 & 5.0 & 12.4 & 6.5 & 3.3 & 5.1 & 9.0 & 1.4 & 5.8 & 5.0 & 9.0 \\
\hline Public Savings (percent of GDP) & -5.9 & -5.3 & 1.5 & -2.3 & -2.3 & -4.9 & -5.6 & -2.0 & -0.9 & -11.6 & -0.4 & -3.6 & -2.0 & -5.3 \\
\hline Investment (percent of GDP) & -7.1 & -14.1 & -4.2 & -6.1 & -12.1 & -13.8 & -12.4 & -5.5 & 2.1 & -8.8 & -5.4 & -8.0 & -5.5 & -12.4 \\
\hline CA balance (percent of GDP) & 8.7 & 19.1 & 8.0 & 5.0 & 14.8 & 21.2 & 12.8 & 6.8 & 2.1 & 6.3 & 6.2 & 8.3 & 8.0 & 12.8 \\
\hline GDP Deflator & 23.5 & 9.3 & 5.8 & 5.7 & -17.5 & 15.0 & 13.5 & -0.4 & 2.6 & 4.3 & 2.9 & 5.8 & 2.6 & 9.3 \\
\hline \multicolumn{15}{|l|}{ Manufacturing Sector: } \\
\hline ULCs & 30.3 & -4.3 & -11.8 & 2.0 & -6.4 & -4.8 & -14.1 & -11.5 & -4.2 & 2.4 & $\ldots$ & -4.6 & -6.4 & -4.3 \\
\hline Nominal Compensation Per Employee & 38.3 & 4.3 & 10.3 & -1.9 & -1.4 & 10.9 & 7.8 & 29.7 & 2.6 & 11.1 & $\ldots$ & 9.1 & 10.3 & 7.8 \\
\hline Real Compensation per Employee & 14.5 & -14.9 & 0.7 & -11.4 & 12.7 & -12.4 & -14.4 & 26.6 & 1.0 & 2.1 & $\ldots$ & 0.9 & 12.7 & -12.4 \\
\hline \multicolumn{15}{|l|}{ Total Economy: } \\
\hline ULCS & 25.2 & 10.1 & -1.4 & 2.3 & $\ldots$ & 2.5 & 0.5 & -10.0 & -2.2 & 1.6 & 0.8 & 1.6 & -1.8 & 2.3 \\
\hline Nominal Compensation per Employee & 38.1 & 9.0 & 5.8 & -2.7 & & -0.6 & 5.6 & 9.0 & 1.9 & 11.6 & 3.4 & 5.8 & 7.4 & 5.6 \\
\hline Real Compensation per Employee & 14.3 & -10.2 & -3.8 & -12.2 & & -23.9 & -16.7 & 5.9 & 0.3 & 2.6 & -0.9 & -3.8 & 3.1 & -12.2 \\
\hline REER-ULC based 1/ & 3.5 & 1.6 & -13.8 & -2.4 & $\ldots$ & -7.4 & -7.2 & 7.4 & -5.6 & -5.5 & 0.2 & -5.5 & -1.0 & -5.5 \\
\hline Peak-to-trough & -6.1 & -7.9 & -13.8 & -5.0 & $\ldots$ & -20.5 & -12.4 & -2.6 & -5.6 & -6.7 & -1.1 & -6.7 & -5.8 & -7.9 \\
\hline REER-CPI & 3.7 & 7.2 & 5.2 & 1.9 & -20.8 & 11.4 & 10.9 & 17.1 & -6.2 & 1.1 & -1.9 & 4.4 & 3.7 & 7.2 \\
\hline Peak-to-trough & -2.1 & -1.9 & -2.5 & 0.5 & -20.8 & -6.6 & -4.4 & 17.1 & -6.2 & -1.9 & -1.9 & -2.3 & -2.5 & -1.9 \\
\hline NEER & 8.9 & -0.1 & 11.0 & -1.5 & -1.8 & 3.5 & 4.5 & 44.1 & -1.6 & 0.8 & -1.2 & 2.2 & 8.9 & 0.8 \\
\hline RPI (CPI-based) & -4.8 & 7.3 & -5.2 & 3.5 & -19.4 & 7.6 & 6.1 & -18.7 & -4.7 & 0.2 & -0.7 & -2.2 & -5.2 & 6.1 \\
\hline o/w Domestic Inflation & 23.8 & 19.2 & 9.6 & 9.5 & -14.1 & 23.4 & 22.2 & 3.1 & 1.6 & 9.0 & 4.2 & 9.5 & 3.1 & 19.2 \\
\hline Trading Partner Inflation & 28.6 & 11.9 & 14.8 & 6.0 & 5.3 & 15.7 & 16.1 & 21.9 & 6.3 & 8.8 & 4.9 & 13.4 & 14.8 & 11.9 \\
\hline Time Period & 1987-1993 & 2008-2011 & $2001-2006$ & 2009-2011 & $1998-2003$ & 2008-2011 & 2008-2011 & 1998-2001 & $1987-1989$ & 2008-2011 & 2008-2011 & & & \\
\hline Number of years & 6 & 4 & 6 & 3 & 6 & 4 & 4 & 4 & 3 & 4 & 3 & 4 & 6 & 4 \\
\hline
\end{tabular}


Figure II-1A. Internal Devaluation Episodes: Sustained Declines in Relative Prices
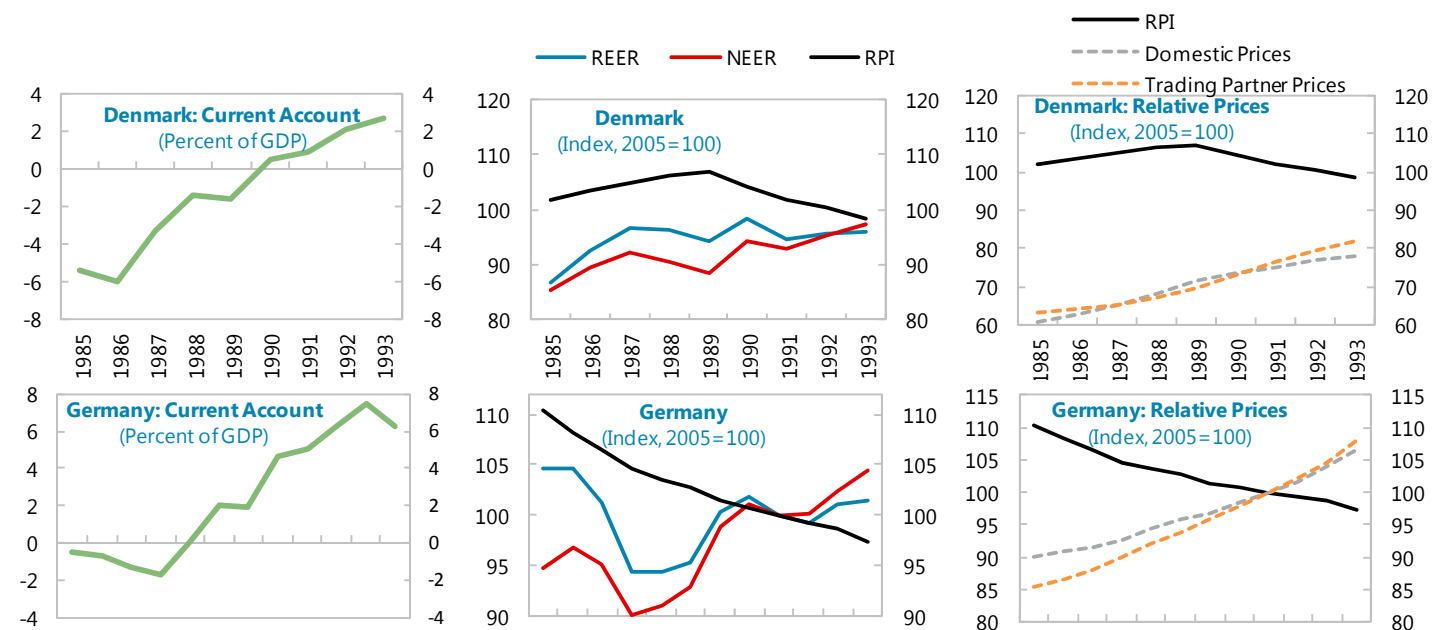

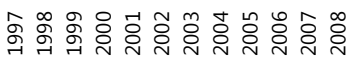
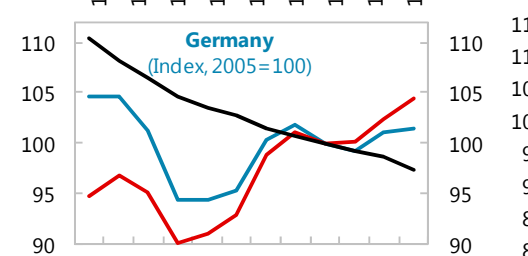

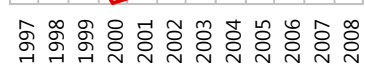

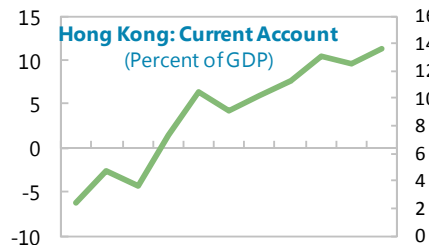

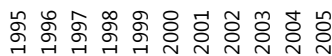

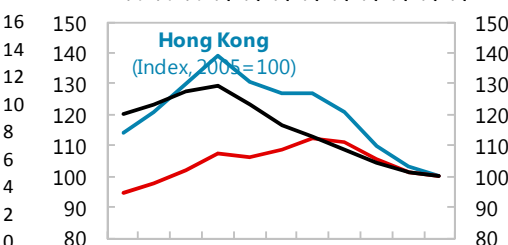

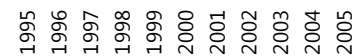

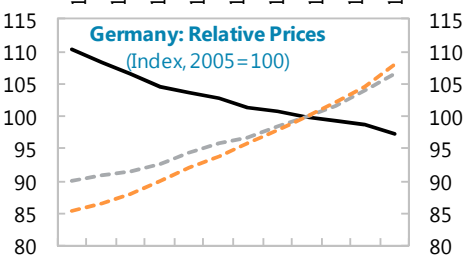

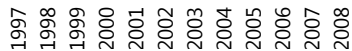

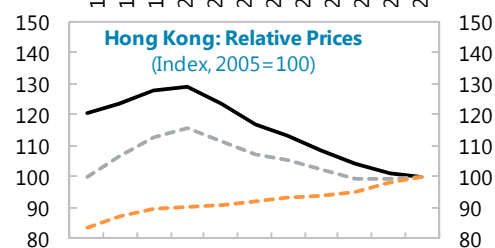

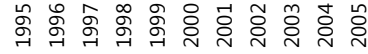
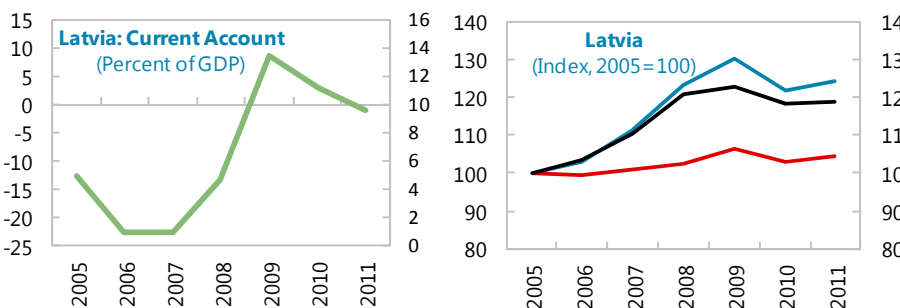

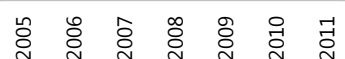
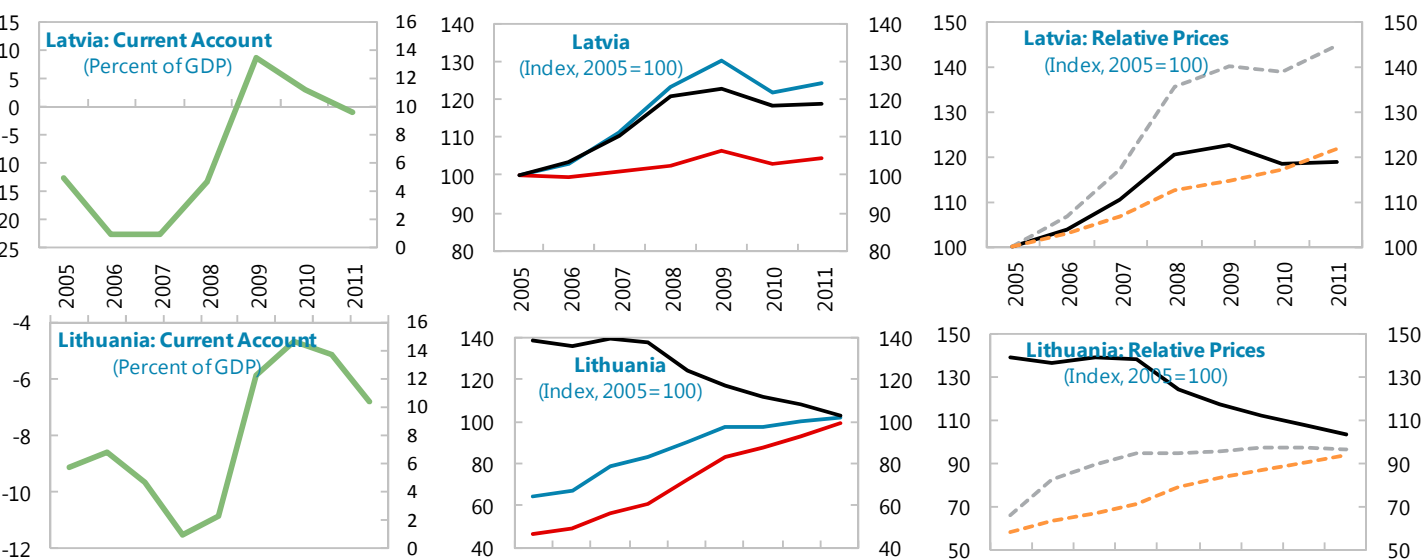

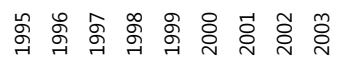

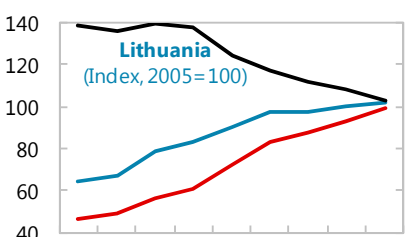

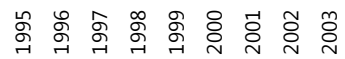
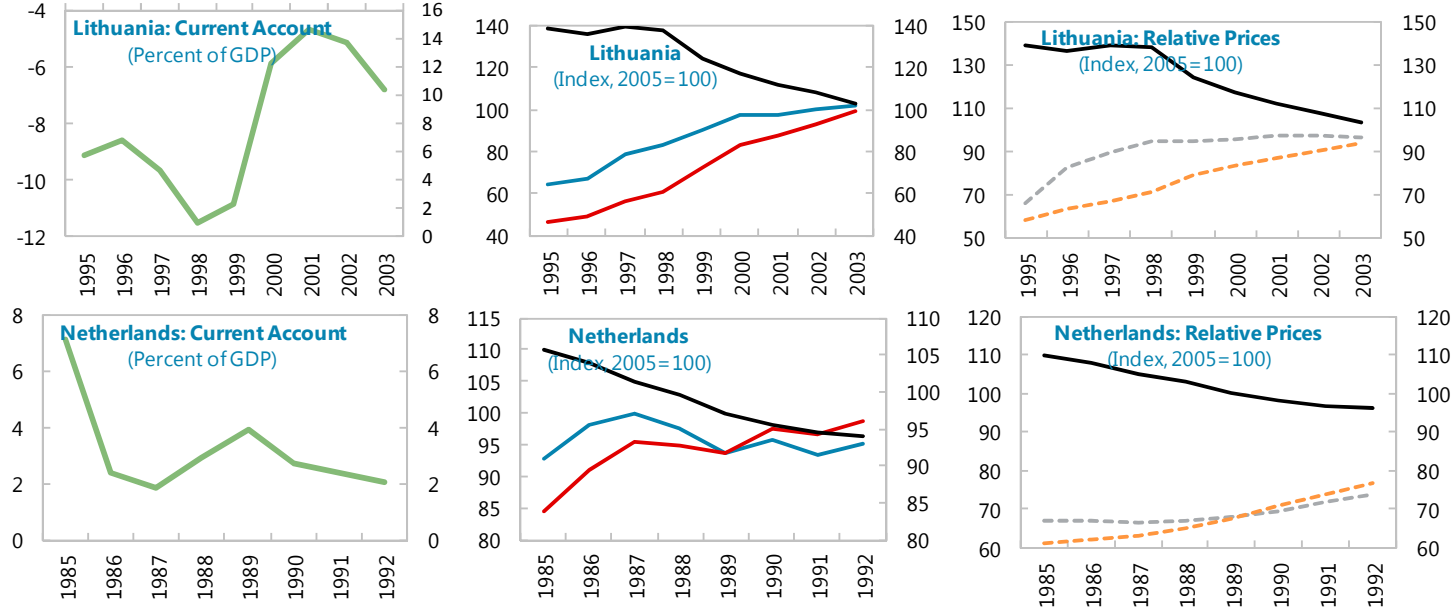

Sources: INS; WEO; and IMF staff calculations. 
Figure II-1B. Internal Devaluation: Limited Relative Price Adjustment
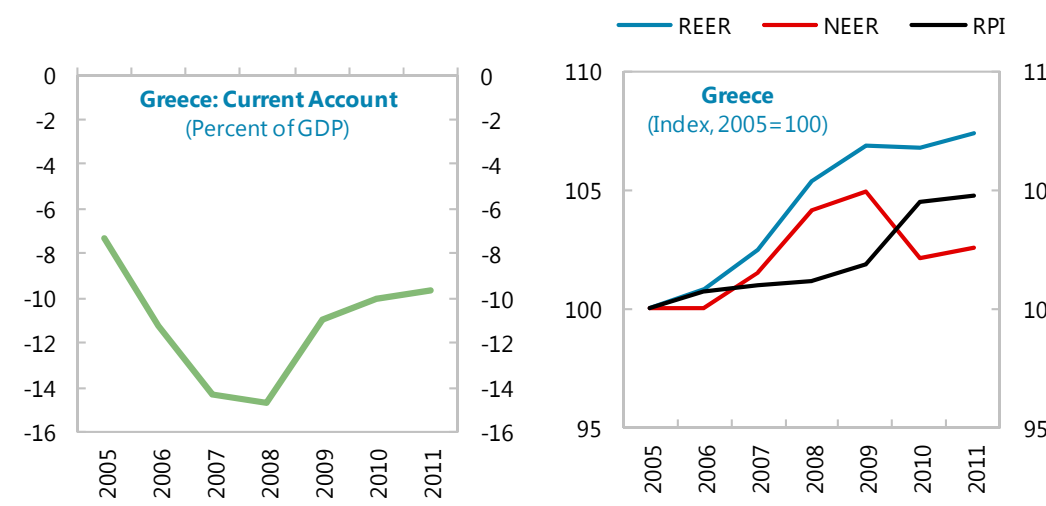

$-\infty-$ Domestic Prices

- - - Trading Partner Prices

125

Greece: Relative Prices

(Index, 2005=100)

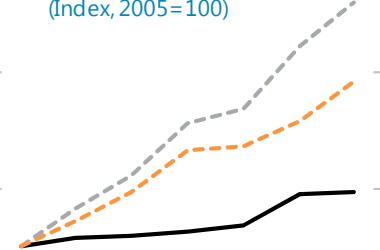

105

105

95

융 융 유 유 육 귱

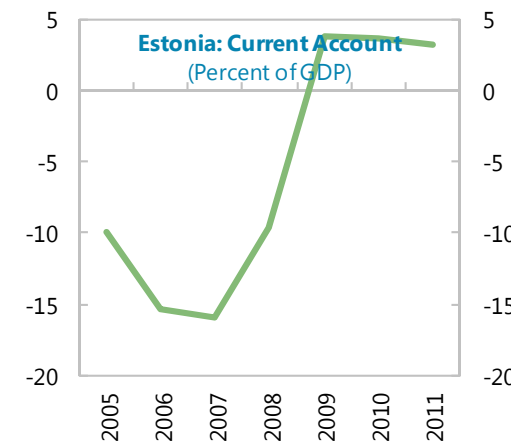

120

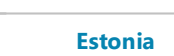

(Index, 2005=100)

115

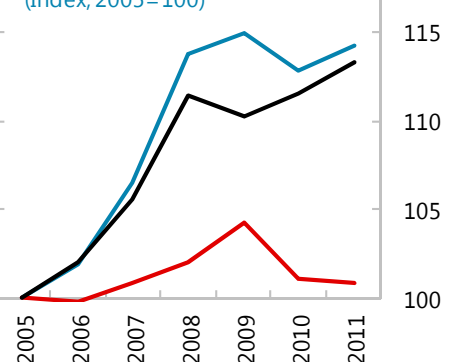

Estonia: Relative Prices

(Index, 2005=100)
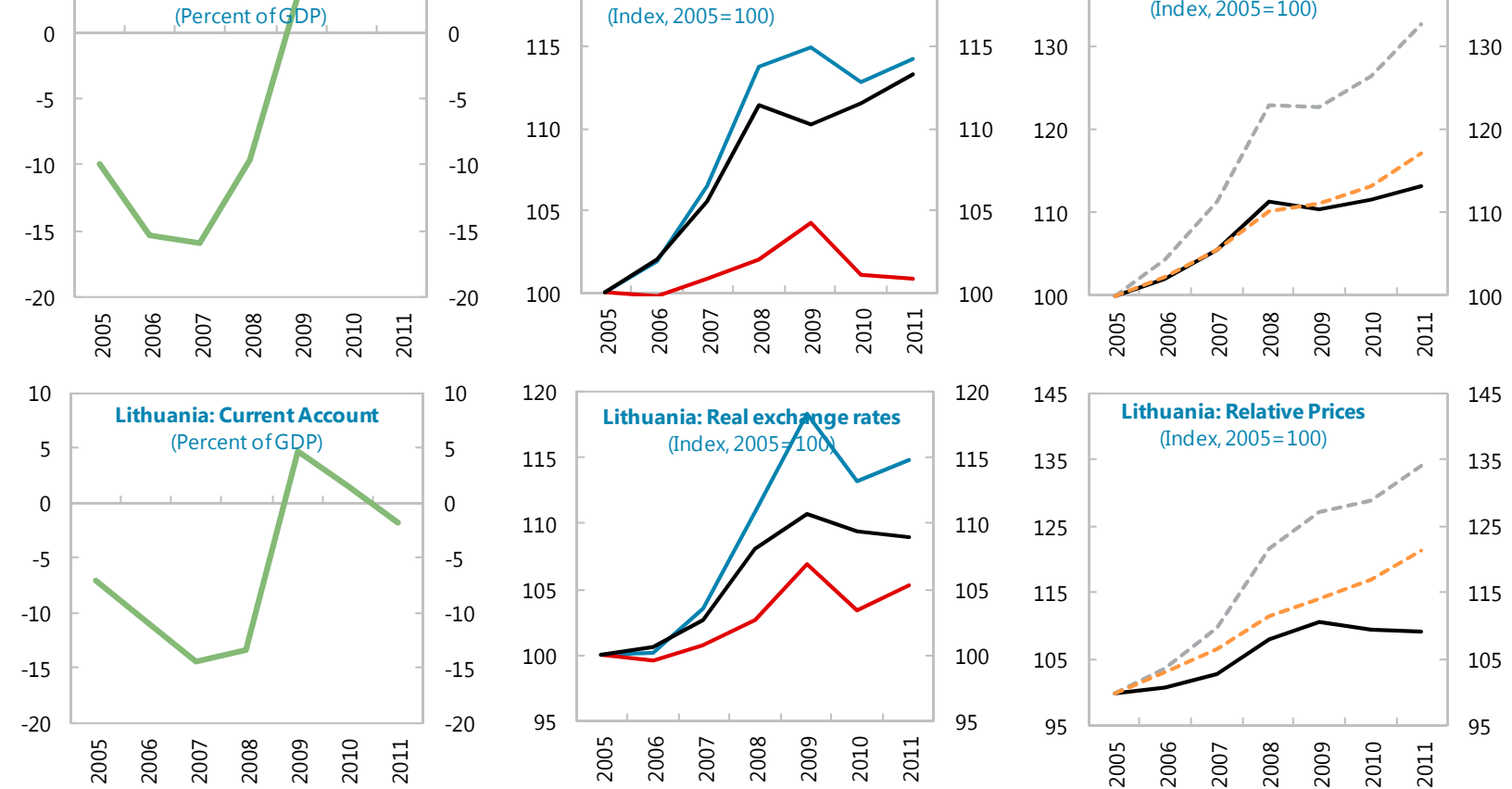

$10 \quad 120$

Lithuania: Realexch

$120 \quad 145$

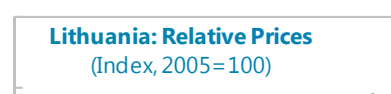

145

Lithuania: Real exch
(Index, 2005

115

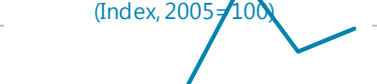

115

135

(Index, 2005=100)

110

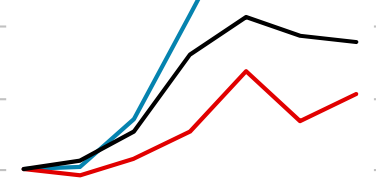

110

125

105

115

100

105

$-15 \quad 100$

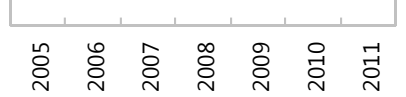

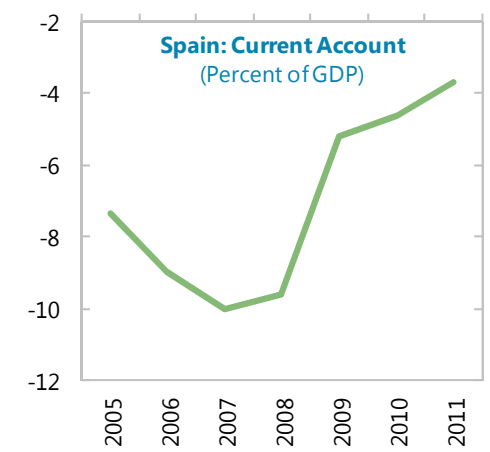

$-2110$

Spain: Real exchange rates (Index, 2005=100)

105

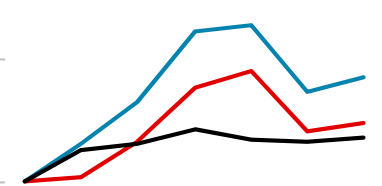

$8 \quad 100$

95

95

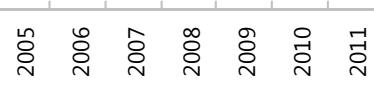

$110 \quad 120$

Spain: Relative Prices

(Index, 2005= 100)

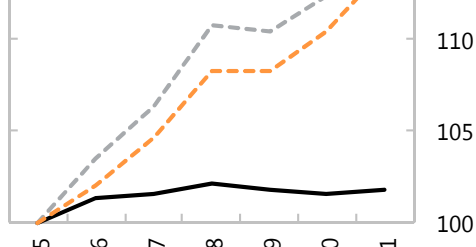

Sources: INS; WEO; and IMF staff calculations. 


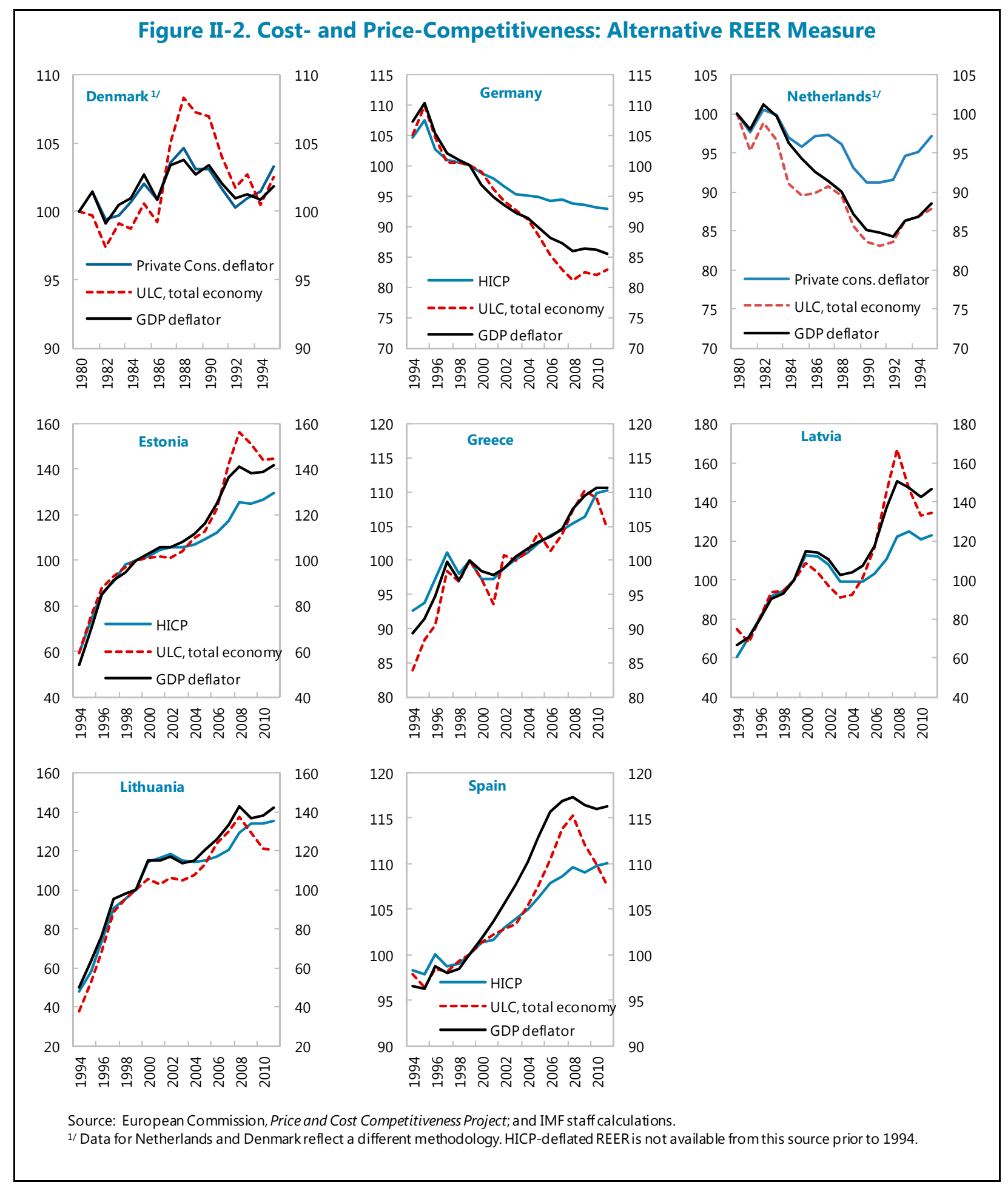




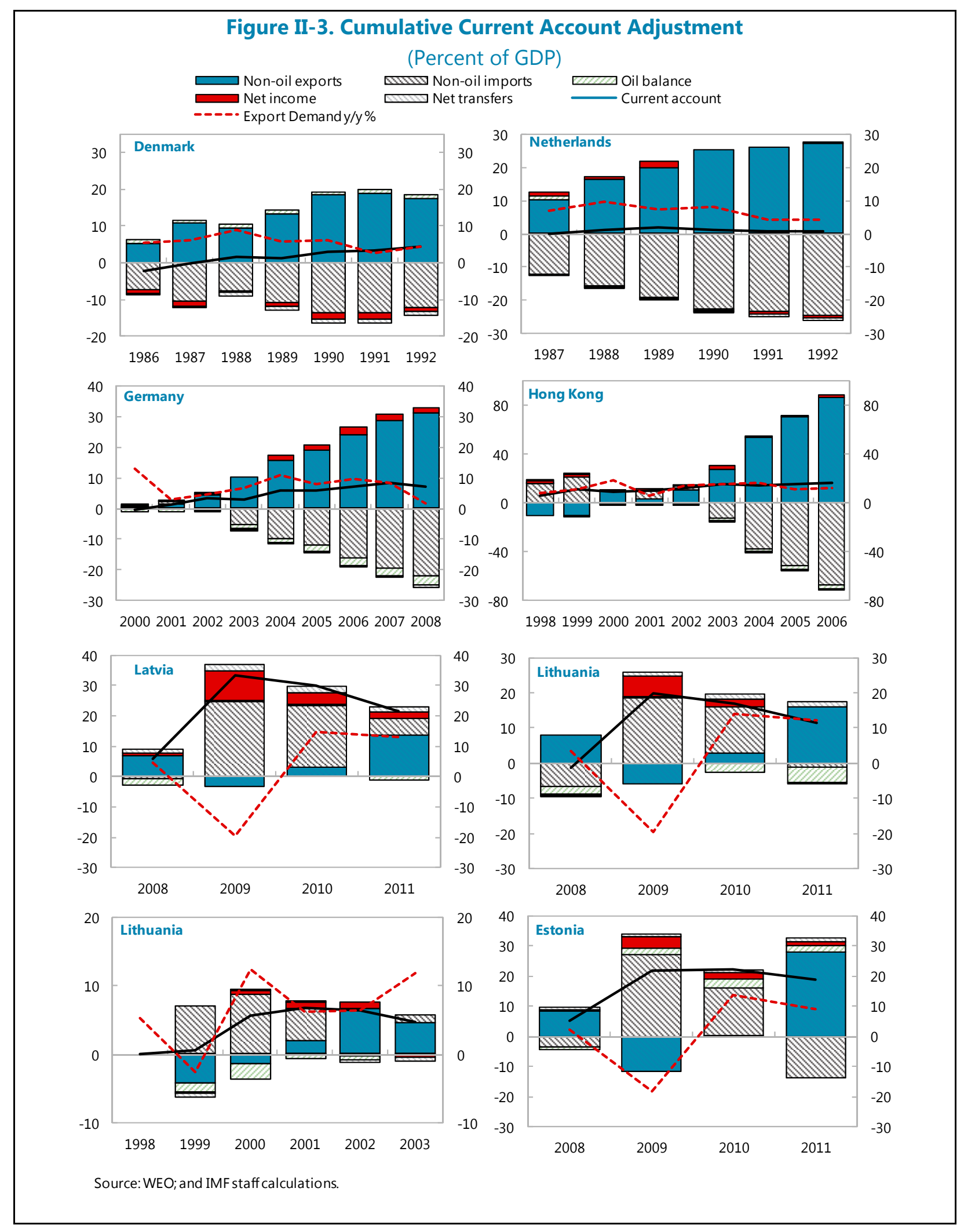




\section{REFERENCES}

Algieri, Bernadina and Bracke, Thierry, 2007, "Patterns of Current Account Adjustment Insights from Past Experience”, CESifo Working Paper No. 2029.

Amador, João, Sónia Cabral and Luca David Opromolla, 2009, “A Portrait of Portuguese International Trade", Ch. 5 in "The Portuguese Economy in the Context of Economic Financial and Monetary Integration", Economics and Research Department, Banco de Portugal, Lisbon, 2009.

Bennet, Herman, Julio Escolano, Stefania Fabrizio, Eva Gutiérrez, Iryna Ivaschenko, Bogdan Lissovolik, Marialuz Moreno-Badia, Werner Schule, Stephen Tokarick, Yuan Xiao and Ziga Zarnic, 2008, "Competitiveness in the Southern Euro Area: France, Greece, Italy, Portugal and Spain, IMF Working Paper WP/08/112.

Blanchard, Oliver, 2007, "Adjustment Within the Euro. The Difficult Case of Portugal”, Portuguese Economic Journal, vol. 6, pp. 1-21.

Chinn, Menzie D. "A Primer On Real Effective Exchange Rates: Determinants, Overvaluation, Trade Flows And Competitive Devaluation," Open Economies Review, 2006, v17(1,Jan), pp.115-43.

Freund, C. and F. Warnock, 2005, "Current Account Defecits in Industrial Countries: The Bigger They are, the Harder They Fall?" NBER Working Paper No. 11823, December 2005

International Monetary Fund, 2007, World Economic Outlook, "Exchange Rates and the Adjustment of External Imbalances", Washington, DC, April 2007.

Lin, Huidan, and Stéphane Roudet, 2012, “How Fast Can Portugal Gorw?", in Portugal: Selected Issues, http://www.imf.org.

Milesi Ferretti, G.M. \& A. Razin, 2000. "Current Account Reversals and Currency Crises, Empirical Regularities," NBER Chapters, in: Currency Crises, National Bureau of Economic Research, Inc., pp. 285-326. 


\section{Portugal's Corporate (De) Leveraging ${ }^{1}$}

\section{A. Introduction}

1. Portugal has one of the most indebted corporate sectors in Europe. This poses two important risks to the country's adjustment program: first, the high debt burden serves as a drag on corporate profitability and investment growth; second, it poses a threat to banks' balance sheets and financial stability through increasing NPLs and corporate bankruptcies. Most importantly, an abrupt corporate balance-sheet adjustment can quickly lead to the migration of substantial losses from the private sector to the sovereign balance sheet. Therefore, reducing debt to more sustainable levels, through an orderly deleveraging process, is crucial to allow resources to be redirected to the most productive and innovative segments of the economy and secure the long-term viability of the private sector.

2. The chapter aims at assessing the risks posed by the corporate sector debt overhang and identifying available policy options to mitigate the upfront costs of corporate deleveraging, in view of Portuguese firms' specific vulnerabilities and key lessons from past corporate balance-sheet adjustment experiences. It is organized as follows: Section B provides a diagnostic of Portugal's corporate vulnerabilities, from both a historical and crosscountry perspectives (the Appendix presents further background on Portuguese firms' leveraging process in the pre-crisis period). Section $C$ discusses the expected macro-financial impact of the ongoing deleveraging process in Portugal through an event study of past crisis episodes exacerbated by high corporate debt overhang. Finally, Section D concludes with the discussions of potential policy options to promote an orderly deleveraging process and strengthen the long-term viability of the Portuguese corporate sector.

\section{B. Diagnostics of Corporate Vulnerabilities and Risks in Portugal}

\section{Portugal's Corporate Sector Vulnerabilities in Perspective}

3. Today, Portugal's corporate debt leverage stands at about 150 percent of equity or 60 percent of corporate assets (as of end-2011), on a consolidated basis. ${ }^{2}$ These levels are well above the high-debt thresholds identified in the literature (see Box A1) and among the highest in the Euro area. Moreover, the indebtedness of Portuguese firms is comparable to

\footnotetext{
${ }^{1}$ Prepared by Manuela Goretti and Marcos Souto (both EUR). The paper benefited from valuable inputs from Wolfgang Bergthaler (LEG) and Andrea Lemgruber (FAD). Upaasna Gupta, Jonathan Manning, and Fernando Martins (all EUR) provided excellent research assistance. We are grateful to staff at the Banco de Portugal, Minister of Finance, and ESAME for invaluable support and helpful comments. The usual disclaimer applies.

${ }^{2}$ While Portugal did not experience an asset price bubble in the pre-crisis period (e.g. increases in house prices were limited to 5 percent during 2001-06 compared to an average of over 40 percent in the other periphery countries), the sharp market losses faced by firms in 2008 more than offset the previous gains in asset prices contributing to a sizable step-up increase in corporate leverage.
} 
previous crisis episodes characterized by high corporate debt levels and sizable post-crisis macro-financial adjustment. Specifically, in a sample of ten crisis countries, only Turkey and the East-Asian countries had higher corporate leverage on the eve of crisis (Figure III-1). ${ }^{3}$

4. The crisis in Portugal has exposed the vulnerabilities of domestic companies' overleveraged balance sheets (see Appendix I). Due to their heavy dependence on the domestic banking sector, high indebtedness, uncertain macro environment, and the sharp tightening in credit conditions, ${ }^{4}$ firms are facing high refinancing risk (resident banks hold around 50 percent of total corporate debt). Specifically, about one third of corporate debt to banks has a remaining maturity of less than one year, implying that firms will need to refinance the equivalent to 15 percent of GDP of their bank debt annually.
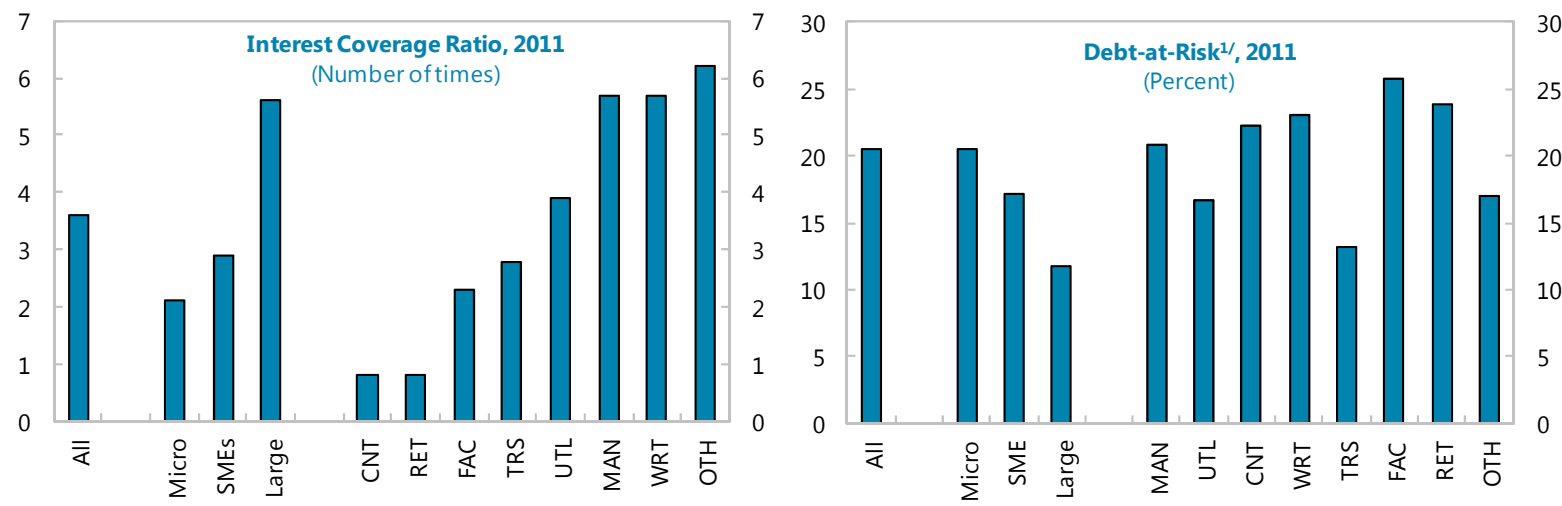

Sources: Banco de Portugal; and IMF staffestimates.

1/ Percentage of firms, in each sector, with ICR $<1$.

5. Firms' capacity to repay their debt, as proxied by their interest coverage ratio (ICR), is also among the lowest in the Euro area. ${ }^{5}$ Nevertheless, firms' financial positions vary substantially across sectors, with much tighter financial conditions in real estate and construction than in manufacturing and trade. ${ }^{6}$ Moreover, while corporate profitability

\footnotetext{
${ }^{3}$ Please refer to Figure III-5 for more detailed information on the sample selection and data comparison limitations.
}

${ }^{4}$ Portuguese companies are among those in the Euro Area paying the highest interest rates.

${ }^{5}$ The ICR is calculated as the ratio of EBITDA — earnings before interest, taxes, depreciation and amortization - to interest payments but can be also decomposed as follows to highlight the main drivers of firms' financial positions:

$$
\frac{1}{I C R}=\frac{\text { Interest }}{\text { EBITDA }}=\frac{\text { Interest }}{\text { Debt }} \times \frac{\text { Debt }}{\text { Assets }} \times \frac{\text { Assets }}{\text { EBITDA }}
$$

where a firm's interest burden (1/ICR) is determined by the cost of its debt, the degree of leverage, and the inverse of its operating profitability (Figure III-2). See Banco de Portugal (2009).

${ }^{6}$ ICR may not always provide a complete picture of a company capacity to repay its debt, if the company can rely on adequate cash (and liquid financial assets) to meet its debt obligations. As of 2010, Portuguese companies held about 21 percent of GDP in cash and bank deposits. 
remains relatively solid for the large companies (with a return on assets of 3.9 percent at end2011), it is significantly lower for the smaller and over-leveraged firms (facing hardly any returns), resulting in worse ICRs. This is especially relevant given the large role played by micro firms and SMEs in the Portuguese corporate sector. ${ }^{7}$

6. Moreover, the share of debt at risk is increasing. A notable threshold in the literature to measure firms' debt at risk and their viability (see Glen, 2005) is when a firm's ICR is less than 1, implying that its earnings are no longer sufficient to service its debt. In 2011, 21 percent of the Portuguese firms presented an ICR of less than 1, accounting for 28 percent of the corporate sector total liabilities (contrasting with 23 percent in 2010). For some of the non-tradable sectors, such as food and accommodation and real estate, this share reaches 25 percent, close to severe crises cases like Indonesia (at 37 percent) and Korea (at 24 percent).

\section{Contingent Claim Analysis}

7. With financial stress in the corporate sector at already high levels, and likely to increase further should downside risks to growth materialize, it is essential to gauge the threat of existing corporate sector vulnerabilities migrating to the balance sheets of banks and the sovereign. In particular, it would be quite useful to be able to estimate this risk in a forward-looking manner as well as to have the capacity to incorporate changes in corporate credit risk that could become highly non-linear during crisis periods.

8. Contingent Claims Analysis (CCA) provides a useful framework to address some of these issues (Merton, 1974). It allows estimating the probability that a company may not be able to meet its debt obligation in the future, thus imposing losses on senior debt claimants (such as banks). It also explicitly incorporates companies' equity volatility, in a non-linear fashion, a feature that can be quite important during crisis periods. Furthermore, as it utilizes market information, the indicators implicitly embed the collective view of market participants regarding the soundness and growth prospects of companies that are traded in the equity market, to the extent that the market incorporates efficiently all relevant information into the companies' equity prices.

9. Moody's-KMV has developed a comprehensive database with information on 31,000 quoted companies around the world, to estimate credit risk indicators using a model that has the same structural features of Merton's model. Indicators provided by Moody's-KMV are used to assess the riskiness of some Portuguese companies and estimate potential losses that could have to be borne by domestic banks. ${ }^{8}$ However, this approach also suffers from

\footnotetext{
${ }^{7}$ Micro firms and SMEs account for about 99 percent of the total number of firms and 63 percent of corporate value added. See Box 1 of IMF Country Report No. 12/292 for a discussion of the SME sector in Portugal.

${ }^{8}$ IMF (2011) and IMF (2012) follow a similar approach for the UK and Spain, respectively.
} 
important shortcomings, particularly in countries like Portugal where equity markets can be quite thin. Small equity transactions can lead to large variations in prices, resulting in overproportionate volatility, which can significantly bias the credit risk estimations. Moreover, the sample of Portuguese companies covered in the MKMV database is relatively small when compared to the total universe of Portuguese firms that report to the BdP's central balance sheet registry (with only 47 quoted firms - generally large and few medium-sized firms with access to capital markets - accounting for 24 percent of total corporate assets). ${ }^{9}$ Still, Moody's-KMV probabilities of default for Portuguese companies seem to be broadly in line with actual defaults and default probabilities estimated by Banco de Portugal using data from the central balance sheet registry and alternative methodologies.

10. Specifically, in the case of Portugal, the expected probabilities of default estimated by MKMV show a clear deterioration in the credit risk profile of traded firms. Indeed, the probability of default of these firms as of end-July 2012, over a one-year horizon, ranges from about 1 percent for firms in the $25^{\text {th }}$ percentile to over 30 percent for firms in the $90^{\text {th }}$ percentile (Figure III-4). Moreover, the fraction of firms with one-year-ahead PD larger than 5 percent has moved from less than 1 percent of total assets in the sample at end-2009 to almost 10 percent as of end-July 2012 (corresponding to $2 \frac{1}{2}$ percent of total corporate assets). Construction and real estate are the riskiest sectors. Moreover, as already discussed, the crisis has particularly exposed the balance sheet of the smaller companies. Based on the MKMV sample, while the average probability of default for large companies is around 3 percent, it has been hovering around 5 and 6 percent for the SMEs in the sample.

11. The recent increases in the probability of default of the Portuguese firms quoted in the markets are largely explained by losses in asset value as well as heightened volatility. Indeed, the probability of default of Portuguese companies back in 2007 was significantly lower and broadly in line with peer countries in the Euro area, including Germany (Figure III-3). The intensification of the crisis and loss of market access have magnified risks for the highly-indebted Portuguese companies, raising probabilities of the default to above the average Euro area sample median. This is especially the case for the construction and real estate sectors, where quoted firms have been exposed to large valuation losses. Nevertheless, with asset prices already at record-low levels, risks of further downwards revisions appear limited, while some upsides could materialize as market conditions start stabilizing.

\footnotetext{
${ }^{9}$ The MKMV sample is on average more leveraged (by 5 percent of equity), and thus relatively closer to the distress point.
} 

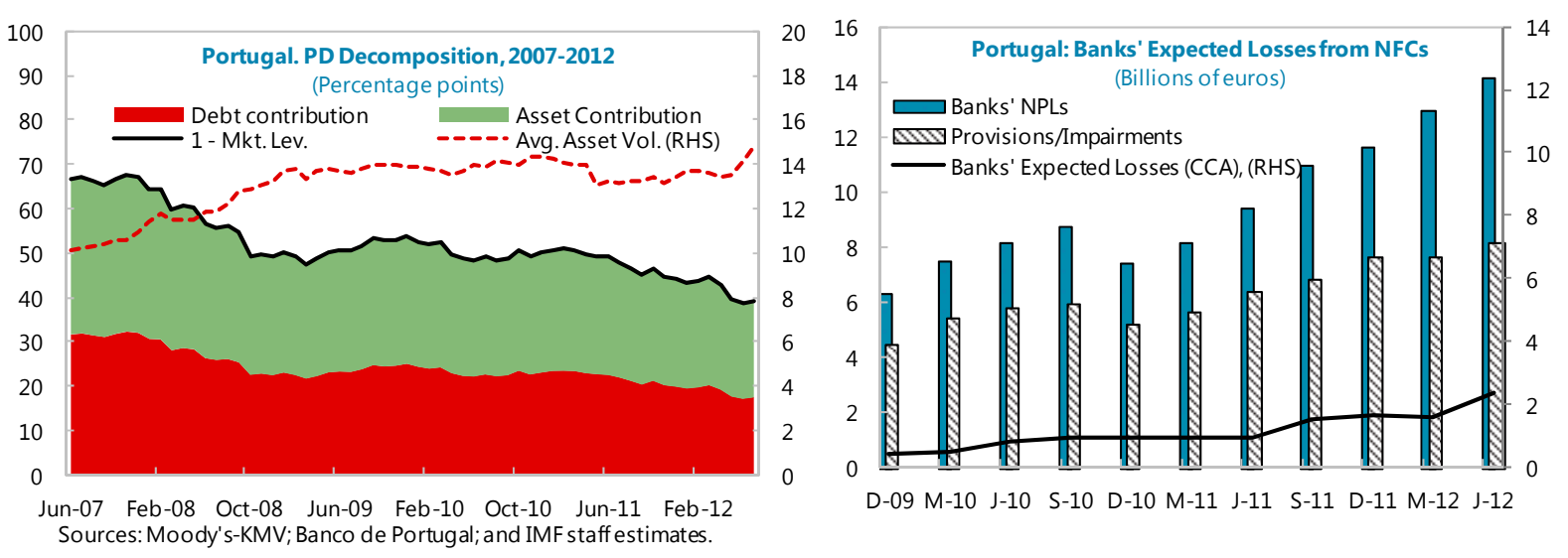

12. While the expected insolvencies in the less productive sectors of the Portuguese economy are part of the deleveraging process needed to secure the medium-term viability of the private sector, they are unavoidably associated with short-term costs. Specifically, the estimated default probabilities for NFCs suggest further increases in banks' losses over a one-year horizon. ${ }^{10}$. As of July 2012, 1-year-ahead banks' expected losses from NFCs can reach up to $€ 2.4$ billion (about 0.5 percent of banks' assets), almost $€ 1$ billion higher than at end- 2011. Nevertheless, banks' provisions for credit overdue and for doubtful debts by domestic NFCs, currently standing at $€ 7.6$ billion, appear to provide adequate buffers against the potential corporate defaults predicted by the CCA model. Yet, risks remain high, as also suggested by the increasing stock of NPLs, calling for continued supervisory efforts through on-site inspections and regularly updated stress test exercises, to ensure prompt updates of impairment levels and provisions.

\section{Sensitivity Analysis}

13. Given the still-significant risks to the macro-financial outlook in Portugal and the high leverage position of the Portuguese firms, it is not sufficient to take a snapshot of the existing vulnerabilities in the corporate sector. It is important to assess the sensitivity of firms' balance sheets to various types of macroeconomic shocks that might further impact their debt servicing capacity and ultimately their viability. The objective of this section is to analyze how many firms could face financial difficulties and limited debt servicing capacity, as proxied by the level of ICR, when subject to macro-financial shocks, in terms of lower profits and/or higher interest payments.

14. The analysis is based on corporate data for 17 sectors over the 2006-11 period, available from Banco de Portugal's BPStat online database. Consistent with previous

\footnotetext{
${ }^{10}$ Building on the CCA results, losses to banks can be roughly estimated as a fraction of the corporate debt in default that is held by banks (adjusted for the share of quoted firms). Quoted-firms book value represents about 22 percent of the total assets of the corporate sector.
} 
exercises, the analysis uses the ICR as a measure of vulnerability. ${ }^{11}$ The elasticities needed to calibrate shocks to sectors' profitability and interest expenses for the sensitivity analysis are estimated over the sample period through a set of panel data regressions, after controlling for fixed effects and accounting for endogeneity. ${ }^{12}$ Finally, the after-shock ICR is calculated with the new EBITDA and interest expenses for the sectors, based on the $2011 \mathrm{~s}$ from the BdP Central Balance Sheet database.

15. The results of the sensitivity analysis highlight how macro-financial shocks can quickly worsen the financial position of firms and exacerbate sectoral differences. For example, a contraction in real GDP growth by an additional 1 percentage point could result approximately in an ICR of 2.6 for the nontradable sector and 4.9 for the tradable sector (down from the baseline values of 4.1 and 6.5 respectively). Under a combined shock scenario (with lending rates also increasing by $200 \mathrm{bps}$ ), the non-tradable sector ICR could drop to 1.8 and tradable sector ICR to $3.3 .^{13}$

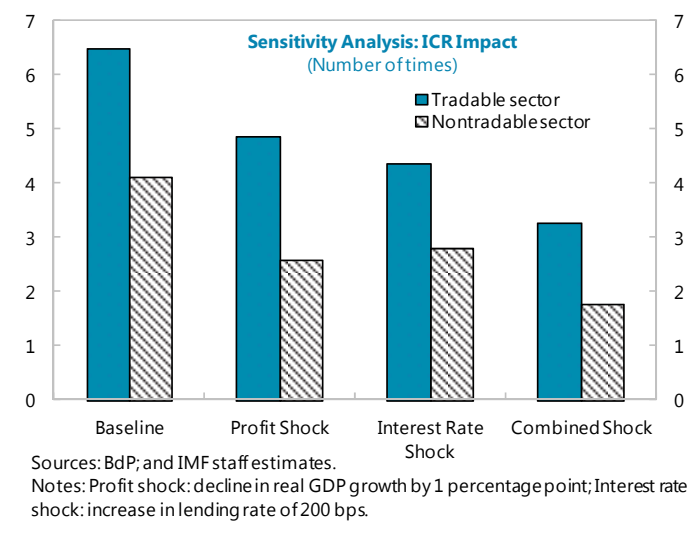

\section{Macro-Financial Implications of Corporate Deleveraging}

16. The global crisis has triggered the balance-sheet adjustment needed to address the deep-rooted corporate-sector vulnerabilities characterizing Portugal and other economies in the region. As expected, the pace and size of this deleveraging process varies across countries, largely depending on their starting conditions. Low-debt corporate sectors (with debt-to-GDP below the 90 percent threshold) have been able to turn around their net borrowing position and achieve sizable adjustments in their debt ratios already in the first years of the crisis. However, the deleveraging process is proceeding only gradually in countries with highly indebted corporate sector, like Portugal, which are less able to diversify their funding sources and have been exposed to greater asset losses from the crisis.

\footnotetext{
${ }^{11}$ See, among others, the analyses carried out in the context of the financial sector assessment programs for the UK (IMF, 2011) and Spain (IMF, 2012).

12 The accuracy of the elasticity estimates is unavoidably constrained by the short time series.

13 The shocks imposed are stylized and do not fully account for the inherent correlation that exists among macro-financial variables.
} 

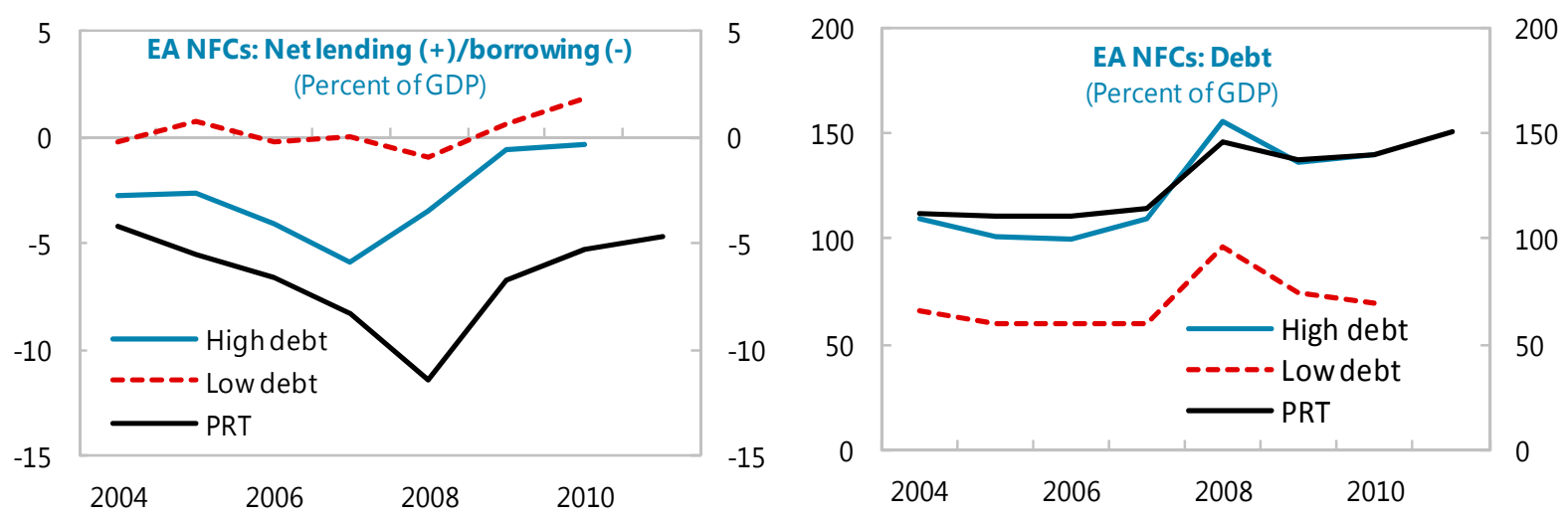

Sources: Eurostat; OECD; and IMF staff estimates.

17. The relatively slow adjustment process experienced by high-debt companies is consistent with past and more recent deleveraging experiences (Figure III-5). The deleveraging episodes in the sample of past crisis cases presented in Section II tended to last for a protracted period of 7-8 years, with an adjustment in the leverage ratio of about 8 percent of assets for the median country. Shorter deleveraging episodes in the sample were normally associated with deeper crises and sharp exchange rate corrections. Moreover, most episodes were triggered by banks' deleveraging, as in the Portugal case where a sizable share of the banks' balance sheet adjustment has actually already materialized (see Box III-1).

18. In past crisis cases, the ability of firms to liquidate assets under depressed market conditions has been limited, as well as the scope for sizable equity issuances. This has left the burden of the adjustment on increasing internal funds and/or reducing corporate investment (Figure III-5). Although most firms achieved savings in operating costs-notably through reductions in compensation of employees, the main driver of the improvement in gross savings was firms' ability to boost profits by diversifying abroad. The sizable increases in foreign sales were largely supported by strong external demand and upfront gains in competitiveness through adjustments in the nominal exchange rate. As a result, while the deleveraging process affected firms' investment decisions, ${ }^{14}$ the overall macroeconomic impact could be partly mitigated by the strong export performance (Figure III-6).

\footnotetext{
${ }^{14}$ While most companies experienced only a temporary slowdown in fixed capital formation, the investment decline reached over 20 percent in the case of Korea and Finland, the latter with sustained contraction in the 4 years after the crisis.
} 


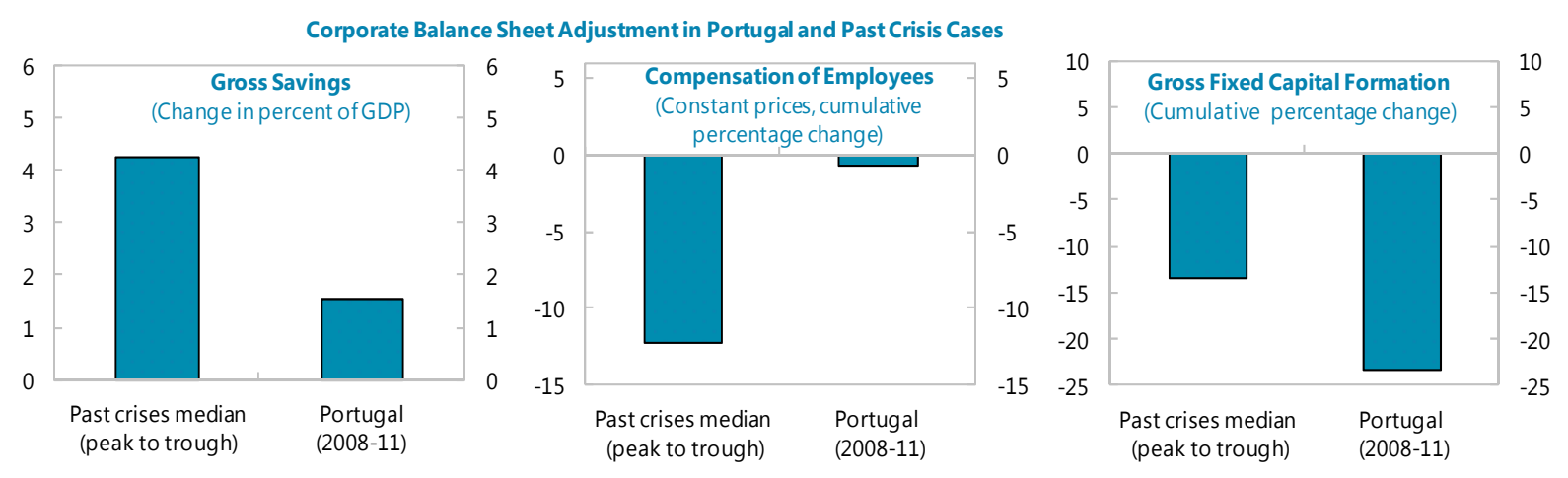

Sources: OECD; UN; National Authorities; IFS; and IMF staff estimates.

19. Although the corporate deleveraging process in Portugal is just beginning, since the onset of the global crisis in 2008, firms have already made sizable adjustments to their operational balances, including more recently through reductions in wage costs. Despite the substantial effort made by some firms to diversify abroad, as evidenced by sustained export growth, their ability to boost foreign sales as in past cases has so far been constrained by the weak external demand in the Euro area and the need to achieve productivity and competitiveness gains through a more gradual internal devaluation process. As a result, the cumulative decline in firms' fixed investment is already sizable, even compared to some of the most severe adjustment episodes of the past. ${ }^{15}$ At the macro-level, this has already translated into a sharp contraction in domestic demand and a record-high unemployment rate.

20. The role of corporate defaults on countries' aggregate sectoral adjustment should also not be underestimated. By 1998, 35 percent of companies in East Asia had non-viable financial structures with an interest coverage ratio below one (Claessens, 2005). NPLs for Indonesia and Thailand reached over 40 percent, with substantial increases in most of the other cases within the first 2-3 years since the onset of the crisis. This compares to an overall NPL ratio of around 8 percent in Portugal in the first quarter of 2012 (with NPLs at 12.3 percent for corporate credit).

\footnotetext{
${ }^{15}$ Any comparison with past crisis episodes is subject to important caveats: (i) the event analysis abstracts from country-specific circumstances, including initial conditions; (ii) the choice of the peak/through (e.g. in presence of double dips) may affect the results; (iii) the timing and composition of the balance sheet adjustment varies across countries and sectors.
} 


\section{Box III-1. Bank and Corporate Deleveraging}

Past corporate adjustments have been often triggered by banking sector deleveraging, with increases in borrowing rates and shortening of maturities. The contraction in private credit growth for the median country was about 20 percent from peak to trough over 6 years, and normally with a 2 year lead with respect to the corporate deleveraging episode. Reinhart and Reinhart (2010) estimate, over a broader crisis sample, a decline in private sector credit of about 38 percent of GDP over a 6 to 8 years. This compares to an expected decline in private sector credit by Portuguese banks of about 20 percent of GDP over a 7 year horizon (of which 15 percent of GDP in corporate sector credit).

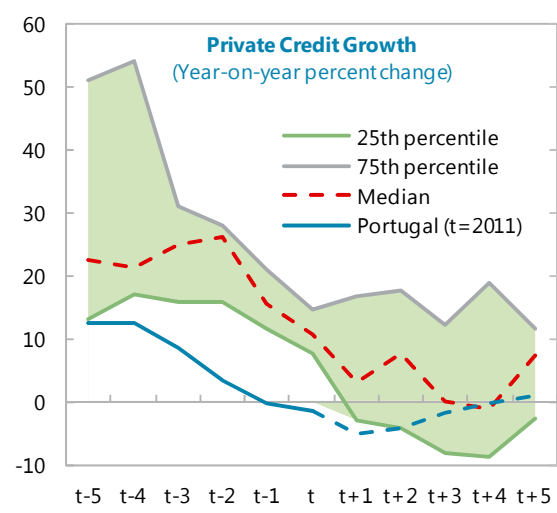

Sources: WEO; IFS; and IMF staff calculations.

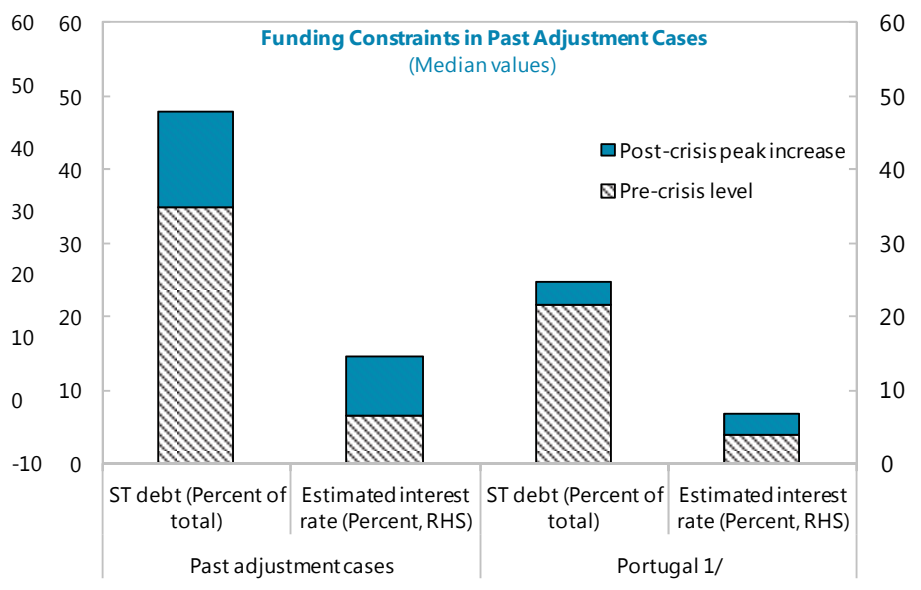

Sources: CVU; Banco de Portugal; and IMF staff estimates.

1/ Portugal ST debt refer sto 2011, INFCs lending rates to Sep 2012 (new loans <€1M)

However, in contrast with previous crisis cases, in Portugal a large share of banks' deleveraging has already materialized (about 20 percent of total). While demand pressures remain the predominant driver of firms' deleveraging decisions, according to the INE Investment Survey, credit conditions have tightened significantly in some segments, including the cost of credit. Available data for Portugal and selected Euro area countries suggest that the deleveraging process is proceeding more rapidly for smaller firms, consistently with their higher indebtedness levels and more limited access to funding. ${ }^{1}$ Nevertheless, the risk of a generalized credit crunch (as in some of the most severe past crisis cases) remains high, highlighting the need for continued liquidity support, especially to the most productive firms, to help smooth the needed deleveraging of Portuguese banks.
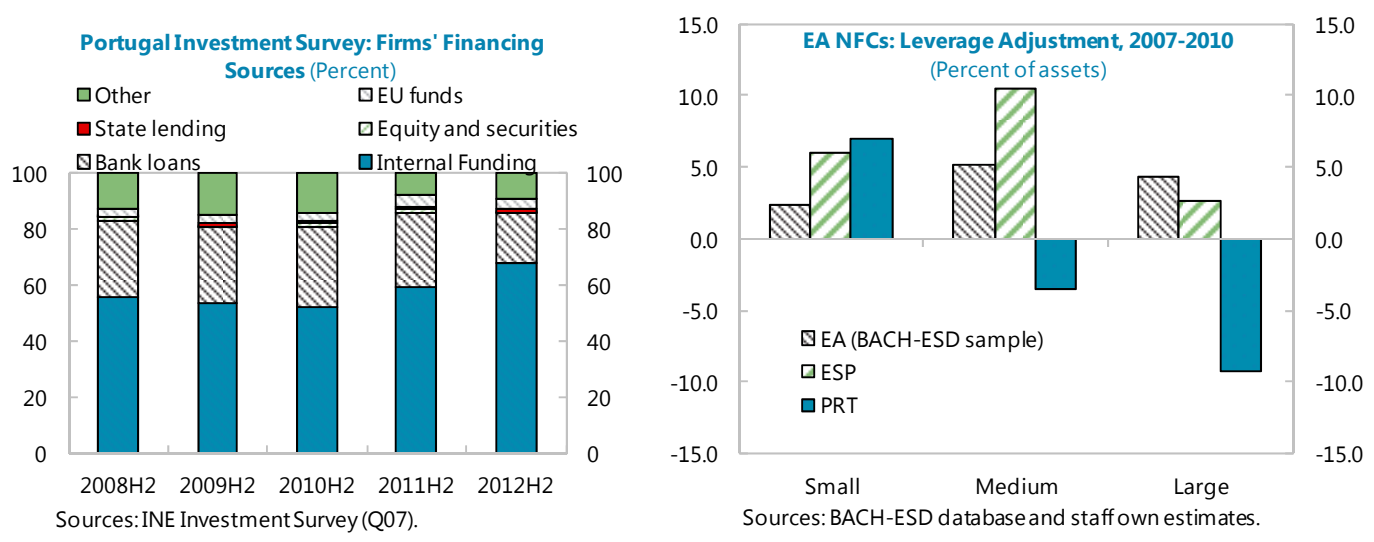

${ }^{\mathbf{1}}$ This confirms earlier results by Antao and Bonfim (2008) in support of a faster adjustment of small firms towards their target leverage ratio in presence of financial constraints. 


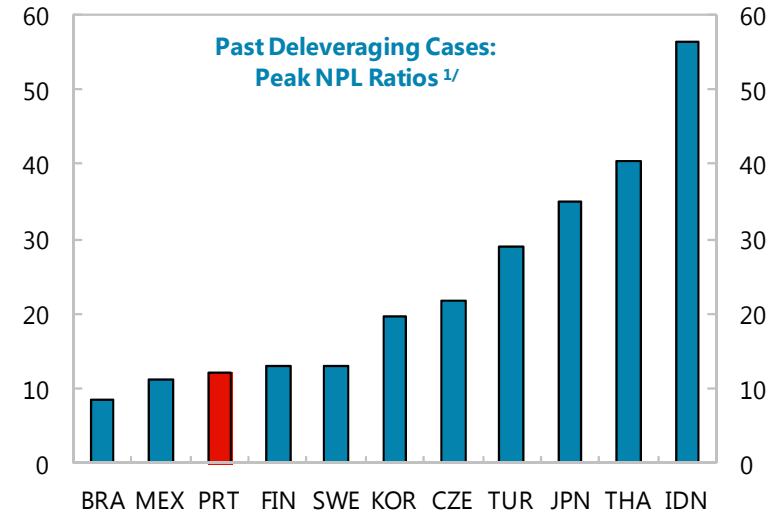

BRA MEX PRT FIN SWE KOR CZE TUR JPN THA IDN

Sources: Claessens (2005); IMF FSI Database; Laeven and Valencia (2008).

1/ Data are not fully comparable due to differences in data sources and classification. The figure for PRT refers to 2012Q2.

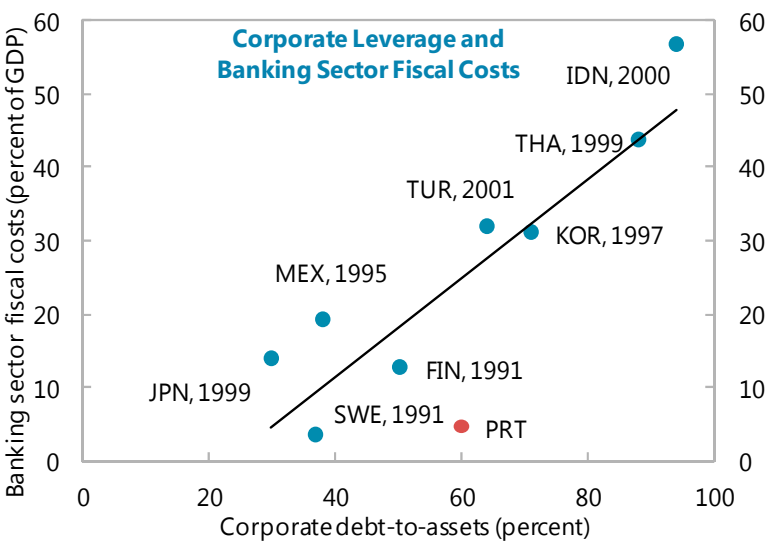

Sources: Claessens (2005); Laeven and Valencia (2008); Banco de Portugal; and IMF staffestimates.

21. The elevated NPL levels in past deleveraging processes have important implications for financial and, ultimately, public sector balance sheets. Almost all the corporate adjustment cases in the sample were associated with or preceded by a banking crisis, with a sizable migration of losses from private to public sector balance sheets, which resulted in a delay of at least 2-3 years in public sector deleveraging. In Portugal, the fiscal costs arising from the banking sector has so far been limited (and largely driven by the sovereign crisis). Nevertheless, with the sovereign highly indebted and fiscally constrained, strengthened policy responses are needed to keep debt off balance sheet.
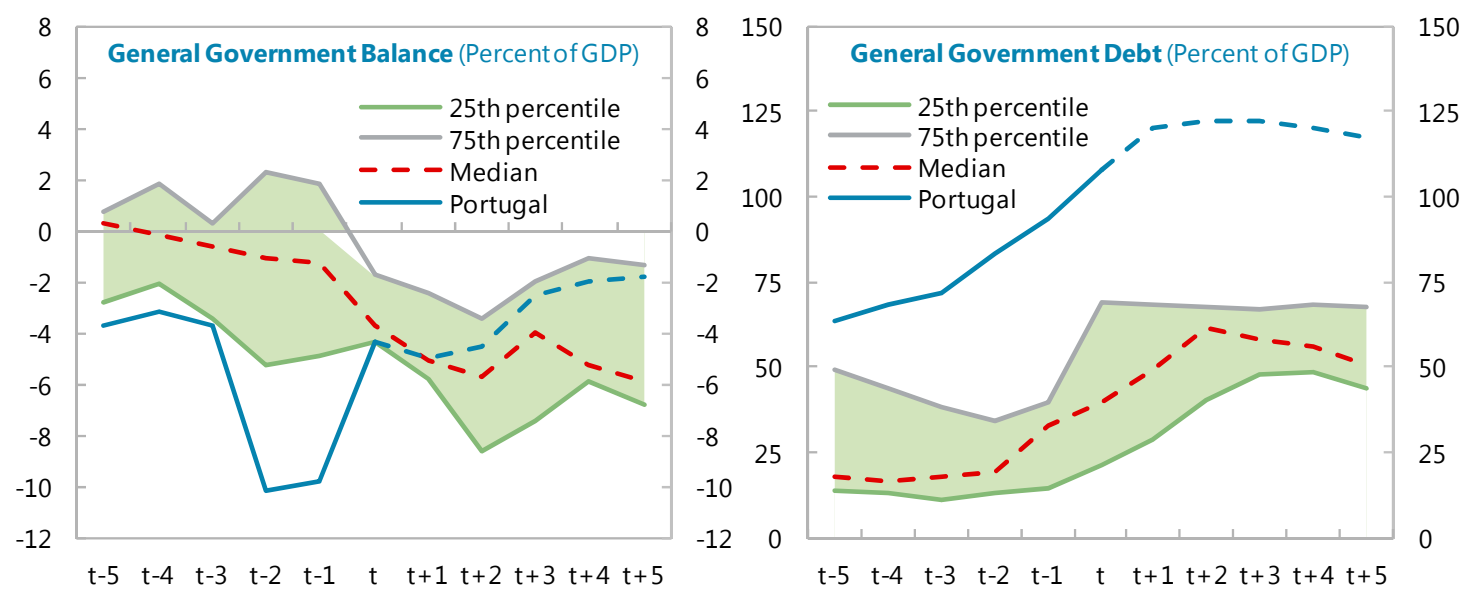

Sources:WEO; and IMF staff estimates.

\section{Key Lessons and Policy Recommendations for Portugal}

22. Past crisis experiences point to sizable risks and macro-financial costs that are often associated with corporate deleveraging episodes. To mitigate these costs and the resulting migration of losses to financial and public sector balance sheets, the policy mix needs to be supportive of an orderly and efficient deleveraging process, aimed at restoring corporate 
productivity and growth. This section reviews the ongoing efforts by the authorities to promote prompt debt restructuring of distressed firms, while ensuring enough credit will continue to flow to the most productive and innovative sectors of the economy. Building on past successful experiences, it also explores the potential role of tax policy and macroprudential supervision to strengthen the institutional framework and set the right incentives to prevent a new build-up of corporate imbalances once market conditions stabilize.

\section{Restructuring Corporate Balance Sheets}

23. Corporate restructuring is widely recognized as an essential element for a sustainable recovery and firms' long-term viability. In general, it entails the re-organization of the financial and operational structure of distressed but still viable firms, as well as the liquidation of non-viable ones. In past episodes, restructuring processes have followed different approaches depending on country-specific circumstances and the severity of the problem at hand. These have ranged from government-directed models, such as the establishment of centralized Asset Management Companies (AMC) in Czech Republic, Turkey, and many East Asian countries, to government-sponsored market-based models, such as the introduction of guidelines for out-of-court debt workouts (along the so-called London Approach).

24. The Portuguese authorities have so far opted for a market-based approach, taking important steps to strengthen the legal framework for corporate debt restructuring and insolvency resolution, initiating a public campaign to raise awareness of the improved toolkit. Indeed, past experiences suggest that across-the-board types of restructuring have, in some cases, delayed rather than accelerated the restructuring process, due to capacity constraints and valuation challenges, while entailing substantial fiscal costs (Claessens et al., 2001). Given Portugal's limited fiscal space and the manageable corporate losses to date, case by case initiatives appear preferable.

25. Specifically, the authorities have recently amended the insolvency law to better support early rescue of viable firms, including through "fast track" court approval procedures. ${ }^{16}$ To give guidance to creditors and debtors who engage in out-of-court restructuring, specific guidelines were also adopted to facilitate voluntary out-of-court workouts and avoid overwhelming the judicial system in line with international best practices

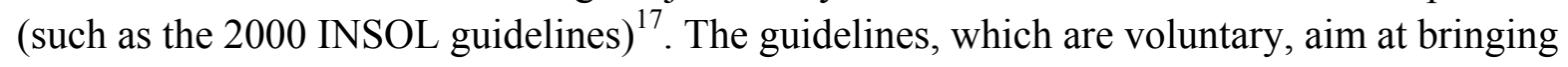

\footnotetext{
${ }^{16}$ Fast track court approval procedures refer to procedures under which the court expeditiously approves a debt restructuring plan negotiated between the debtor and its main creditors in a consensual manner before the initiation of insolvency proceedings. This technique draws upon the most significant advantage of a courtapproved restructuring plan (i.e., the ability to make the plan binding on dissenting creditors or cram down), while leveraging speedy out-of-court negotiation process.
}

${ }^{17}$ http://www.insol.org/page/57/statement-of-principles. 
the main creditors and viable debtors in financial difficulties to the negotiating table to enable an early restructuring of the debtor. More formal approaches were not deemed necessary at this stage. In the past (e.g. Turkey in 2001), these have included agreement by all or most financial institutions to follow specified procedures and actions in out-of-court restructurings; formal arbitration with specific deadlines; and penalties for noncompliances. $^{18}$

26. The authorities have also created a program, mainly tailored for SMEs, with a conciliation procedure (SIREVE) mediated by IAPMEI, the public agency for SMEs and Innovation. The procedures may be initiated by a company in economic distress with the objective of reaching an agreement with 50 percent or more of its creditors and IAPMEI may facilitate the agreement. ${ }^{19}$ Upon initiation, the procedure provides for an automatic standstill for all of the enterprise's creditors, although these may opt out. Provided the agreement is approved by at least 50 percent of the SME's creditors, the "fast track" process under the Insolvency Law may also be used to cram down dissenting creditors.

27. Tailored restructuring approaches for SMEs have been also common in past crisis cases. In Thailand during the crisis, the Corporate Debt Restructuring Advisory Committee introduced a simplified process for SMEs (accounting for 40 percent of NPLs) and identified more than 12,000 cases for monitoring and follow-up, of which, by 2001, 73 percent were completed or in process and the remaining 27 percent subject to legal action. In addition, Bank of Thailand set targets for financial institutions to resolve a certain number of SME cases each month. This and other experiences to monitor and target progress with SME restructuring may be usefully transposed to the Portuguese context, also in view of the rising deterioration of the SME portfolios and related risks for banks. ${ }^{20}$ In particular, recent instructions issued to the banks by the BdP to monitor changes in the credit terms of debtors facing financial difficulties and any resulting NPLs can represent an important step not only to reduce ever-greening but also to promote prompt restructuring of distressed loans in line with past experiences.

\section{Promoting Alternative Funding Sources}

28. While the deleveraging and restructuring processes take their course, policies need to be in place to secure adequate liquidity to the viable and productive firms in the economy, thus avoiding an abrupt adjustment and ensuring the necessary conditions to restore

\footnotetext{
${ }^{18}$ More recently, Serbia introduced an out of court restructuring mechanism by law with voluntary participation.

${ }^{19}$ The tax and social securities authorities must participate in the negotiations, although they may refuse to join an agreement if it is inconsistent with their specific rules for debt restructurings. Ensuring that tax authorities (AT) and the social security (SS) system are willing to renegotiate their portion of the debt, within the limits of the law, is essential for the success of these procedures.
}

${ }^{20}$ See Claessens (2005) for a review of past experiences with special programs for SMEs. 
productivity and growth. In Portugal, several factors have so far been at play mitigating the risk of a generalized credit crunch. These have included the stability of customer deposits, continued liquidity support by the Eurosystem, and, more recently, the resources released by the government capital injections. Nevertheless, the cost of credit remains among the highest in the euro area, posing important constraints on firms and hampering their competitiveness.

29. To promote continued access to funding at affordable rates for productive and innovative firms, the Portuguese authorities have been actively engaged in developing funding alternatives to bank credit, especially for the more-exposed SME segment, supporting firms' increasing reliance on internal funding (as per INE Investment Survey):

- $\quad$ Guarantees. The Government has extended guarantee lines for a total amount of around $€ 10$ billion to increase available liquidity to SMEs, including, more recently, about $€ 1.5$ billion through the PME Crescimento. ${ }^{21}$ Although in line with past experiences (e.g.

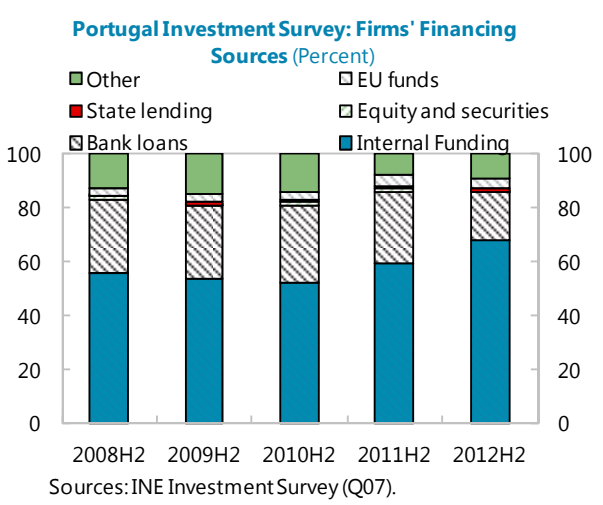
Korea, 1998 and 2004), the scope for these programs is necessarily limited given that they create important contingent liabilities to the government. ${ }^{22}$ Moreover, in the case of Portugal, the low sovereign ratings limit the guarantees' ability to lower funding costs.

- Access to capital markets. Recent proposals under consideration by the authorities to improve firms' access to capital markets focus on promoting the Portuguese retail market for corporate bonds, following successful issuances by a few large companies, including about $€ 1.8$ billion placed in external markets. In the SME context, the government is exploring with banks and other investors the possibility of aggregating SME debt instruments into larger portfolios to enable their access to capital markets (the Italy's "minibond" for SMEs is a recent example of this type of initiatives); moreover, measures to stimulate the creation of privately-run investment funds specialized in SMEs are being considered in order to facilitate SMEs' access to equity capital markets.

\footnotetext{
${ }^{21}$ These are, for the most part, partial guarantees, covering on average 50-75 percent of the loan, depending on the size of the loan and the company risk profile.

${ }^{22}$ Similar considerations apply to government-led initiatives to impose moratoria by banks on guaranteed SME debt falling due. Past and more recent experience in Korea suggest that these types of support schemes may create perverse incentives not to restructure, especially in presence of inadequate burden sharing with the banks (see also IMF, 2006b).
} 
- $\quad$ Alternative financing sources. Recent proposals to support alternative financing options for firms include the possible creation of a Portuguese Working Capital Platform for SMEs, in line with past examples in Latin America, to enhance information sharing and facilitate commercial transactions. Potential forms of structured funding with support by the EIB are also under consideration, although the need to limit fiscal risks is likely to reduce scope for low remuneration rates. Possible options to rationalize existing government initiatives, including through better targeting of EU structural funds, are also being discussed.

\section{Securing Long-Term Viability}

30. Macro-prudential policies. As already discussed, the supervisory role of the BdP, including regular stress tests and on-site inspections, is crucial to secure banks' recognition of losses and to promote prompt recourse to debt restructuring. Looking forward, as market conditions stabilize, a broader set of macro-prudential measures can also be considered to avoid new build-ups of imbalances and risks in specific niches of the economy. Beyond standard balance sheet tools (including the forthcoming Basel III requirements on leverage and net stable funding ratios), sectoral capital requirements, or variable risk weights, can help target specific sectors showing signs of exuberance, by requiring banks to hold additional capital buffers - the higher risk weights on commercial real estate loans in Australia in 2004 and on corporate lending in India in 2005-06 are recent examples of the use of these tools. ${ }^{23}$

31. Governance and transparency. The authorities can also play a critical role in promoting transparency and information sharing on the Portuguese corporate sector. Portugal has a relatively low standing compared to peer EA countries in terms of corporate governance, as proxied by the Corporate Governance Quality (CGQ) index by De Nicolo et al. (2009). ${ }^{24}$ Moreover, even though it ranks increasingly well on the overall Ease of Doing Business (according to the 2013 World Bank indicators), it is among the Euro area countries with the weakest "firms' ability of getting credit" (together with Italy and Slovenia). This low rank is largely due to the relatively small private credit bureau coverage (of only 23 percent compared, for example, with 100 percent in Ireland). ${ }^{25}$ Credit bureaus play

\footnotetext{
${ }^{23}$ See also Bank of England (2011) for a review of macro-prudential tools.

${ }^{24}$ The CGQ index is calculated from a simple average of three indicators: (i) accounting standards — based on the amount of information disclosed by firms; (ii) earning smoothing - estimated as the correlation between cash flows and profits and proxying the ability of managers to conceal firms' performance through accruals; and (iii) stock price synchronicity - calculated with respect to average returns at country level, with higher comovements associated in the literature to lower financial development and corporate governance.

${ }^{25}$ According to the WB Doing Business Indicators, private credit bureau coverage refers to the number of individuals or firms listed by a private credit bureau with current information on repayment history, unpaid debts, or credit outstanding. The number is expressed as a percentage of the adult population.
} 
an important role in providing the necessary information to assess credit standing of firms and thus facilitating the link between creditors and borrowers. ${ }^{26}$ This is particularly relevant in the case of Portugal given the limited share of quoted firms and predominance of SMEs. The authorities' recent initiative to promote the creation of an SME credit bureau could be an important step in this direction, although consistency with the relevant Portuguese and EU laws would need to be ensured.

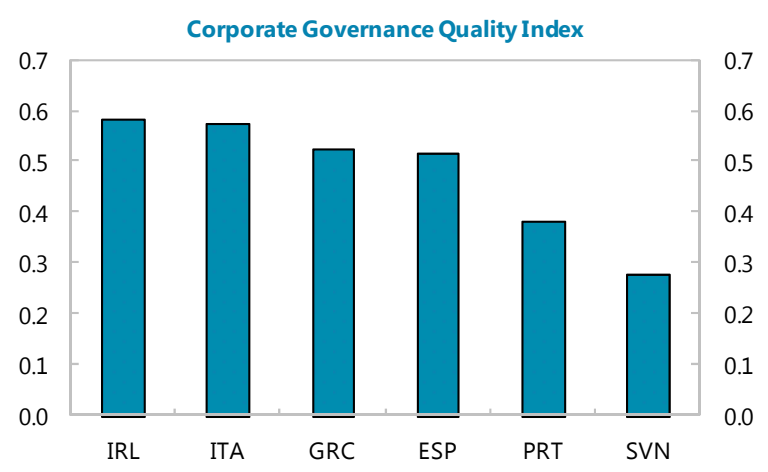

Sources:IMF CVU; and CGQ index by Nicolo, Laeven, and

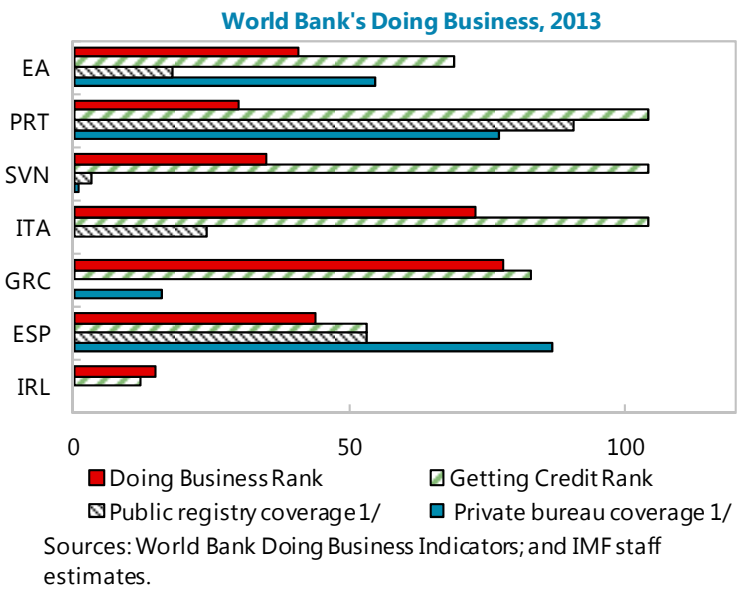

32. Tax policy. While in Portugal the ability of supporting the corporate deleveraging process through countercyclical fiscal policies is limited, evidence from past episodes suggest that targeted tax measures can help strengthen balance sheets and improve the medium-term viability of the corporate sector in the long run. ${ }^{27}$ Accordingly, the Portugal's tax framework is being enhanced along several dimensions:

- $\quad$ Temporary tax incentives for debt restructuring. In past episodes, time-bound tax incentives - over 2-3 years - have been introduced by governments (e.g. Thailand, and more recently, Iceland and Latvia) to accelerate corporate debt restructuring. ${ }^{28}$ These temporary measures can include, among others, (i) upfront deduction of written-off debt from the taxable income of the creditor, with additional regulatory benefits for banks; (ii) limitation of taxes on restructurings that involve interest rate reductions by creditors; and (iii) elimination or deferral of corporate income tax on written-off debts for the debtor. Recently, and in line with past experiences, Portugal

\footnotetext{
${ }^{26}$ See also IMF (2006b).

${ }^{27}$ See Pomerleano (2005) and Claessens et al. (2001) for a review of tax policy measures in past episodes.

${ }^{28}$ It is important to make tax incentives conditional on completion of the restructuring to avoid misuse. In Turkey, commencement of the legal proceedings to recover the debt was sufficient to qualify for the tax incentives, creating perverse incentives for banks to pursue cosmetic legal action rather than real restructuring. Portugal makes the tax incentives conditional on companies deemed viable and being part of a revitalization plan.
} 
has included in the new corporate insolvency framework (entered into force in May 2012), the possibility for creditors of deducting the losses arising from debt restructuring from the corporate income tax. Likewise, debtors will not be taxed over any positive variation in their assets as a result of the debt restructuring (Article 268, of the corporate insolvency law).

- $\quad$ Tax treatment of mergers and acquisitions. Specific fiscal measures have also been used in the past to promote mergers and balance-sheet consolidation. These include provisions for tax-free mergers, including through the elimination of taxes arising from the immediate realization of capital gains. In Portugal, capital gains originating from mergers or acquisitions are indeed not taxable, with any losses deductible in the new company P\&L, with authorization from the Minister of Finance. This is especially relevant for Portugal given the large number of micro companies and SMEs. ${ }^{29}$

- $\quad$ Tax-induced debt bias. Key measures to strengthen firms' balance sheets should focus on minimizing the distortions resulting from the different tax treatment of debt versus equity. The Portugal tax framework currently envisages "thin capitalization rules" limiting the amount of interest expenditure deductions allowed for overleveraged firms. The 2013 draft budget enhances this model, by limiting the deductible net interest cost to $€ 3$ million or 30 percent of the EBITDA (and de facto applying mostly to large companies). More substantial reductions could further reduce tax-induced debt bias but would also have an undesired impact on capital investment. The introduction of an allowance for new corporate equity (the so-called ACE) can be effective in enhancing tax neutrality, while avoiding pro-cyclicality, along recent experiences in Latvia and, more recently, Italy. Portugal had introduced an ACE for small companies (in place until 2013). However, further deepening of this measure has been ruled out at this stage, in view of limited fiscal space.

\footnotetext{
${ }^{29}$ The recent elimination in Portugal of the reduced tax rate for small firms is also expected to have removed an important structural bias in firms' size.
} 


\section{Appendix I. Portuguese Firms' Leveraging Process in the Run-uP to the CRISIS}

1. The corporate finance literature shows that financial deepening can help boost productivity levels and reduce macro volatility by diversifying firms' funding options. ${ }^{1}$ However, if leverage becomes excessive, it can more than offset the benefits by amplifying firms' sensitivity to income and interest shocks, leading to larger and more persistent cyclical fluctuations in the economy (Bernanke and Gertler, 1989). The experience of Portugal, as well as of other countries with highly leveraged corporate sectors, provides evidence in support of these findings.

\section{As Portugal's EMU membership became} reality, interest rates quickly converged to European levels, reflecting a sharp reduction in currency and country risk. ${ }^{2}$ And, by the time the euro was introduced, they started tracking closely developments in Germany, leading firms to increase their reliance on bank borrowing. Improved access to credit provided initially an important stimulus to the corporate sector, supporting investment spending.

3. However, since the late 1990s, bank credit

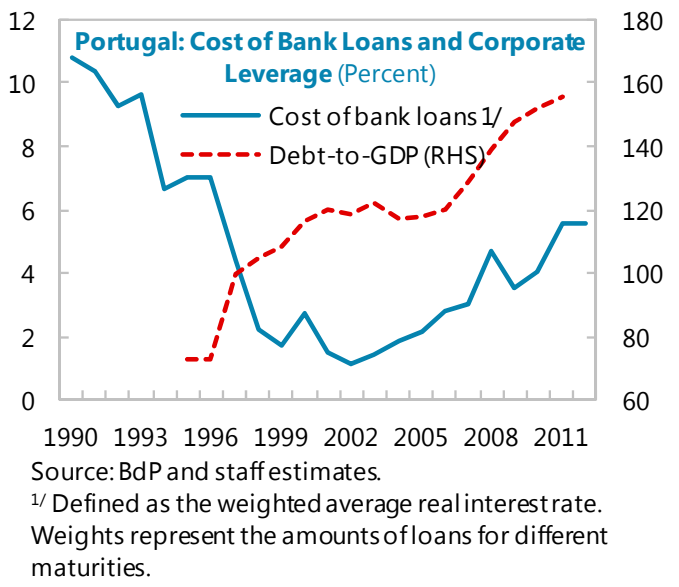
was increasingly channeled to the non-tradable sectors, notably construction, real estate, and wholesale/retail trade. By 2010, the share of debt of non-tradable firms had risen to about 120 percent of GDP, from just 65 percent in 1997. Moreover, the increase in firms' net borrowing no longer reflected productive investment, but rather sustained declines in gross savings (of about 4.5 percent of GDP over 2000-08), associated with sizable increases in operating costs, notably compensation of employees and net property expenses. ${ }^{3}$ In turn, the surge in corporate indebtedness generated high interest burdens for the most leveraged Portuguese firms, despite record-low interest rates (Figure III-2), further eroding corporate profitability and proving a drag on productive investment and growth.

\footnotetext{
${ }^{1}$ In a world of perfect capital markets, a firm's investment decisions should be completely unaffected by the type of security used to finance it (Modigliani-Miller, 1985). However, in presence of market imperfections, notably asymmetric information, firms' capital structure would matter, favoring debt to equity.

${ }^{2}$ See Banco de Portugal (2009) for an in-depth review of Portugal's economic and financial integration process.

${ }^{3}$ The flow-of-funds identity linking corporate funds' uses and sources provides a useful reference to understand the main channels of corporate debt build up $(\Delta \mathrm{D})$ :

$$
\Delta \mathrm{D}=(\mathrm{I}+\Delta \mathrm{FA}-\mathrm{IF})-\Delta \mathrm{E}=\text { Corporate Gap }-\Delta \mathrm{E}
$$

where I refers to capital investment, $\Delta \mathrm{FA}$ to the change in net financial assets, IF to the firm's internal funds arising from its gross savings, and $\Delta \mathrm{E}$ to the net issuance of equity. This implies that higher indebtedness can result from the deterioration of a firm's corporate gap and/or lower reliance on equity.
} 

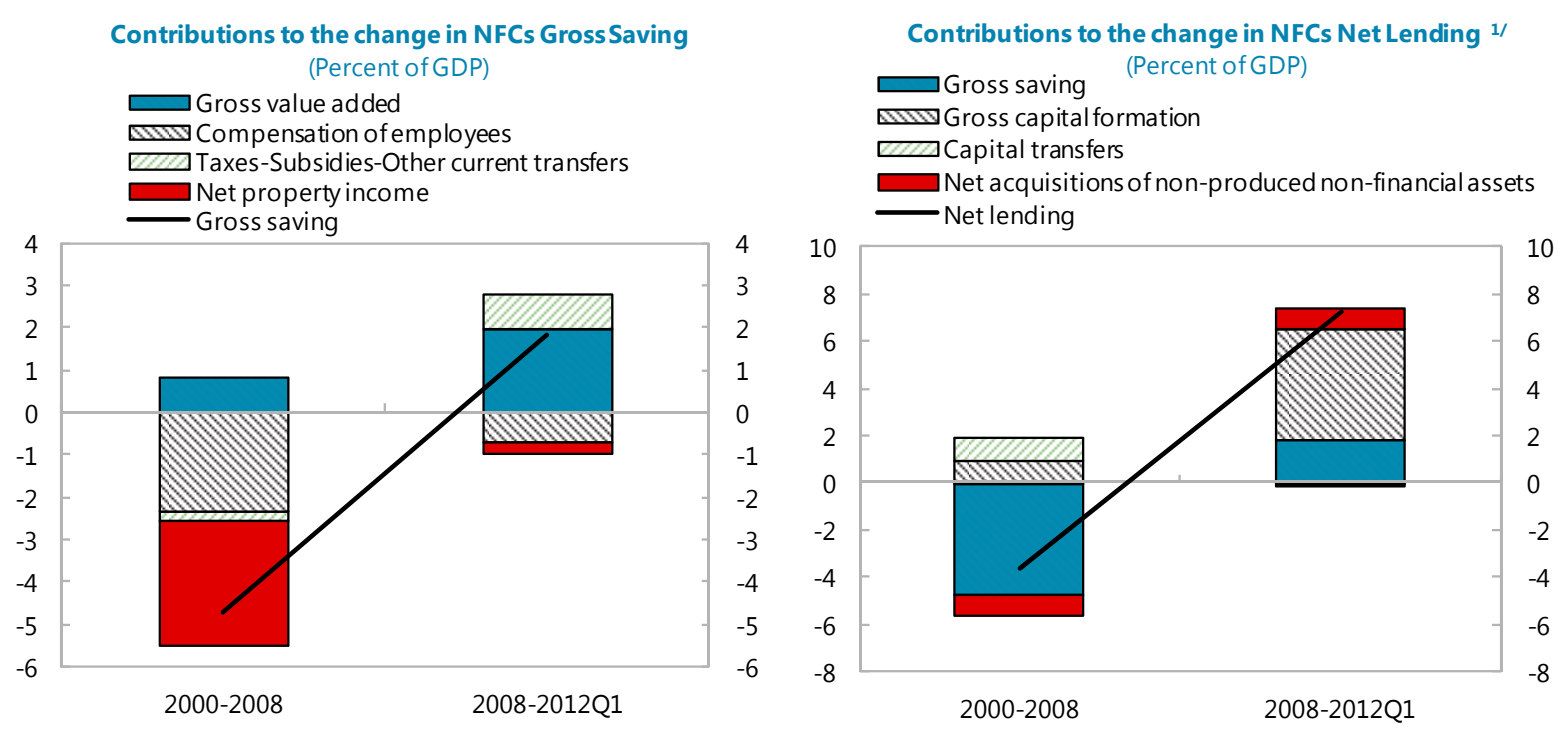

Source: Banco de Portugal.

1/ A negative (positive) value corresponds to a decline (increase) in net lending,i.e, an increase (decline) in net borrowing.

4. The turning point in the late 1990s in the corporate profitability and investment behavior of the Portuguese corporate sector appears consistent with cross-country evidence in the literature of a negative relationship between firms' debt overhang and investment, with asymmetric effects beyond certain threshold levels (see Box A1 below). These findings are also confirmed at macro-level, among others, by Cecchetti et al. (2010) who - based on a sample of 18 OECD countries from 1980 to 2010 - find that a country corporate debt becomes a drag on

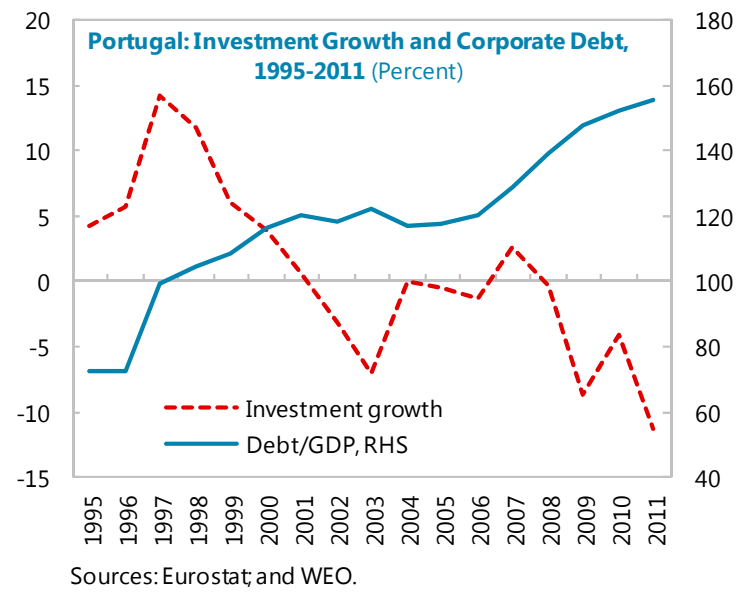
growth for levels beyond 90 percent of GDP, especially if combined with high government debt. 


\section{Box A1. Corporate Debt Overhang and Investment}

The relationship between corporate indebtedness and investment has been widely tested in the empirical literature. Building on earlier work by Vermeulen (2000) and IMF (2006a), we follow a panel-data approach to test the hypothesis that firms' investment decisions are indeed affected by their balance sheet position. For the analysis, we use the BACH database, maintained by the Banque de France, with aggregated firm-level data for eight Euro area countries, including Portugal, and 21 sectors of activity over the period 1991-2011.

The results confirm the negative sensitivity of firms' investment-to-capital ratio (IK) to their debt overhang (D), after controlling for their performance in terms of sales-to-capital (SK) and lagged investment behavior. The debt overhang variable is proxied by a standard leverage measure, debt to equity, as well as a firm's capacity to repay its debt, its interest coverage ratio. Consistent with the literature, higher leverage and low capacity to repay are found to significantly reduce investment.

The panel results also confirm important nonlinearities between investment and corporate debt overhang, with a shift in the sign of the relationship as the debt burden exceeds certain threshold levels, $\tau$ (the $25^{\text {th }}$ percentile of the representative firms in the sample or around 125 percent of equity for leverage, and the standard threshold of 1, proxying firms' capacity to repay, for the ICR).

The results are not significantly different if the panel regression is restricted to the Portugal-specific observations, consistently with the negative correlation between corporate investment and indebtedness in Portugal during the pre-crisis period. Moreover, more accurate firm-level results for Portugal by Farinha (1995) and Barbosa et al. (2007), using similar methodologies, show that smaller firms tend to be more affected in their investment decisions by their financial structure.

\begin{tabular}{|c|c|c|c|c|}
\hline \multicolumn{5}{|c|}{$\begin{array}{l}\text { Corporate Debt Overhang and Investme } \\
\qquad \mathrm{IK}_{\mathrm{it}}=\alpha+\beta \mathrm{IK}_{\mathrm{it}-1}+\mathrm{ySK}_{\mathrm{it}-1}+\delta \mathrm{D}_{\mathrm{it}-1}+\varepsilon_{\mathrm{it}}\end{array}$} \\
\hline & \multicolumn{2}{|c|}{$D=D E$} & \multicolumn{2}{|c|}{$\mathrm{D}=\mathrm{ICR}$} \\
\hline & (1) & (2) & (1) & (2) \\
\hline Constant & $8.58^{\star \star *}$ & $7.53^{\star * *}$ & $5.32^{\star \star *}$ & $5.60 * * *$ \\
\hline $\mathrm{IK}_{\mathrm{it}-1}$ & $0.05^{\star * \star}$ & $0.06^{\star \star \star}$ & $0.05^{\star \star *}$ & $0.05^{\star \star \star}$ \\
\hline $\mathrm{SK}_{\mathrm{it}-1}$ & $1.83^{\star \star \star}$ & $2.07^{\star \star \star}$ & $2.11^{\star \star \star}$ & $2.01^{\star \star \star}$ \\
\hline$D_{i t-1}$ & $-0.23^{* \star *}$ & & $0.37^{* \star *}$ & \\
\hline$D_{\text {it-1 }} \times 1\left\{D_{i t-1}<\tau\right\}$ & & $0.30^{\star \star \star}$ & & $'-1.81^{\star \star \star}$ \\
\hline$D_{\text {it-1 }} \times 1\left\{D_{\text {it- } 1 \geq \tau\}}\right.$ & & $-0.19 * \star \star$ & & $0.39 * \star *$ \\
\hline $\begin{array}{l}A R(1) \text { test } \\
A R(2) \text { test } \\
\text { Hansen test }\end{array}$ & $\begin{array}{c}-2.43^{\star \star} \\
0.44 \\
53.54\end{array}$ & $\begin{array}{c}-2.43^{\star *} \\
0.59 \\
65.38\end{array}$ & $\begin{array}{c}-2.43^{\star \star} \\
0.53 \\
58.43\end{array}$ & $\begin{array}{c}-2.44^{\star \star} \\
0.61 \\
62.59\end{array}$ \\
\hline Obs. & 965 & 965 & 965 & 965 \\
\hline
\end{tabular}

Notes: Dynamic panel data with GMM two-step system estimator. ${ }^{* *},{ }^{* *}, *$ indicate significance at 1,5 , and 10 percent 


\begin{tabular}{|c|c|c|c|c|c|c|c|c|c|c|c|c|c|c|c|}
\hline \multicolumn{16}{|c|}{ Table III-1. Portugal: Leverage of Nonfinancial Corporations, 1997-2011 1/ } \\
\hline & 1997 & 1998 & 1999 & 2000 & 2001 & 2002 & 2003 & 2004 & 2005 & 2006 & 2007 & 2008 & 2009 & 2010 & 2011 \\
\hline & \multicolumn{15}{|c|}{ In percent of $G D P$} \\
\hline \multicolumn{16}{|l|}{ Stocks } \\
\hline Total assets & 217.9 & 225.3 & 229.7 & 229.0 & 221.1 & 211.3 & 221.4 & 221.1 & 224.0 & 229.3 & 241.3 & 234.5 & 255.6 & 261.1 & 259.4 \\
\hline Non-financial assets & 146.1 & 146.3 & 150.9 & 145.6 & 137.4 & 134.9 & 133.5 & 132.0 & 132.1 & 144.3 & 156.1 & 152.2 & 164.2 & 164.1 & 166.9 \\
\hline Financial assets & 71.8 & 79.0 & 78.9 & 83.4 & 83.8 & 76.3 & 87.9 & 89.1 & 92.0 & 84.9 & 85.2 & 82.3 & 91.4 & 97.0 & 92.5 \\
\hline Held domestically & 55.0 & 54.4 & 55.9 & 52.9 & 48.6 & 43.4 & 48.8 & 48.4 & 51.3 & 42.9 & 40.7 & 38.6 & 43.7 & 47.5 & 42.8 \\
\hline Held externally & 16.8 & 24.6 & 22.9 & 30.5 & 35.2 & 32.9 & 39.1 & 40.6 & 40.7 & 42.0 & 44.5 & 43.6 & 47.7 & 49.5 & 49.7 \\
\hline Total debt & 101.4 & 104.0 & 108.7 & 116.3 & 120.0 & 118.3 & 121.9 & 116.9 & 117.6 & 120.1 & 128.8 & 138.9 & 147.7 & 152.1 & 155.6 \\
\hline Held by banks & 35.1 & 39.0 & 45.0 & 51.9 & 55.9 & 57.2 & 59.2 & 57.7 & 59.6 & 62.2 & 67.6 & 77.0 & 80.1 & 77.4 & 77.1 \\
\hline Held by other domestic & 51.7 & 46.3 & 46.2 & 46.3 & 40.2 & 36.2 & 37.4 & 36.0 & 33.3 & 32.8 & 36.0 & 36.0 & 39.0 & 43.4 & 43.9 \\
\hline Held by external & 14.5 & 18.6 & 17.5 & 18.1 & 23.9 & 24.8 & 25.4 & 23.2 & 24.7 & 25.1 & 25.2 & 26.0 & 28.6 & 31.4 & 34.6 \\
\hline Equity & 116.5 & 121.3 & 121.0 & 112.8 & 101.1 & 93.0 & 99.5 & 104.2 & 106.5 & 109.2 & 112.5 & 95.6 & 107.9 & 108.9 & 103.7 \\
\hline Quoted shares & 27.8 & 33.1 & 34.8 & 29.0 & 21.7 & 16.1 & 17.0 & 19.8 & 20.6 & 28.4 & 33.1 & 15.1 & 22.1 & 22.4 & 21.7 \\
\hline Unquoted shares & 88.7 & 88.2 & 86.2 & 83.7 & 79.4 & 76.9 & 82.5 & 84.4 & 85.9 & 80.8 & 79.4 & 80.5 & 85.8 & 86.5 & 82.0 \\
\hline \multicolumn{16}{|l|}{ Flows } \\
\hline Investments & 22.2 & 24.0 & 23.5 & 28.7 & 24.0 & 15.3 & 24.2 & 15.9 & 11.8 & 14.0 & 16.7 & 16.2 & 14.9 & 11.7 & 10.8 \\
\hline Capital expenditure & 11.6 & 13.7 & 14.8 & 14.9 & 14.1 & 12.7 & 11.9 & 12.2 & 12.4 & 12.4 & 13.3 & 13.9 & 11.8 & 10.6 & 9.5 \\
\hline Financial assets & 10.6 & 10.3 & 8.7 & 13.9 & 9.9 & 2.6 & 12.3 & 3.8 & -0.7 & 1.6 & 3.4 & 2.3 & 3.2 & 1.1 & 1.3 \\
\hline Financing & 22.5 & 23.8 & 23.1 & 30.3 & 26.0 & 17.0 & 25.7 & 17.3 & 12.2 & 15.3 & 17.4 & 16.7 & 15.6 & 14.4 & 12.2 \\
\hline Internal funds & 9.3 & 10.2 & 8.8 & 8.1 & 8.7 & 8.8 & 8.8 & 8.3 & 6.6 & 6.2 & 5.8 & 3.4 & 5.3 & 6.4 & 4.9 \\
\hline New debt & 9.5 & 10.5 & 10.5 & 15.2 & 15.5 & 4.1 & 9.5 & 4.8 & 2.7 & 4.8 & 13.0 & 13.2 & 6.3 & 5.7 & 4.9 \\
\hline Equity & 3.7 & 3.1 & 3.8 & 7.0 & 1.7 & 4.1 & 7.4 & 4.2 & 2.9 & 4.3 & -1.4 & 0.1 & 4.0 & 2.3 & 2.4 \\
\hline \multirow[t]{2}{*}{ Statistical discrepancy ${ }^{2 /}$} & 0.3 & -0.2 & -0.4 & 1.6 & 1.9 & 1.7 & 1.5 & 1.4 & 0.4 & 1.3 & 0.7 & 0.5 & 0.7 & 2.7 & 1.4 \\
\hline & \multicolumn{15}{|c|}{ In percent except when indicated otherwise } \\
\hline \multicolumn{16}{|l|}{ Leverage indicators } \\
\hline Debt-to-equity & 87.0 & 85.7 & 89.8 & 103.1 & 118.7 & 127.1 & 122.6 & 112.3 & 110.4 & 110.0 & 114.6 & 145.3 & 136.9 & 139.7 & 150.0 \\
\hline Debt-to-assets & 46.5 & 46.2 & 47.3 & 50.8 & 54.3 & 56.0 & 55.1 & 52.9 & 52.5 & 52.4 & 53.4 & 59.2 & 57.8 & 58.3 & 60.0 \\
\hline \multicolumn{16}{|c|}{$\begin{array}{l}\text { Source: ECB, Eurostat, INE, Banco de Portugal and staff estimates. } \\
1 / \text { On a consolidated basis. Includes SOEs outside the General Government. } \\
\text { 2/ Difference between financial balances derived from the capital account and from the financial account; plus (minus) sign means that financial account balance is smaller (larger) than capital account } \\
\text { balance. }\end{array}$} \\
\hline
\end{tabular}


Figure III-1. Corporate Vulnerability Indicators

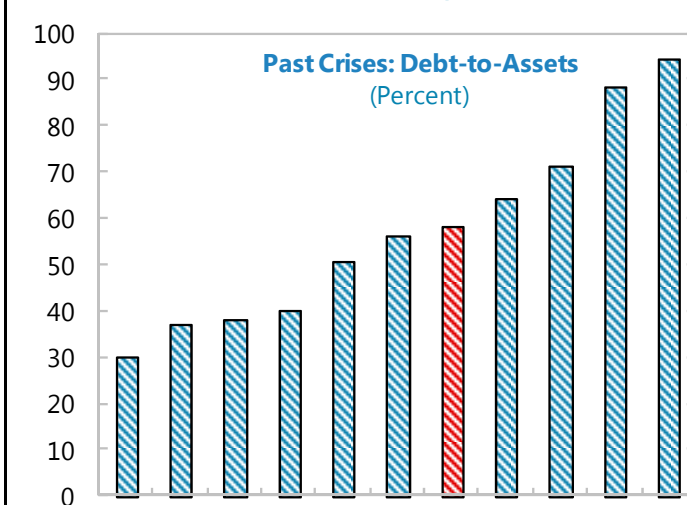

JPN, SWE, MEX, CZE, FIN, BRA, PRT, TUR, KOR, THA, IDN, 19991991199519991991199920112001199719992000

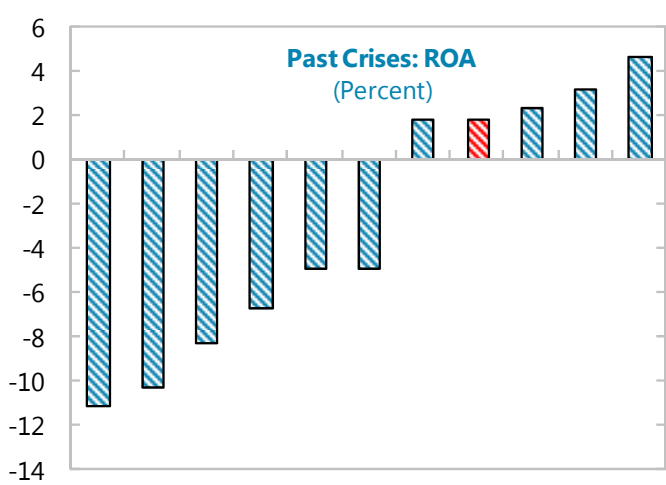

THA, IDN, KOR, TUR, CZE, BRA, FIN, PRT, JPN, MEX, SWE, 19971998199820011999199919912011199919951992

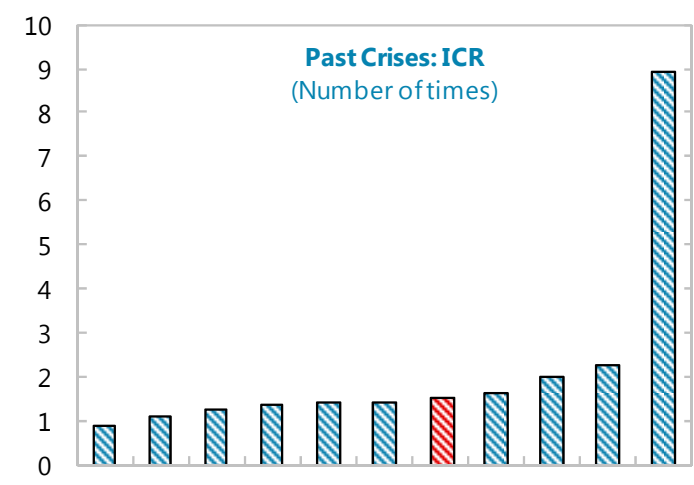

IDN, TUR, CZE, FIN, KOR, BRA, PRT, MEX, SWE, THA, JPN, 20002001199919911998199920111995199219981998
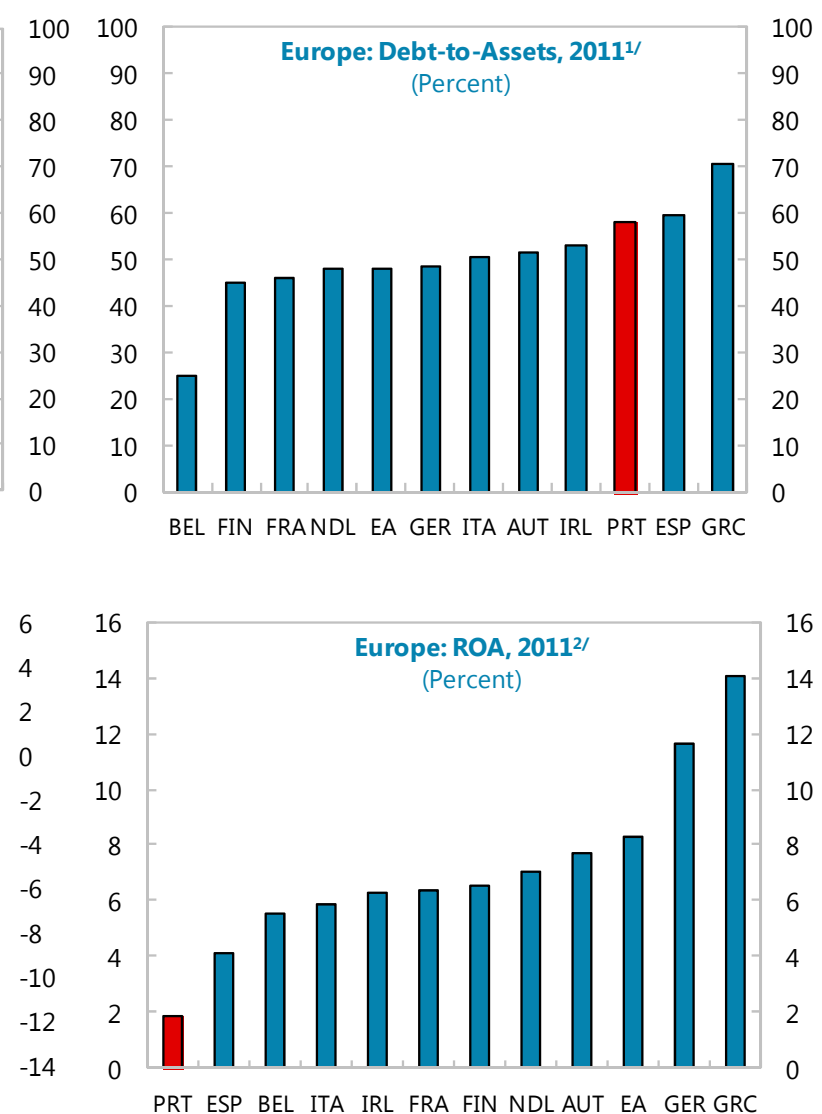

PRT ESP BEL ITA IRL FRA FIN NDL AUT EA GER GRC
00

90

80

70

60

40

30

20

BEL FIN FRANDL EA GER ITA AUT IRL PRT ESP GRC

10

8

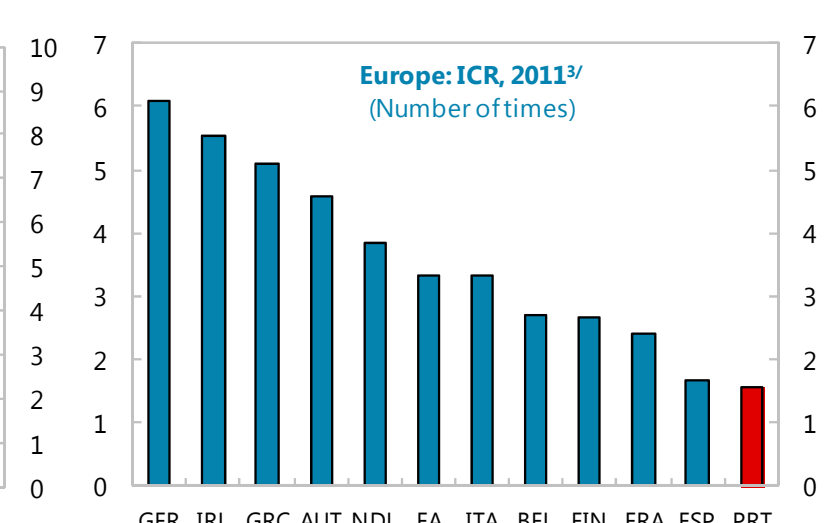

GER IRL GRC AUT NDL EA ITA BEL FIN FRA ESP PRT

Sources: Claessens (2005) for past episodes; Eurostat and INE for Portugal and rest of Europe in 2011.

1/ Total debt includes securities other than shares, loans, insurance technical reserves, trade debt and other accounts payable. Total assets is defined as total debt plus total equity.

2/ Net entrepreneurial income is used as net income to estimate ROA. Net entrepreneurial income equals net value added plus subsidies on production and property income receivable from financial assets owned by non-financial corporations (including profits of foreign subsidiaries), minus compensation of employees, taxes on production, interestand (land) rents payable.

3/ EBITDA estimated as net entrepreneurialincome plus taxes and interest. 
Figure III-2. Portugal: Evolution of Firms' Capacity to Repay Indicators, 1991-2011
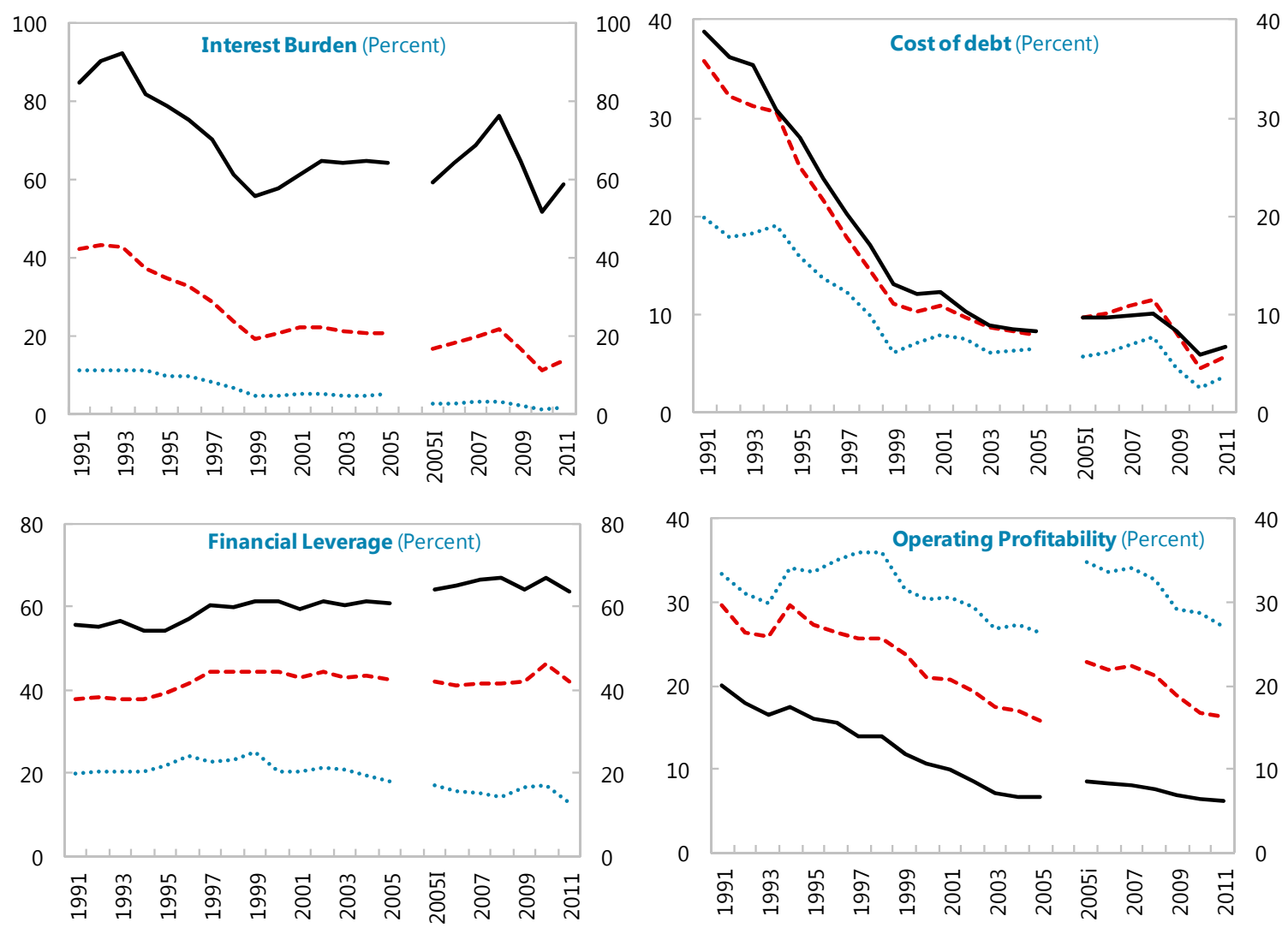

First Quartile of Interest Burden

- - - Central Quartile of Interest Burden

— Fourth Quartile of Interest Burden

Source: Banco de Portugal.

Notes: (i) interest burden = interest payment/EBITDA, (ii) cost of debt $=$ interest payment/debt, (iii) financial leverage $=$ debt/assets, (iv) operating profitability $=$ assets $/$ EBITDA. 
Figure III-3. Portugal: Corporate Vulnerability Indicators By Firm Size, 2011 1/
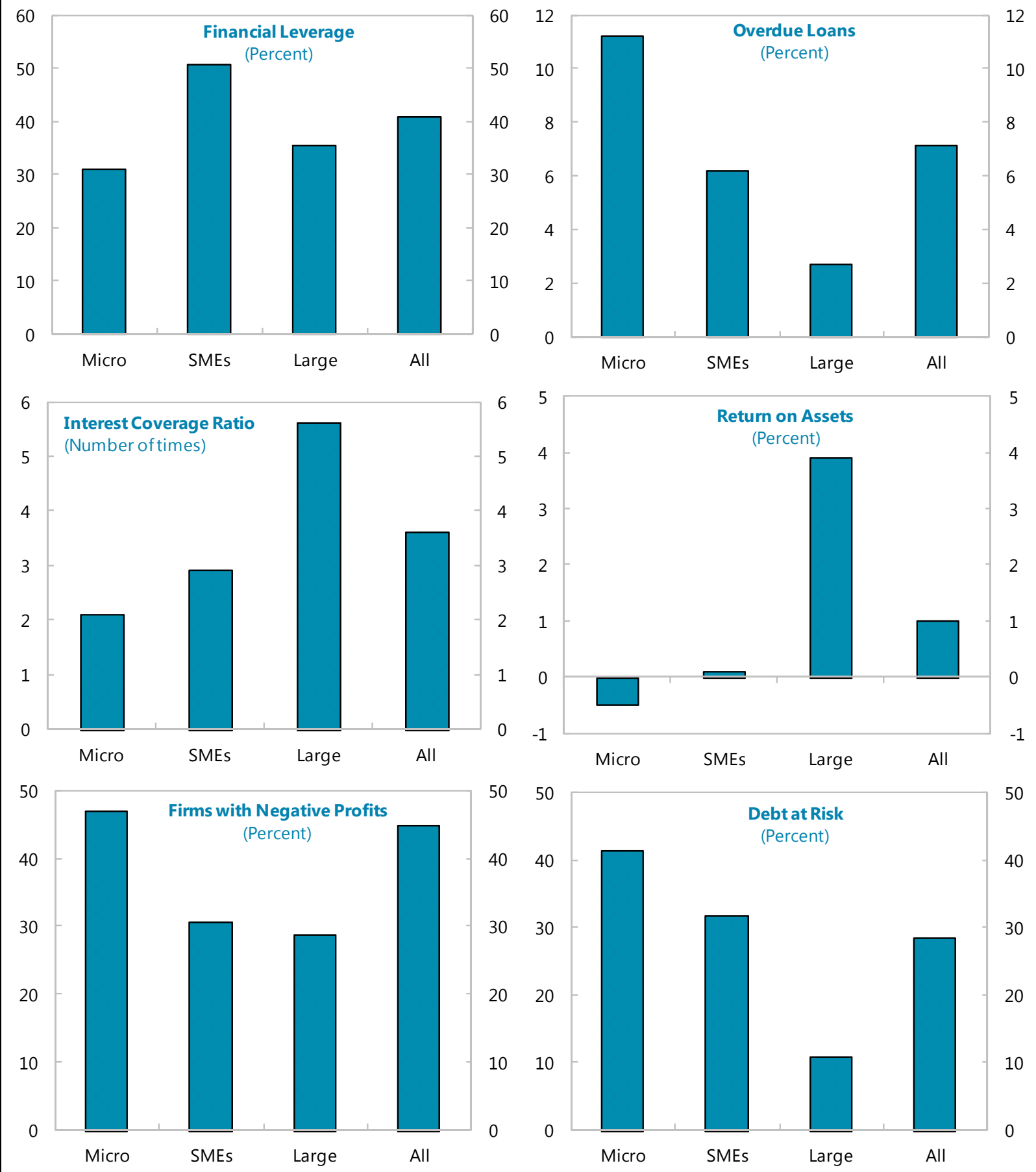

Source: Banco de Portugal.

1/ Micro companies have less than 10 employees or annual sale less than EUR 2 million, small companies have between 10 and 50 employees or annual sales ranging from EUR 2 to 10 million, and medium companies have between 50 an d 250 employees or annual sales between EUR 10 and 50 million. Finally, companies are classified as large if they have more than 250 employees or annual sales superior to 50 million. 


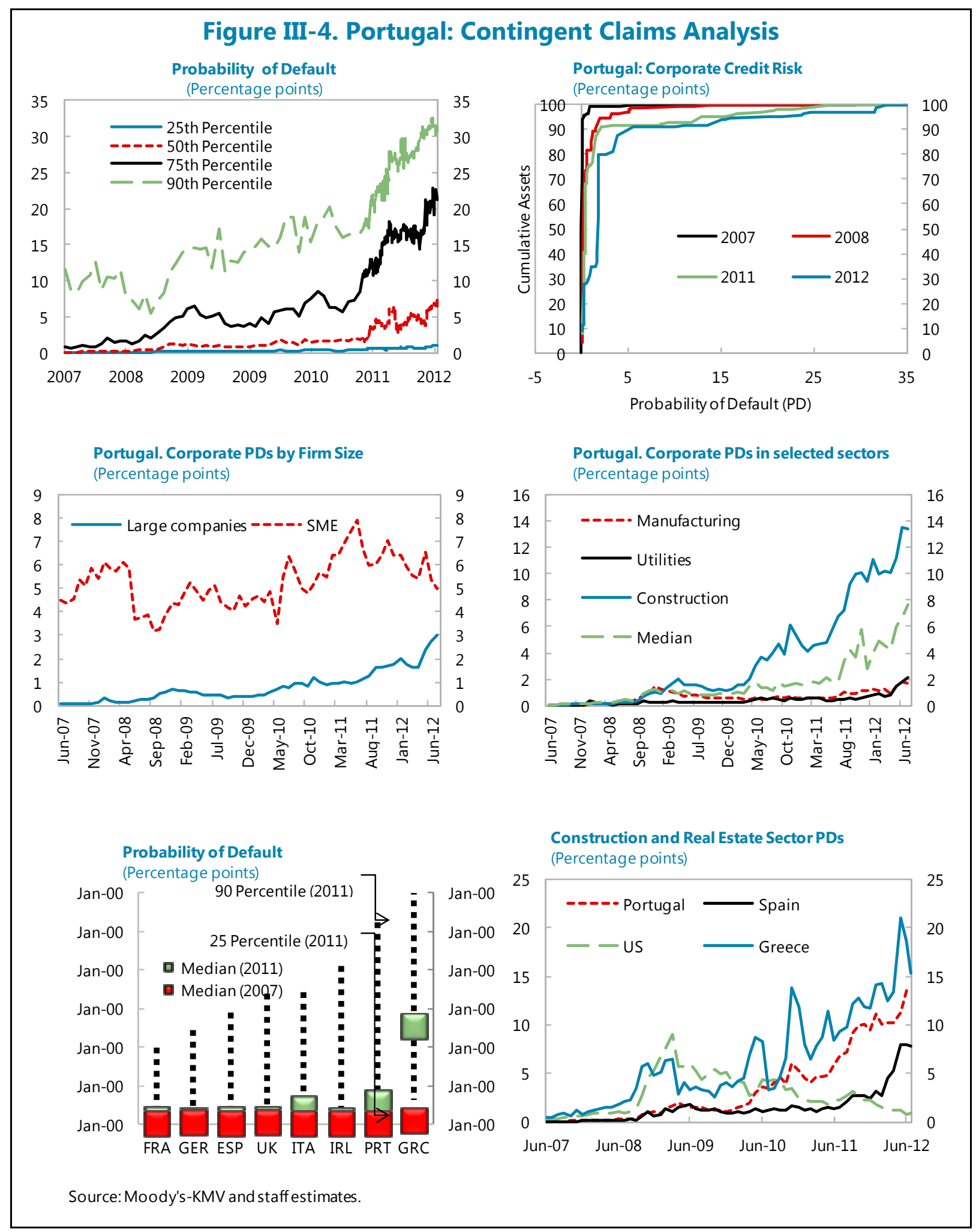


Figure III-5. Corporate Balance Sheet Adjustment in Past Crisis Episodes 1/
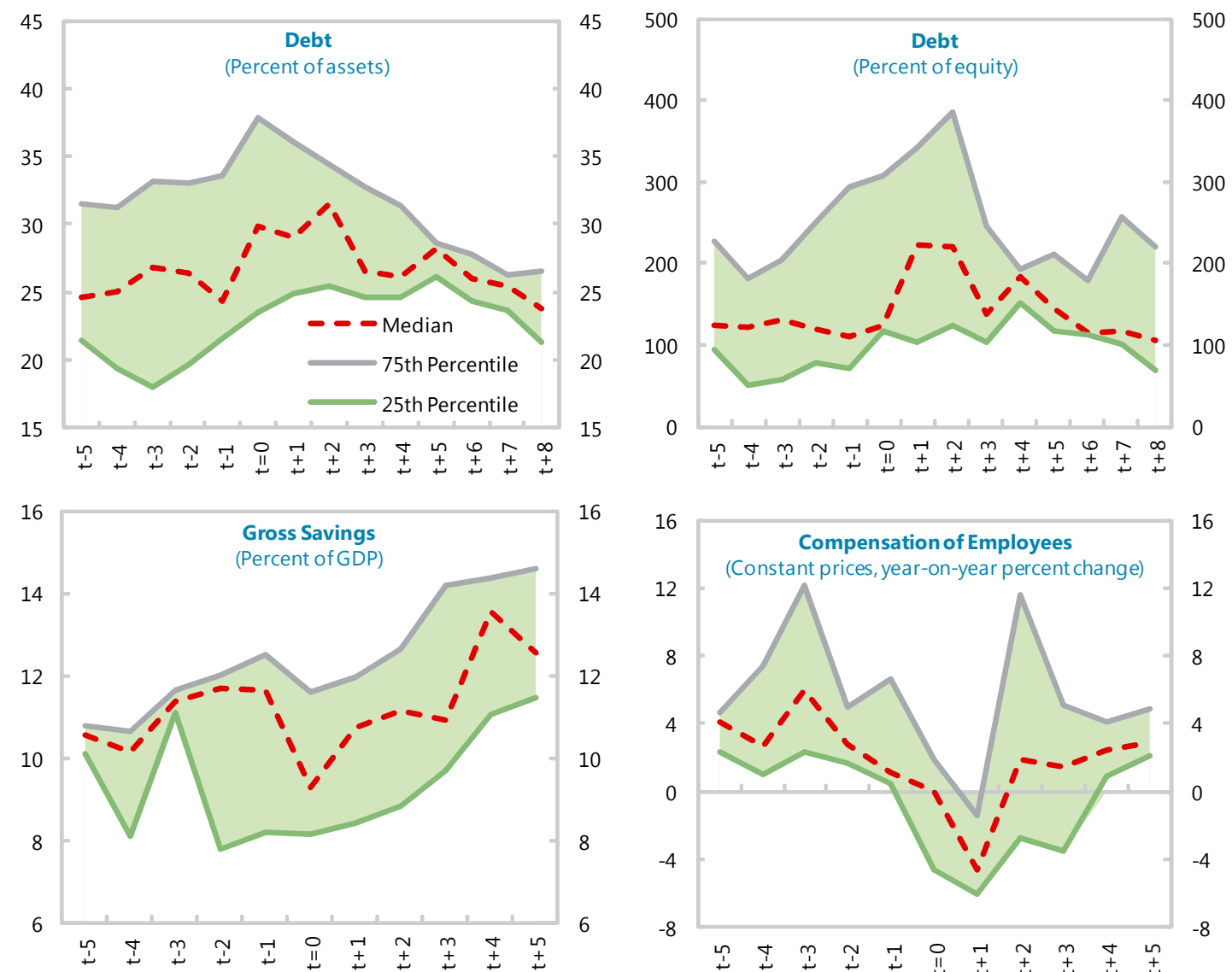

16
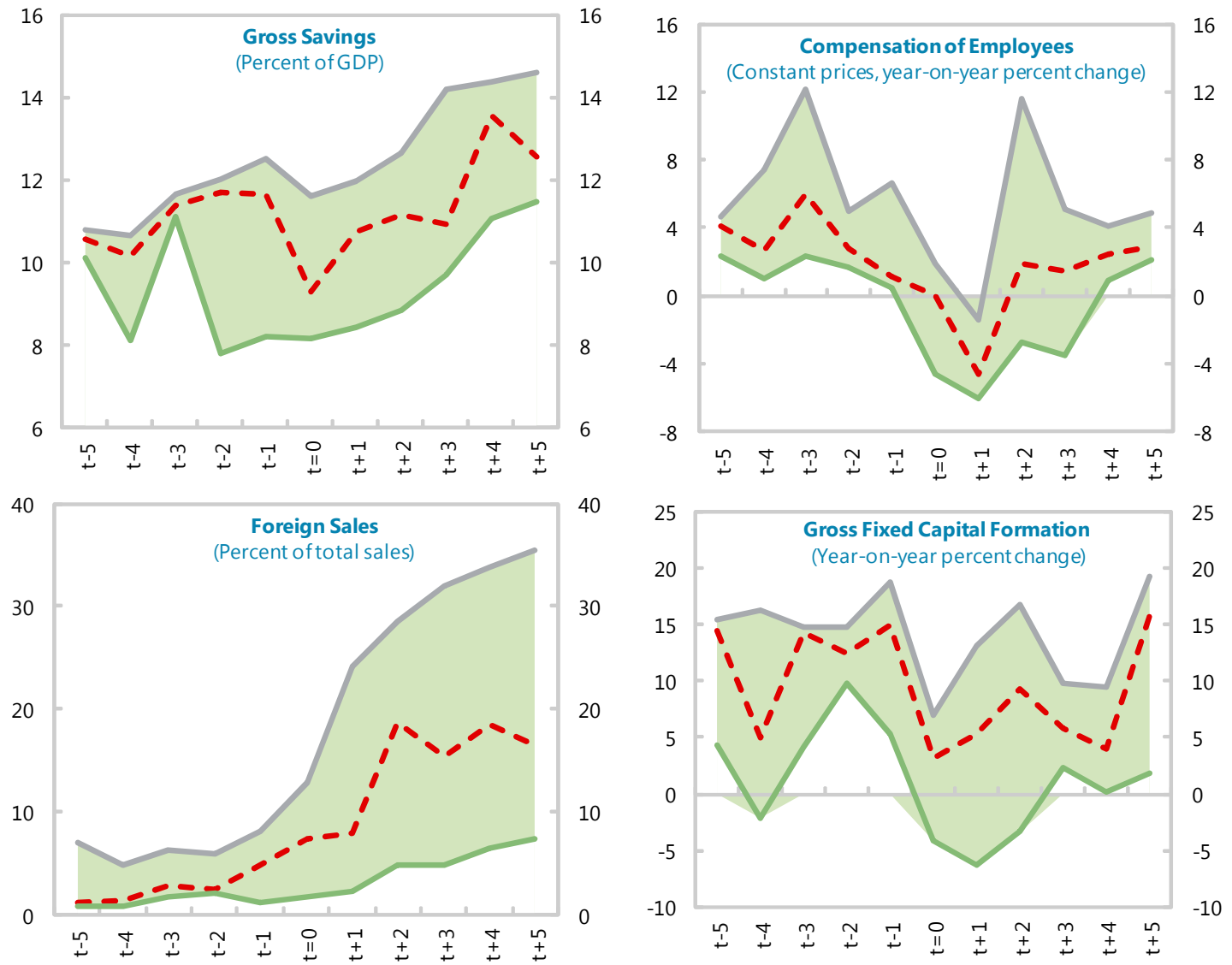

Sources: OECD; U.N.; National authorities; IMF, International Financial Statistics; and IMF staff estimates.

1/ Beginning of deleveraging episode at yeart. Crisis countries include Brazil (1998), Czech Rep. (1997), Finland (1990), Indonesia (2000), Japan (1997), Korea (1998), Mexico (1995), Sweden (1990), Thailand (1997), and Turkey (2001). t is set to 2011 for Portugal.

Note: Due to constraints in data availability, the analysis of pastepisodes is limited to the period 1990-2011. The Argentina and Uruguay experiences of 2002 are not included given the specific crisis characteristics. All the identified episodes were preceded or coincided with a banking crisis, although the Japan episode was not associated with a deleverag ing of the total economy because of stimulative policies and the increase in public debt. See also McKinsey (2010) for a review of historic public and private sector deleveraging episodes. 
Figure III-6. Macro-Economic Developments in Past Crisis Episodes 1/

(Year-on-year percent change)
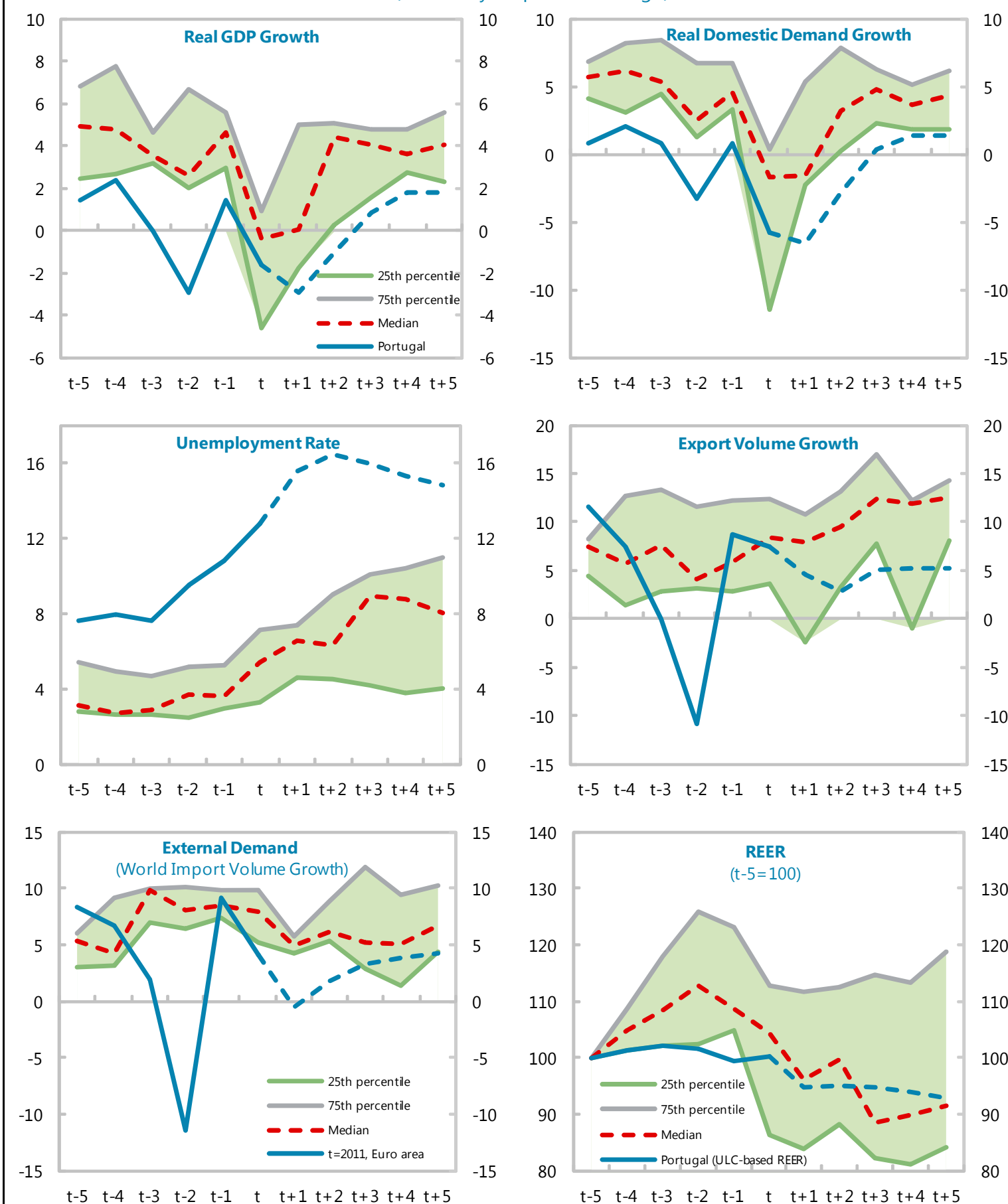

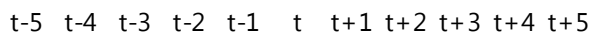

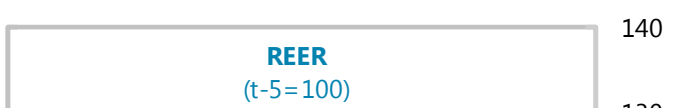

$t-5 \quad t-4 \quad t-3 \quad t-2 \quad t-1 \quad t \quad t+1 \quad t+2 \quad t+3 \quad t+4 \quad t+5$

Sources: IMF, World Economic Outlook; and IMF staff calculations.

1/ Beginning of deleveraging episode at year t. Crisis countries include Brazil (1998), Czech Rep. (1997), Finland (1990), Indonesia (2000), Japan (1997), Korea (1998), Mexico (1995), Sweden (1990), Thailand (1997), and Turkey (2001). t is set to 2011 for Portugal. 


\section{REFERENCES}

Antão, Paula, and Diana Bonfim, 2008, Capital Structure Decisions in the Portuguese Corporate Sector, Financial Stability Report 2008, Banco de Portugal, pp. 173-90.

Banco de Portugal, 2009, The Portuguese Economy in the Context of Economic, Financial and Monetary Integration, Economics and Research Department, Banco de Portugal.

Bank of England, 2011, Instruments of Macroprudential Policy: a Discussion Paper, Bank of England, December.

Barbosa, L., A. Lacerda, and N. Ribeiro, 2007, Investment Decisions and Financial Standing of Portuguese Firms, Economic Bulletin, Banco de Portugal, Winter 2007.

Bernanke, B. S., and M. Gertler, 1989, Agency Costs, Net Worth, and Business Fluctuations, American Economic Review, Vol. 79 (March), pp. 14-31.

Cecchetti, S.G., M.S. Mohanty, and F. Zampolli, 2011, The Real Effects of Debt, BIS Working Papers 352, Bank for International Settlements, September.

Claessens, S., 2005, Policy Approaches to Corporate Restructuring around the World: What Worked, What Failed?, in Corporate Restructuring: Lessons from Experience, edited by M. Pomerleano and W. Shaw, The World Bank.

Claessens, S., D. Klingebiel, and L. Laeven, 2001, Financial Restructuring in Banking and Corporate Sector Crises: What Policies to Pursue?, NBER Working Paper 8386, July.

De Nicolo, G., L. Laeven, and K. Ueda, 2008, Corporate Governance Quality: Trends and Real Effects, Journal of Financial Intermediation, Vol. 17, pp. 198-228.

European Commission, 2010, Quarterly Report on the Euro Area, Volume 9 No 3, Directorate General for Economic and Financial Affairs.

Farinha, L., 1995, Investment, Liquidity Constraints and Firm Size: The Portuguese Case, Economic Bulletin, Banco de Portugal, December.

Glen, J., 2005, Debt and Firm Vulnerability, in Corporate Restructuring: Lessons from Experience, edited by M. Pomerleano and W. Shaw, The World Bank.

Hubbard, R. G., 1998, Capital-Market Imperfections and Investment, NBER Working Paper 5996, April.

International Monetary Fund, 2012, Spain: Vulnerabilities of Private Sector Balance Sheets and Risks to the Financial Sector, Technical Note, Spain FSAP, June. 
International Monetary Fund, 2011, Vulnerabilities of Household and Corporate Balance Sheets and Risks for the Financial Sector, Technical Note, United Kingdom FSAP, July.

International Monetary Fund, 2006a, Explaining Corporate Investment in Portugal, Selected Issues, IMF Country Report No. 06/386, October.

International Monetary Fund, 2006b, A Strategy for Restructuring the SME sector in Korea, IMF Country Report No. 06/381, October.

International Monetary Fund, 2004, Corporate Balance Sheets and Investment: Empirical Estimates for Portugal and Other EU Countries, Selected Issues, IMF Country Report No. 04/81, March.

Laeven, Luc and Fabian Valencia, 2008, Systemic Banking Crises: A New Database, IMF Working Paper, WP/08/224.

Martinez-Carrascal, C. and A. Ferrando, 2008, The Impact of Financial Position on Investment: An Analysis for Non-Financial Corporations in the Euro Area, ECB Working Paper No. 943, September.

McKinsey Global Institute, 2010, Debt and Deleveraging: The Global Credit Bubble and its Economics Consequences, January.

Merton, R. C., 1974, On the Pricing of Corporate Debt: The Risk Structure of Interest Rates, Journal of Finance, Vol. 29, No. 2, May.

Meyers, S. C., 1984, Capital-Market Imperfections and Investment, Journal of Economic Literature, pp.193-225.

Modigliani, F. and M. H. Miller, 1958, The Cost of Capital, Corporation Finance and the Theory of Investment, American Economic Review, Vol. 48 (June), pp. 261-97.

Pomerleano, M., 2005, Towards Better Practices in Systemic Corporate Restructuring, in Corporate Restructuring: Lessons from Experience, edited by M. Pomerleano and W. Shaw, The World Bank.

Reinhart. C.M. and V.R. Reinhart, 2010, After the Fall, FRBKC Jackson Hole Symposium Proceedings, August.

Vermeulen, P., 2000, Business Fixed Investment: Evidence of a Financial Accelerator in Europe. ECB Working Paper No. 37, November. 


\section{Growth-Friendly, Equitable, AND Sustainable Fiscal Reform in PORTUGAL $^{1}$}

\section{A. The Scale of the Challenge}

1. Fiscal policy in Portugal has traditionally been lax. ${ }^{2}$ Over the last 30 -odd years, the government has incurred a structural deficit each year. Even in recent years, when output growth has been slow, public spending growth has been very high. For example, expenditure grew by 33 percent in real terms between 2000 and 2010, mainly fueled by the expansion of social protection, while real GDP increased by 6 percent. The increase in primary spending was more pronounced still. The fiscal space created by the membership of the euro area (interest payments decreased by about 3 percentage points of GDP between 1995 and 2005) was more than offset by permanent spending increases. Moreover, revenues failed to keep pace with the spending trajectory, despite improvements in tax administration. Two

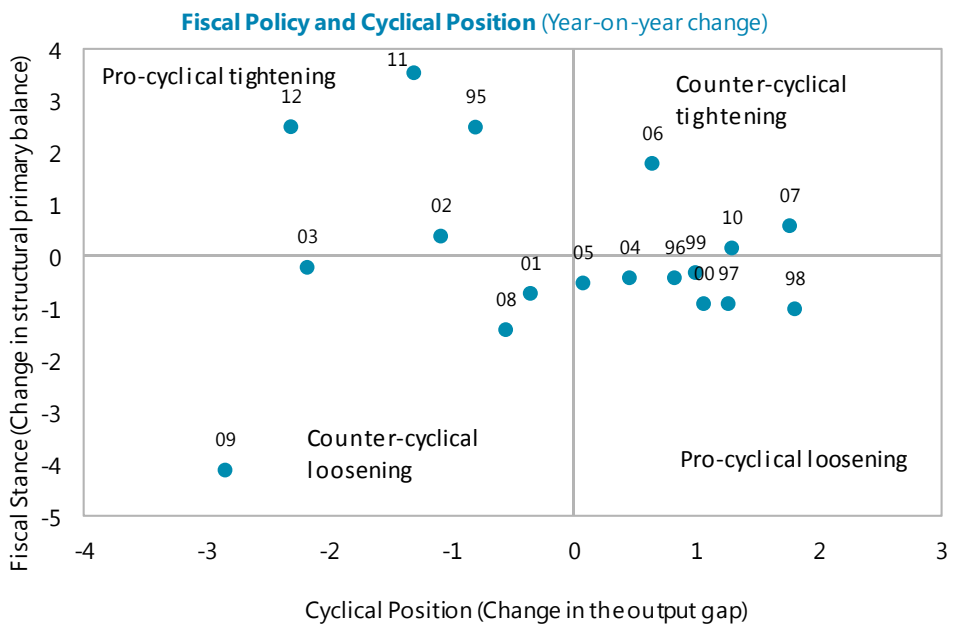

Source: Cunha e Braz (2009), Eurostat, IMF Staff es timates

consolidation episodes were

implemented in the last decade, but were short-lived. ${ }^{3}$ In particular, the 2006-07 adjustment was followed by a significant fiscal stimulus in 2009. Fiscal policy has been pro-cyclical for most of the years since $1995 .^{4}$ As a result, fiscal imbalances accumulated over time.

\footnotetext{
${ }^{1}$ Prepared by Andrea Lemgruber and Mauricio Soto (both FAD). Upaasna Gupta (EUR), Ariel Binder and Asad Zaman (both FAD) provided excellent research assistance. We are grateful to staff at the Minister of Finance, Bank of Portugal, European Commission, and European Central Bank for helpful comments. Usual disclaimers apply.

${ }^{2}$ For a review of Portugal's pre-crisis public finances developments, see Cunha e Braz (2009).

${ }^{3}$ During the 2006-07 adjustment, relevant structural measures were adopted, such as the pension reform and changes in the civil service promotion rules.

${ }^{4}$ The cyclical fiscal position is measured here by looking at changes at the structural primary balance.
} 

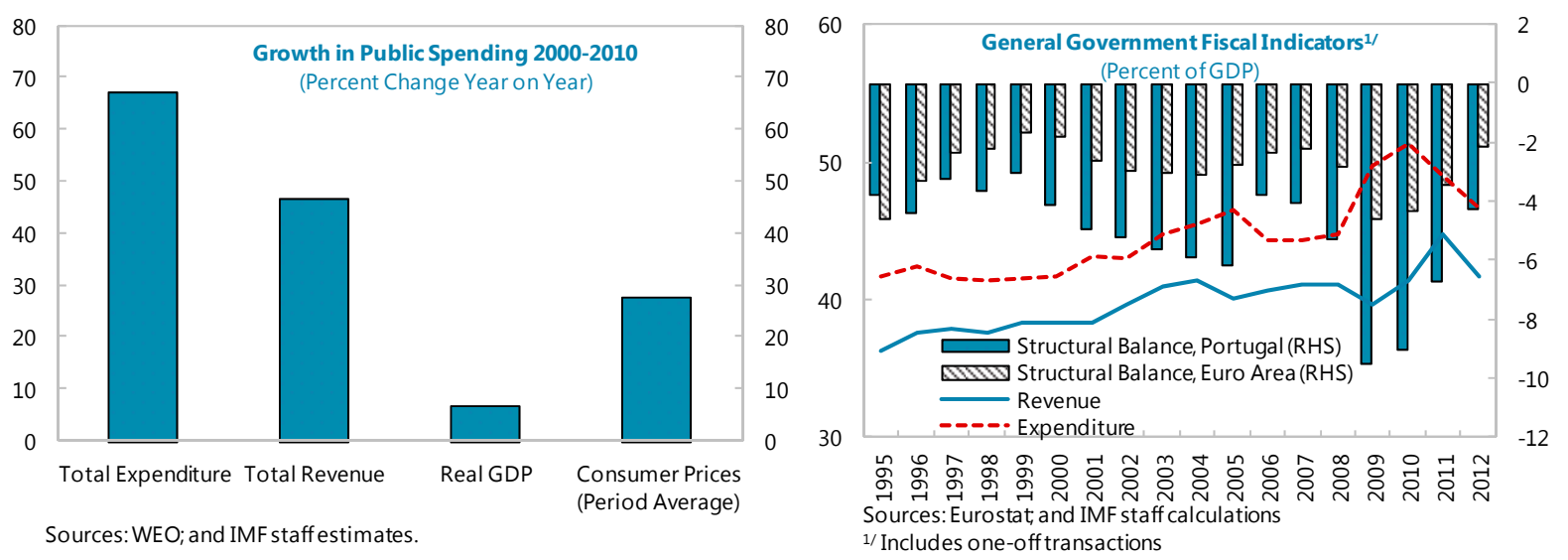

2. The deterioration of the fiscal accounts was accompanied by aggressive offbudget spending, leading to a buildup of substantial contingent liabilities. The most important of these off-balance transactions was capital spending implemented through PPPs (15 percent of GDP in cumulative investment at 2012 prices, substantially above international practice). On average, this implied around 1 percentage point of GDP higher fiscal deficits over the period in which these concessions were granted (1995-2010). In light of a weak public financial management framework, these investments took place in the absence of an effective value-for-money assessment to ascertain their fiscal sustainability. The budgetary impact of this policy is projected to peak in 2014-16, but payments will last till about 2040. Similarly, the state-owned-enterprise (SOE) sector also expanded greatly, often to circumvent stricter policies applied to the general government entities, minimizing the impact of relevant transactions on the deficit and debt indicators.

3. The effect has been to leave Portugal as one of the most indebted countries in the euro area. With the advent of the global financial crisis and subsequent recession, plus the reclassification of hitherto off-balance sheet items and entities in the general government perimeter, public debt has increased sharply from about 65 percent of GDP in 2006 to some 120 percent of GDP at end-2012. Moreover, there remain sizable contingent liabilities posing a risk to the sovereign, including about 11 percent of GDP in SOE debt currently being serviced by companies classified outside the general government.

4. Since late 2010, the government has

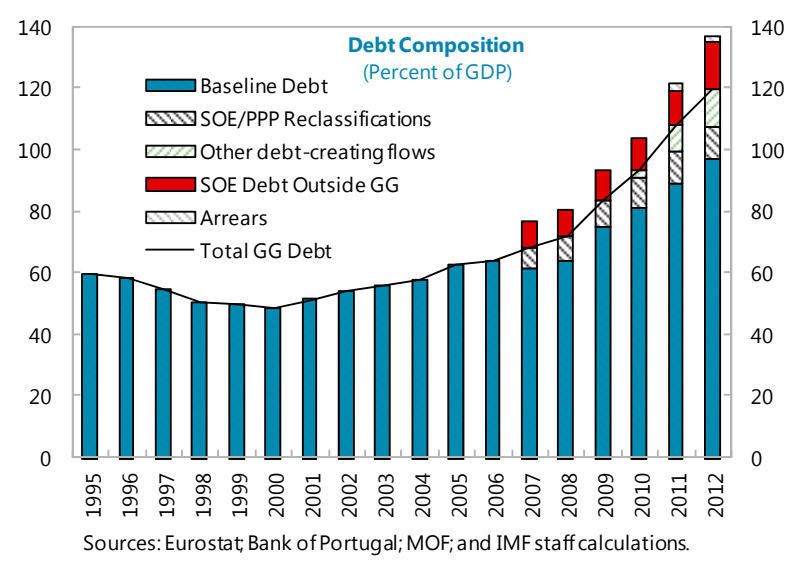
adopted an ambitious fiscal consolidation program to reduce the large fiscal imbalances. Under the EU/IMF-supported program (signed in May 2011), a sharp improvement in the primary balance to stabilize debt and a strengthening of fiscal institutions 
are central objectives. ${ }^{5}$ In particular, the structural primary balance is targeted to improve by some $93 / 4$ percentage points of GDP between 2011 and 2014 to reach a surplus of $3 \frac{1}{2}$ percent of GDP in 2014. This will help stabilize debt at some 122 percent of GDP by 2014. The planned composition of this sizable adjustment envisaged a more expenditure-led consolidation. However, particularly in 2013, the consolidation effort tilted more towards the revenue side. Looking ahead, designing a fiscal policy with smaller output losses would require rebalancing this adjustment mix.

\section{But the ongoing fiscal adjustment is a first step; putting the adjustment on a}

more permanent footing is the next hurdle. Going forward, if public debt is to decline to more manageable levels, Portugal needs to generate large primary surpluses for an extended period. For example, under an illustrative scenario, lowering public debt to 60 percent of GDP by 2030 requires an average primary surplus over this period of some 4 percent of GDP. Assuming total revenues remain at around 42 percent of GDP (higher than the pre-crisis levels), then primary spending would need to be reduced by about 5 $\frac{1}{4}$ percentage points of GDP relative to its 2013 level. And if, instead, public debt is to be reduced to 80 percent of GDP by 2030, the corresponding primary surplus would be 3 percent of GDP and, thus, a $3 \frac{3}{4}$ percentage points of

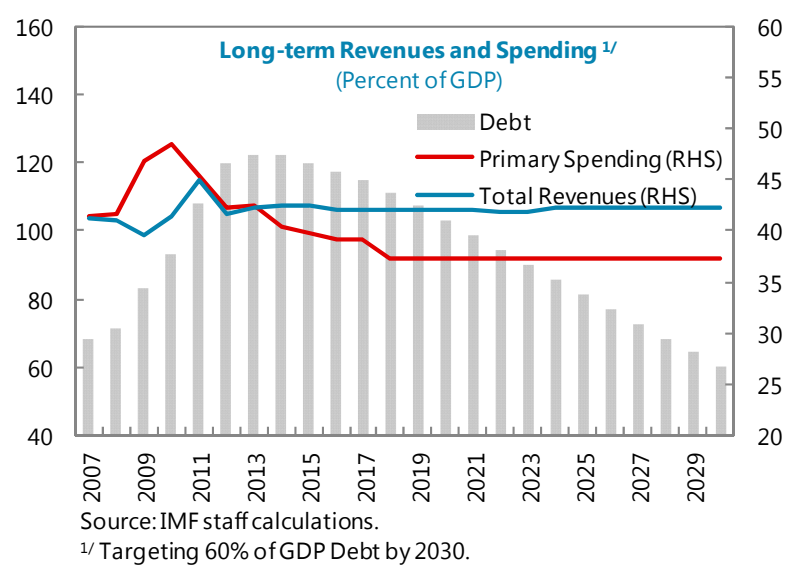
GDP reduction in primary spending from its current level would be needed. ${ }^{6}$

\section{Moreover, spending pressures related to population aging would need to be} accommodated within the lower spending envelope in the coming years. The old-age dependency ratio is projected to increase from 26.9 to 38.3 percent between 2010 and 2030, putting pressures on pension and long-term health care spending. ${ }^{7}$ Over the long run, the projected increase due to higher health care costs, mainly driven by technology changes,

\footnotetext{
${ }^{5}$ In order to underpin the adjustment and minimize fiscal risks going forward, the authorities launched a broad fiscal structural agenda aiming at containing fiscal risks and streamlining the public sector. Such an agenda included the adoption of a new budgetary framework law, the operational restructuring and privatization of the SOE sector, a comprehensive health reform, and the modernization of the revenue administration.

${ }^{6}$ These estimates do not take the effects of the cycle into consideration. They assume the revenue-to-GDP ratio remains constant and primary expenditure do not fluctuate with the cycle. Fiscal space generated as the output gap closes would help ease the estimated adjustment and/or could be used for tax rate reductions (see section III).

${ }^{7}$ According to the Ageing Report 2012, the old-age dependency ratio measures the projected number of elderly persons (65 years old and above) and the projected number of persons in working age (from 15 to 64 years old).
} 
poses greater pressures on public finances than pensions spending - the latter has a more moderate spending path due to the 2007 pension reform (see below).

\section{Reducing public debt and spending will thus require a careful assessment of the} size and the role of public spending in Portugal, and how to pay for it. If the current level of spending is to be maintained, then taxes would need to increase significantly more in the coming years. The discomfort regarding the tax increases in the 2013 budget, however, points to limited appetite for further tax increases. The alternative would be significant spending cuts. And there may be scope to do this in a manner that will not compromise (and maybe even improve) public service delivery and equity. There appears to be room to move toward the efficiency frontier on various public spending outlays, implying that public services could be sustained in some areas with lesser inputs if efficiency can be increased.

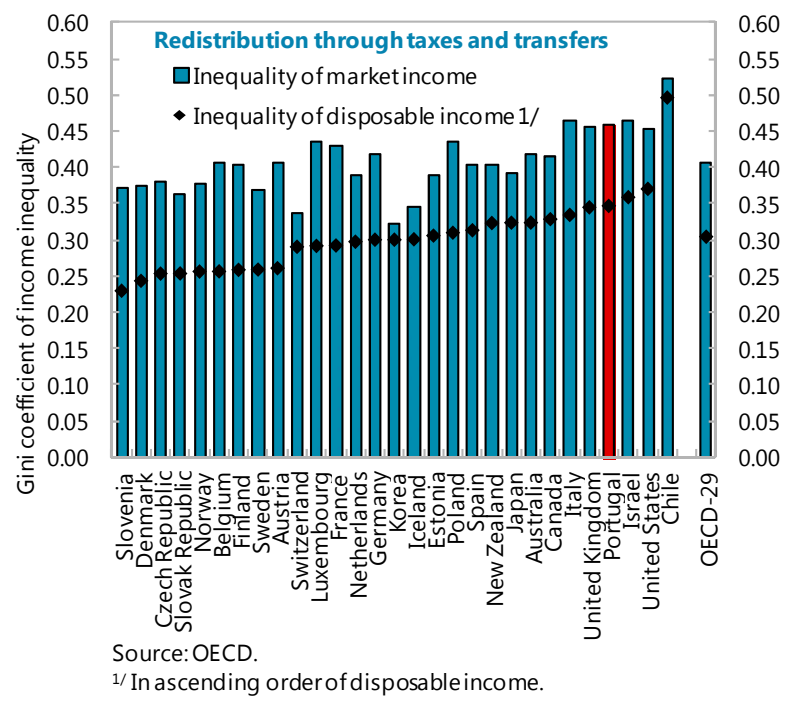
Moreover, Portugal has one of the most regressive market income distributions among OECD countries, which is not significantly corrected by fiscal policies, despite the generosity of the social security system. At a minimum, there is scope to better direct social benefits to those at risk of poverty.

\section{B. Towards A More Efficient and Better Targeted Expenditure Profile}

\section{Overall Considerations on Expenditure Policy}

\section{Spending Level}

\section{Public spending in Portugal is high relative to countries with a similar level of} development. Although Portugal's total expenditure as a share of GDP remains below the euro area average, it has been above the OECD average since 2005. This difference reached its peak in 2010, when Portugal's public spending — at 51.4 percent of GDP—surpassed the OECD average by nearly $3 \frac{1}{2}$ percentage points. ${ }^{8}$ This large size of government reflects a divergence between real growth of public spending and output growth over the past decade. Although many other countries also increased spending, often at a faster rate than Portugal, this was generally accompanied by stronger output growth. The increase in the Portuguese

\footnotetext{
${ }^{8}$ In 2010, expenditure in Portugal included about 21/4 percent of GDP in one-off measures. Even without these measures, spending remained higher than the OECD average and above the countries at similar levels of GDP per capita. The acquisition of two submarines may also explain higher spending on order and safety compared to peers.
} 
public sector was, however, accompanied by anemic growth over the last decade. It is also noteworthy that the rapid increase in public spending preceded the global financial crisis, rather than being a consequence of the crisis or higher interest payments since then.
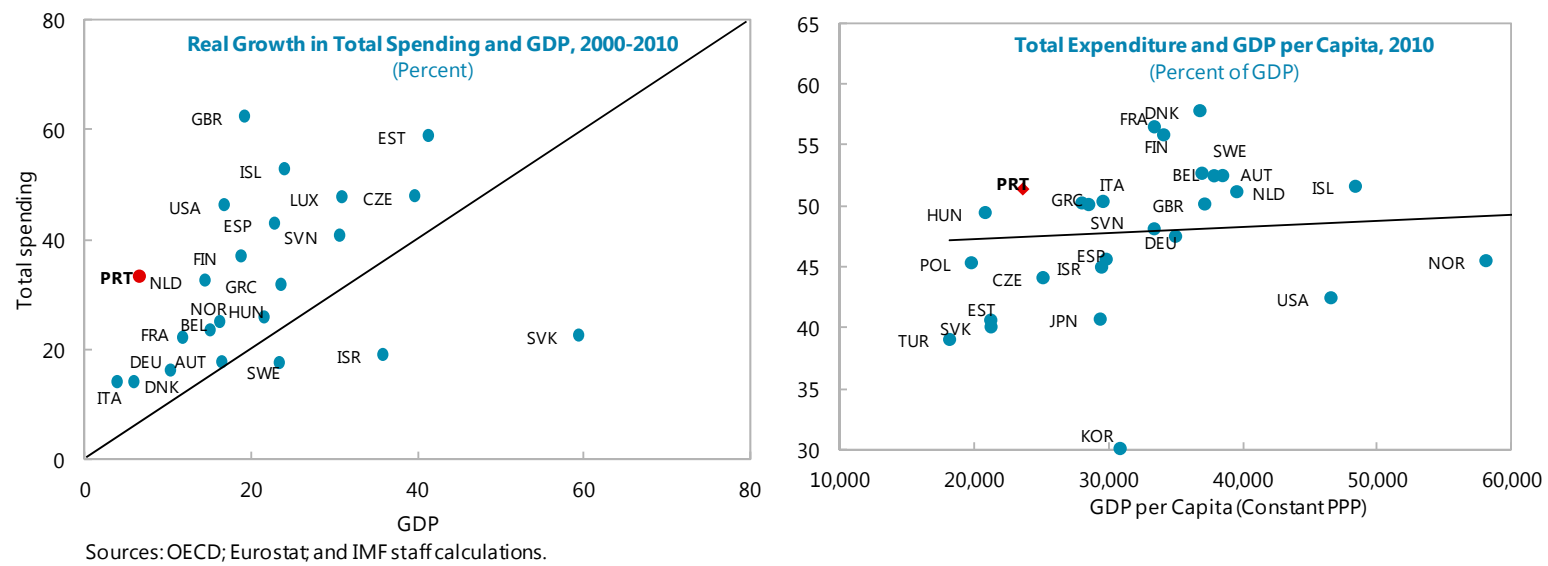

\section{Spending Mix}

9. Spending is heavily concentrated in pensions and wages. These two categories represented 57 percent of primary spending in 2012. In terms of the functional composition, Portugal has relatively high spending on social protection, education, and law enforcement compared to OECD countries. On the other hand, health care spending is broadly in line with OECD countries and even below European peers. Finally, capital expenditures have declined sharply since the crisis and currently are about 2 percent of GDP. If the off-budget spending in PPPs is taken into consideration, this amount would go up. And in terms of spending outcomes, Portugal has high ratings in terms of the quality of its overall infrastructure (see Appendix II).

\section{By Function}

\begin{tabular}{lrrr}
\hline & Portugal & $\begin{array}{c}\text { OECD } \\
\text { Average }\end{array}$ & $\begin{array}{c}\text { Euro } \\
\text { Average }\end{array}$ \\
\hline Public services excl. interest & 4.0 & 3.9 & 4.1 \\
Defense & 1.7 & 1.7 & 1.4 \\
Order and safety & 2.4 & 1.8 & 1.8 \\
Economic affairs & 5.6 & 5.5 & 6.0 \\
Environment & 0.7 & 0.7 & 0.8 \\
Housing & 0.6 & 0.9 & 0.8 \\
Health & 7.0 & 6.9 & 7.5 \\
Education & 6.5 & 5.7 & 5.8 \\
Social protection & 18.7 & 17.2 & 20.1 \\
Interest & 3.0 & 2.5 & 2.6 \\
Total & 51.4 & 48.1 & 52.2 \\
\hline
\end{tabular}

By Economic Activity

\begin{tabular}{lrrr}
\hline & Portugal & \multicolumn{1}{c}{ OECD } & Euro Average \\
& & & \\
& & & \\
& 12.2 & 11.3 & 12.0 \\
Compensage & & & \\
Intermediate consumption & 5.0 & 7.1 & 6.9 \\
Subsidies & 0.7 & 1.3 & 1.5 \\
Property Income & 3.0 & 2.5 & 2.6 \\
Social transfers & 21.9 & 18.6 & 21.3 \\
Other current transfers & 2.8 & 2.4 & 2.5 \\
Capital transfers & 1.9 & 2.1 & 2.6 \\
Gross capital formation & 3.7 & 2.9 & 3.0 \\
Total & 51.4 & 48.1 & 52.2 \\
\hline
\end{tabular}




\section{Social Spending}

\section{Level of Spending and Equality}

\section{The increase in old-age pension payments is a major factor for the sharp} expansion in total spending over the last decade. Social protection programs (including pensions, family benefits, and unemployment benefits) increased by some $81 / 2$ percentage points of GDP between 2000 and 2012, more than half of which was due to pensions. Some of the increase in social protection was well motivated since social protection spending in Portugal in 2000 was 3 percentage points below the 15-percent-of-GDP average in OECD countries at that time. Currently, however, social protection spending is around 2 percentage points of GDP beyond what Portugal's level of development would suggest.

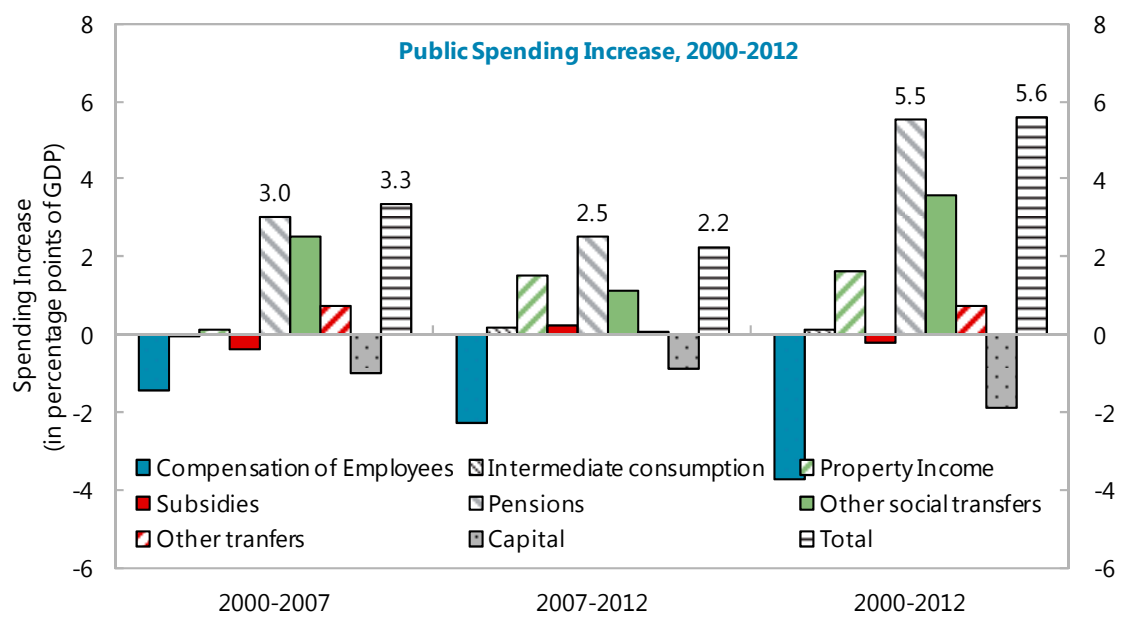

\section{But the high spending on social protection has not been effective in alleviating} poverty. Public cash transfers ${ }^{9}$ account for a higher share of households' disposable income in Portugal than in the average OECD country-20 percent for the working-age households and 74 percent for the retirement-age households compared to the OECD averages of 16 percent and 68 percent, respectively. But the cash transfers are highly regressive because a larger share of these transfers goes to the richer households. This is true for both cash transfers aimed at working-age households and for retirement-age households. Only in Turkey and Mexico are public cash transfers more regressive. This suggests that cash transfers programs, as currently configured in Portugal, may even be exacerbating inequality. This is partly explained by the reliance on contributory social insurance programs (including pensions and unemployment benefits) which generally go to the relatively well-off households instead of targeted social assistance programs which generally go to the most needy.

\footnotetext{
${ }^{9}$ Public cash transfers include pensions (old age, disability, and survivor), sick leave, family benefits, unemployment insurance, and housing (cash) benefits.
} 

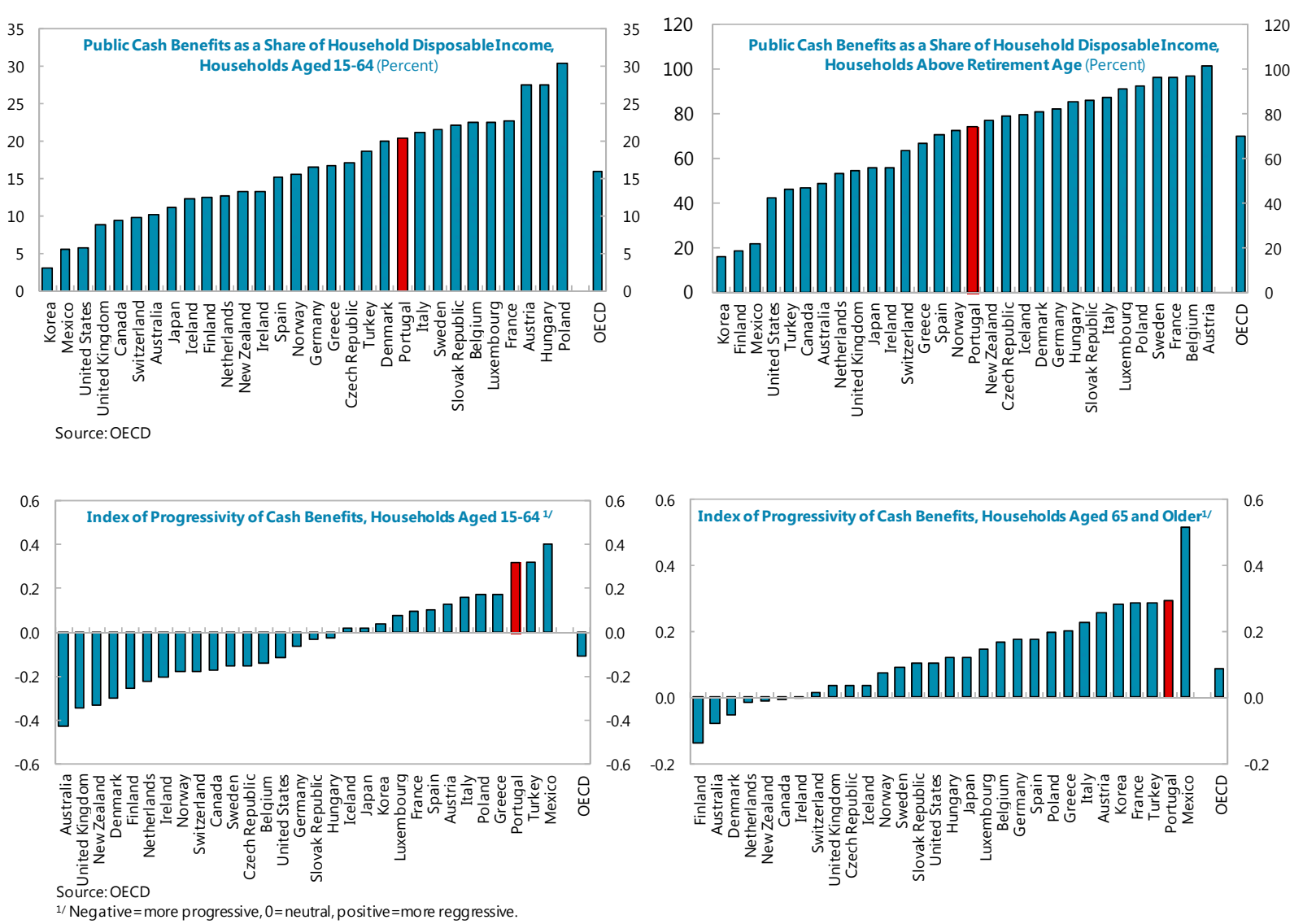

\section{Pensions}

12. Policy changes rather than demographic factors such as aging have been the key contributor to the sizable increase in pension spending. Between 2000 and 2012, pension spending increased by some $5 \frac{1}{2}$ percentage points of GDP. Specifically:

- $\quad$ Around 45 percent of this increase is due to policy changes that increased the relative generosity of pensions (including increases to the minimum pension in the early 2000s), and another 10 percent has been due to increases in the number of retirees beyond what is implied by aging. In particular, the economic replacement rate - the ratio of pension spending per individual aged 65 and older to GDP per worker - reached 37 percent in 2010, about 10 percentage points higher than in 2000.

- Only about 30 percent of the spending increase was due to population aging.

- The natural maturation process of the pension system might have also put pressure on spending. However, this is likely to be a small factor since most pensioners receive minimum pensions and the benefit formulas have changed to account for full contribution careers. 
- The remaining 15 percent corresponds to macroeconomic factors (for example, employment dropped from about 72 percent of the population aged 15-64 in 2000 to nearly 65 percent of the population aged 15-64 in 2012).

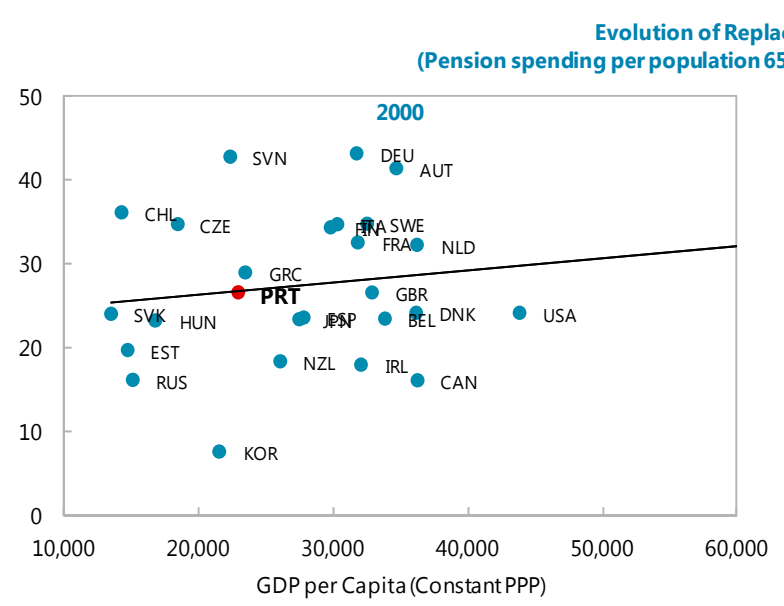

Evolution of Replacement Rates, 2000-2010

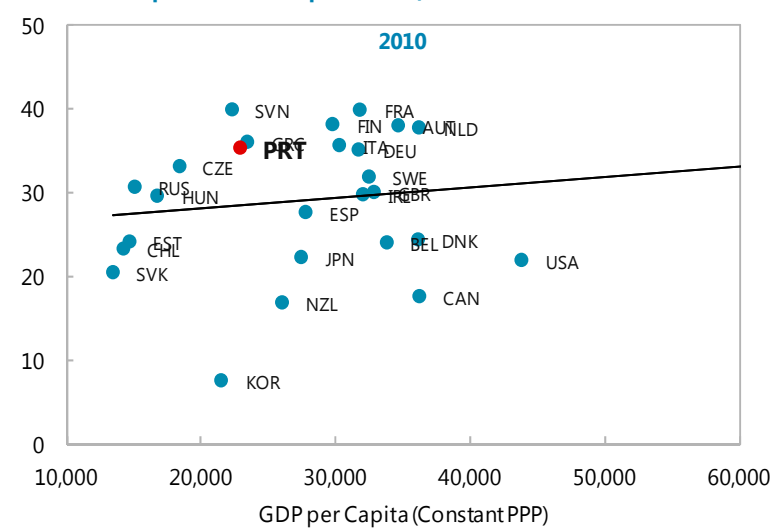

Sources: OECD; Eurostat, and IMF staff calculations.

\section{Pension expenditure is also relatively inefficient at reducing old-age poverty.}

Despite one of the highest pension spending-to-GDP ratios in the EU, the risk of being in poverty at old age is among the highest in Portugal. ${ }^{10}$ Hence, old-age spending is inefficient: each percentage point of pension spending reduces old-age poverty by only 4.9 percentage points, well below the European average of 7 percentage points. Part of the reason for this is that 40 percent of old age pension spending goes to the top 10 percent of the income distribution in the whole population. This poor allocation of pensions suggests that there is room to reevaluate benefits without compromising equity goals. ${ }^{11}$

\footnotetext{
${ }^{10}$ The at-risk-of-poverty here is defined as the share of persons 65 and older with incomes below 40 percent of the national median income (after social transfers). Using a threshold of 60 percent of median income for the atrisk-of-poverty measure does not alter the conclusion: about 20 percent of the elderly have incomes below 60 percent of the median income, above a 16 percent average in Europe; each percentage point in spending on old-age, disability, and survivors benefits reduces at-risk-of-poverty rates (60 percent threshold) by 4.3 percentage points compared to 7 percentage points on average for Europe.

${ }^{11}$ The large share of pensions going to households in the top percentiles of income distribution reflects in part the nature of social insurance, under which those who contribute more receive higher benefits. Reforms to increase equity require careful measures to avoid moral hazard. For example, focusing on benefit reductions for high-end pensions could potentially erode the link between contributions and benefits and increase incentives for informality.
} 


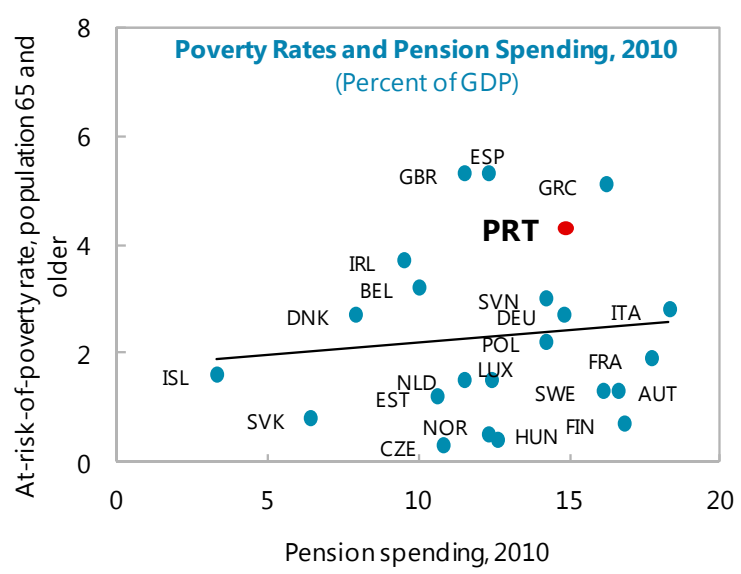

Sources: Eurostat, and IMF staff calculations.

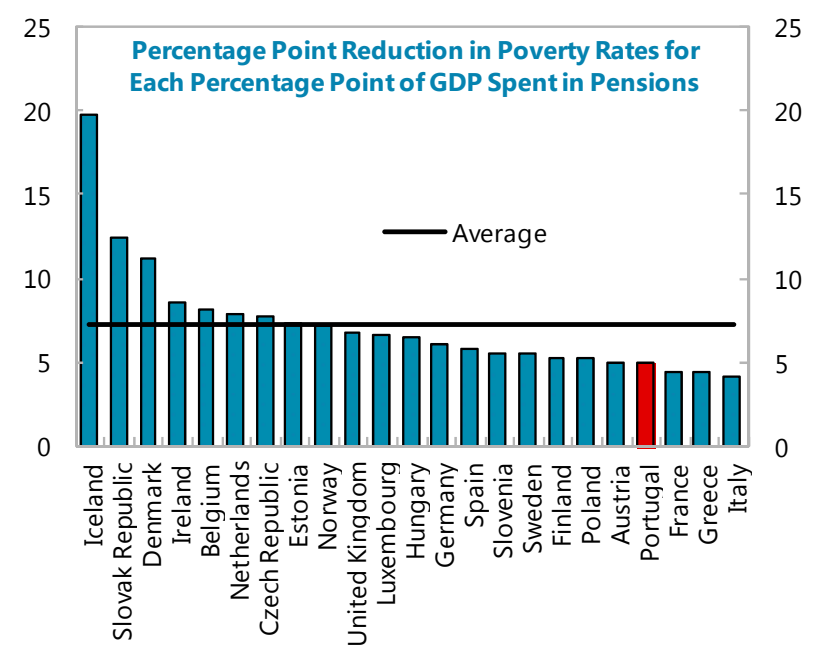

14. The inefficacy of the public pension spending at reducing old-age poverty can partly be explained by the difference in benefits for workers in the private and public sectors. Pensioners from the civil service, namely CGA (special system for the civil service workers) beneficiaries, account for about 15 percent of all retirees but receive 35 percent of all pension spending. The average old-age pension in the civil service system is more than three times the average of an old-age pension in the general regime. The differences in pensions exceed the differences in earnings. This suggests that civil service pensions have a premium of at least 20 percent relative to private sector pensions. This is further exacerbated by considering that civil servants work fewer hours per week and, in many cases (e.g., for the military, diplomats, and justice officers), have a benefit formula that counts more than one year of contributions for each year of work. In addition, the slow transition under the recent reform still allows many to retire early: nearly 55 percent of all new retirees of the public pension system were younger than age 60 in 2012.

Comparative Indicators Between CGA (Public System) and GCR (General Regime)

\begin{tabular}{|c|c|c|c|c|c|c|}
\hline & \multicolumn{3}{|c|}{ CGA } & \multicolumn{3}{|c|}{ GCR } \\
\hline & 2000 & 2010 & 2012 & 2000 & 2010 & 2012 \\
\hline $\begin{array}{l}\text { Contributors (thousand) } \\
\text { Average annual wage of contributors (euro) }\end{array}$ & & 586 & $\begin{array}{r}538 \\
22,575\end{array}$ & & 4,171 & $\begin{array}{r}4,127 \\
10,556\end{array}$ \\
\hline $\begin{array}{l}\text { Spending (percent of GDP) } \\
\text { Pensioners (thousand) } \\
\text { Average annual benefit (euro) }\end{array}$ & $\begin{array}{r}3.3 \\
426 \\
9,749\end{array}$ & $\begin{array}{r}4.9 \\
577 \\
14,560\end{array}$ & $\begin{array}{r}4.8 \\
603 \\
13,218\end{array}$ & $\begin{array}{r}5.4 \\
2,480 \\
2,746\end{array}$ & $\begin{array}{r}7.9 \\
2,896 \\
4,730\end{array}$ & $\begin{array}{r}8.6 \\
2,968 \\
4,793\end{array}$ \\
\hline $\begin{array}{l}\text { Average benefit to wage of contributors } \\
\text { Average benefit to GDP per worker } \\
\text { Pensioners to Population } 65 \text { and older }\end{array}$ & $\begin{array}{l}38.4 \\
0.25\end{array}$ & $\begin{array}{l}42.0 \\
0.30\end{array}$ & $\begin{array}{l}58.6 \\
37.3 \\
0.31\end{array}$ & $\begin{array}{l}10.8 \\
1.48\end{array}$ & $\begin{array}{l}13.6 \\
1.51\end{array}$ & $\begin{array}{l}45.4 \\
13.5 \\
1.50\end{array}$ \\
\hline Percent of new pensioners younger than age 60 & & & 54.9 & & & 16.9 \\
\hline
\end{tabular}

\section{Measures adopted in recent years have started addressing some of these} problems, but only in a limited way. The 2002-07 pension reforms were successful in containing long-term pressures due to the adoption of, among other measures, equal benefits across all workers (civil service and private sector), a sustainability factor linked to life expectancy, and higher penalties for early retirement. Indeed, after taking into account these 
reforms, pension spending is projected to increase by 0.7 percentage points of GDP over 2010-30 rather than by about $4 \frac{1}{2}$ percentage points of GDP - an increase that would have taken place due to demographics in the absence of policy changes. ${ }^{12}$ Still the reforms so far have not addressed the current high level of pension spending. Some recent measures have helped alleviate this problem, but in a provisory way. These include the temporary suspension of the $13^{\text {th }}$ and $14^{\text {th }}$ payments in 2012 , the suspension of the $14^{\text {th }}$ payment in 2013, and the introduction of progressive benefit reductions. ${ }^{13}$ There seems to be further scope to address the short-term fiscal pressures while increasing the equity of the pension system. Options to consider include further reducing benefits for current pensioners (particularly for the more generous civil service regime), and fully equalizing benefit formulas for all future pensioners (including for years of service prior to enacted reforms that have generally been grandfathered under old, more generous formulas). In addition, benefit eligibility for future pensioners could be curtailed for example by increasing the statutory retirement age (currently 65 years old).

\section{Non-pension Social Benefits}

\section{Non-pension social spending comprises various programs that are not} particularly expensive compared with peer countries, but are poorly targeted. The programs include unemployment insurance (generous for those who qualify but with very low coverage), family benefits (e.g. parental leave, children benefits), and others (e.g. funeral expenses). These programs are not sufficiently targeted at the needy. For instance, in 2009 the top 20 percent of income earners received 33.8 percent of total social protection spending, while the bottom 20 percent received 13.2 percent. Options to increase the efficiency and equity of this spending could include: improving the coverage of the unemployment benefits scheme while reducing its generosity; expanding means-testing for family allowances; and enhancing targeting and rationalizing remaining benefits, including by avoiding fragmentation.

\section{Wage Bill}

\section{The public sector wage bill in Portugal has traditionally been high relative to} peer countries. The wage premium for public employees in Portugal is about 10 percent above the average European country, even after controlling for factors associated with earnings level (marital status, education, labor market experience, managerial responsibility, full time status, and geographical variables) (Giordano and others, 2011). Most of this

\footnotetext{
${ }^{12}$ See IMF (2011) and EC (2012). Note that these projections do not take into account the current consolidation efforts.

${ }^{13}$ Pensions are reduced progressively (from a 3.5 percent reduction for monthly pensions of $€ 1,350$ to 10 percent reduction to pensions $€ 3,750$ per month and above). In addition, an extra 15 percent reduction is applied to pensions above $€ 5,030$ per month and 40 percent for those above $€ 7,545$ per month.
} 
disparity is explained by the relatively high pay for workers with lower qualifications. Recent efforts have helped to reduce the wage bill (from 12.7 percent of GDP in 2009 to a projected 10.4 percent of GDP in 2013), due to temporary compensation cuts and employment restrictions. In terms of wage levels, efforts have focused on reducing high wages, which has further flattened the public wage structure. In terms of employment levels, the effort so far has focused on attrition and, hence, has not been the right tool to curb excess employment, which is concentrated in the areas of education and security. These are the sectors that show inefficiencies and employ more people than peer countries, even after controlling for number of students and inhabitants. Finally, the Portuguese public sector works the least hours (35 hours per week) among OECD countries, which leads to a widespread use of overtime pay, particularly in the health sector.

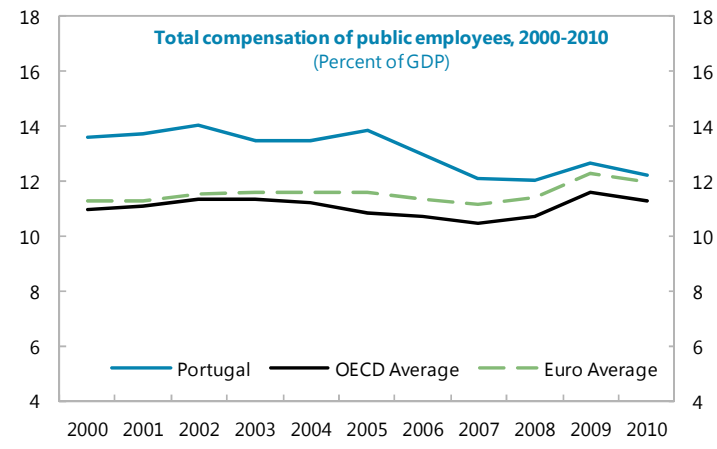

Sources: OECD and IMF Staff calculations

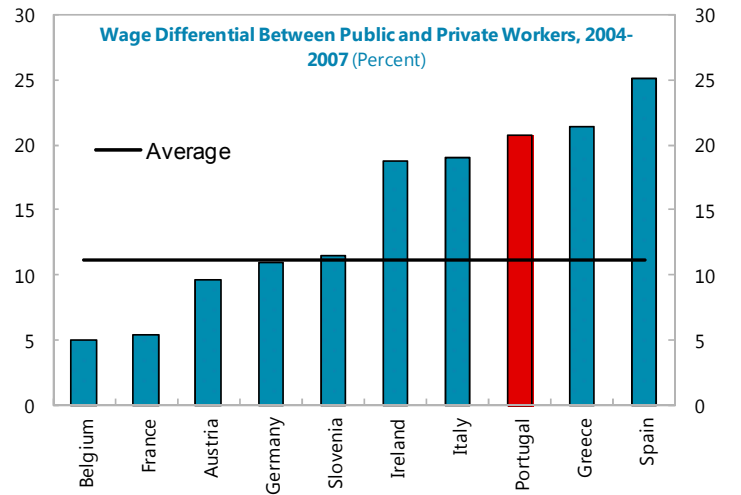

Source: Giordano and others (2011)

\section{Among the reform options are to review both public employment and wage}

levels. The measures taken to date to rationalize the wage bill pose two problems: first, they have been of a temporary nature, and, second, the attrition policy mainly moved spending from the wage bill outlay to pensions, thus, not contributing to a net permanent reduction in public expenditure. Looking ahead, a mix of policy tools could be considered to reduce the wage bill: (i) adopting a compensation policy that encourages meritocracy and higher education, while reducing the wage premium in the public sector; (ii) increasing working hours in the public sector to improve productivity and reduce recourse to overtime pay; and (iii) targeting a permanent reduction in the number of employees in areas with excess employment.

\section{Education and Health Sectors}

\section{Reforms in education could have a potentially large impact on efficiency and}

equity. The share of spending devoted to public education ( $61 / 2$ percent of GDP) is among the highest in the OECD — as noted above, mainly on account of the wage bill. But educational attainment indicators are below peer countries, suggesting scope to improve the efficiency in the sector. For example, only 48.2 percent of population aged 25-34 attains upper secondary education or higher, well below the OECD average of 81.5 percent. Only Mexico and Turkey 
have lower educational attainment rates for this age cohort. Moreover, standardized assessments indicate that, while Portugal's performance has been improving toward the OECD average in reading, scores remain below the OECD average in mathematics and science. Despite the improvement in PISA scores for those in the system, the issue of coverage also remains unaddressed. The high dropout rates in primary/secondary education is leading to very low shares of the population with tertiary degrees (about 10 percent), one of the lowest among peers. The main driver of costs and inefficiencies in the education sector is the low pupil-to-teacher ratios that reflects the presence of many teachers with reduced or no teaching assignments. Improving the efficiency of spending and raising the educational outcomes is key to support productivity and contribute to long-term economic growth.

\section{Given that the bulk of the education in Portugal is publicly financed, the state} plays a key role not only in policy-making but also in implementation. Beyond the considering reductions in the number of excess teachers and wage premiums, a new strategy for the education sector could be developed to reduce Portugal's human capital gap. Hence, fiscal consolidation could be the trigger for a more structural objective than just short-term savings. In particular, the school network could be further rationalized, given that primary schools are facing decreasing demand (due to demographics) and some have unused capacity. On the other hand, college education faces increasing demand but the legal restrictions to cost-recovery in the public university system may be a limiting factor on the availability of new resources for this area. Also, vocational education could be further developed to better match labor market needs.

\section{Efficiency increases in the health sector are also important to contain the long-} term pressure caused by ageing and technology. At some 7 percent of GDP in 2010, spending on health care in Portugal is in line with the OECD average. Ongoing reforms are reducing health spending further, particularly with regards to pharmaceutical costs—which were above European levels in 2010. As a result, further budgetary savings are hard to envisage within the scope of services currently defined. However, long-term projections are more worrisome: in the absence of reforms that limit rate of growth in health care costs, the

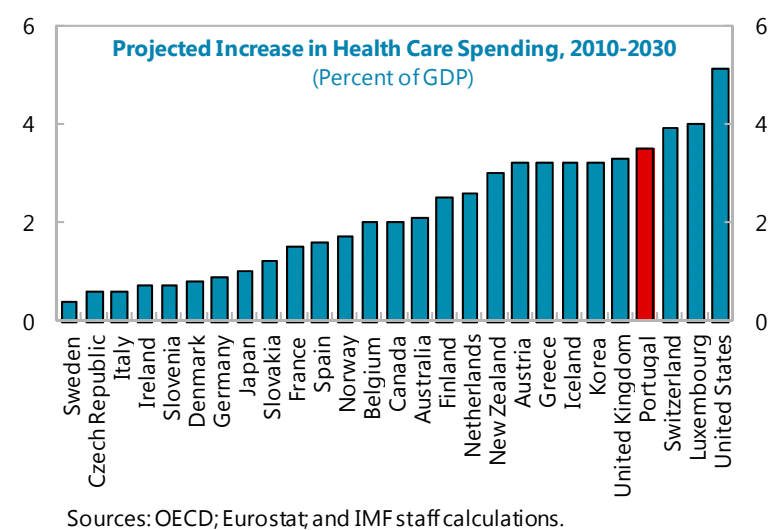
continuation of historic trends would lead to public health care spending increase by $2 \frac{1}{2}$ to $4 \frac{1}{2}$ percentage points of GDP over the next two decades. ${ }^{14}$ This is one of the largest projected increases in public health care spending

\footnotetext{
${ }^{14}$ Portugal experienced one of the highest increases in public health spending over the last three decadesspending went from under 4 percent of GDP in the early 1980s to nearly 7 percent of GDP by 2010 . Note that the EC 2012 Aging Report projects an increase in public health spending of 0.7 percentage points of GDP over
}

(continued...) 
among the advanced economies, and would bring the Portuguese health spending to about 10 percent of GDP by 2030 - clearly incompatible with the debt-reducing objectives. Therefore, the current far-reaching health care reform is a step in the right direction to address this issue, but the government will need to assess over time if the scope of the reform is sufficient to contain these costs. Some options that could be further explored are: raising user fees for those who can afford them and for nonessential medical procedures; continue rationalizing the hospital network and tighten the performance benchmarking system; and keep reducing the fragmentation of the system (e.g., parallel systems for public employees).

\section{PPPs and SOEs}

\section{Rationalizing a series of public and quasi-public entities that have been a source} of drag on the fiscal accounts is crucial for achieving long-term sustainability. The amount spent on PPPs increased fourfold between 2008 and 2011, when it reached about 1 percent of GDP. Moreover, contingent claims arising from PPP contracts have created an additional burden. For instance, spending on PPPs in 2011 was 25 percent higher than projected due to these claims. The NPV of gross spending on PPPs is estimated at 14.6 percent of GDP at 2012 values, or about 8 percent of GDP in net terms (if toll revenues are considered). ${ }^{15}$

\section{Current policies aim at putting the SOE sector in operational balance. Even} though this is a positive initial achievement, the financial results of these companies will still pose a significant burden over the medium term. For instance, in 2011 SOEs' overall deficit was 0.8 percent of GDP and its negative net worth about 0.6 percent of GDP. ${ }^{16}$ These results reflect a sizable deterioration in the financial balance of SOEs between 2010 and 2011, which more than offset the improvement in the operational accounts. Overcoming this imbalance over the long term would require sustained structural reforms, in particular in the transport sector. The government has started improving the SOEs' financial management, strengthening its operational efficiency, and pursuing a privatization program. A key longterm objective to reduce its burden on the public accounts would be to bring the SOE sector into overall balance.

2015-30 taking into account mainly the demographic trend. This lower increase relative to the IMF estimates reflects an assumption that technology does not increase costs, which would be a sharp break from past trends (IMF, 2010).

\footnotetext{
${ }^{15}$ See Ministério das Finanças (2012), Parcerias Público-Privadas e Concessões, Relatório 2012, Agosto/2012.

${ }^{16}$ See Ministério das Finanças (2012), Setor Empresarial do Estado, Relatório 2012, Julho/2012.
} 


\section{Designing a Growth-Oriented Tax Policy}

\section{Overall Considerations for Reforming the Portuguese Tax System}

\section{The Tax Level}

24. Portugal's tax burden has historically been below the European average, but the ongoing consolidation is pushing it to a higher level. Indeed, relative to its per capita income ${ }^{17}$, the tax effort in Portugal was in line with average in 2011, also taking into account the generally high level of taxation in Europe. ${ }^{18}$ This level is being pushed further in light of the 2013 tax measures, with a projected tax burden of 37 percent of GDP. This suggests that increasing the tax burden much above current levels could be particularly difficult (from a tax administration perspective) and relatively distortionary (retarding growth).
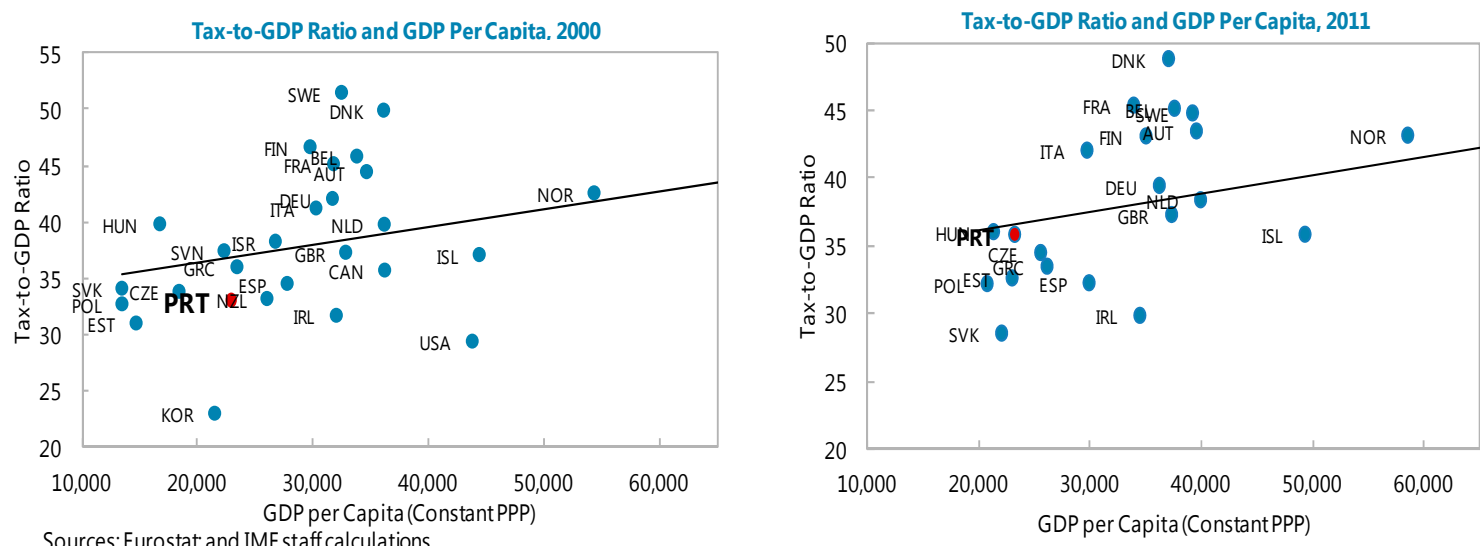

\section{The Tax Mix}

\section{Portugal has opted for taxing capital} more intensely than peer countries, while labor taxation has been lighter than

European average. The higher implicit tax rate (ITR $)^{19}$ on capital relative to labor income in Portugal contrasts with the practice of most other European countries. The lower overall ITR on labor is being pushed up following the significant increases in personal income tax rates

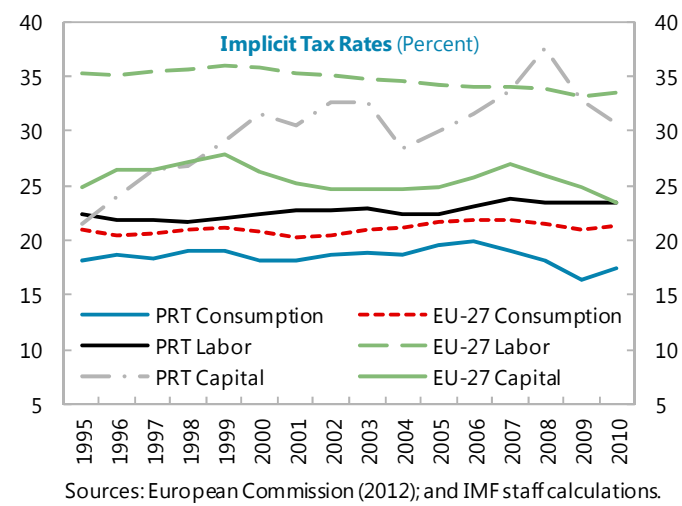

\footnotetext{
${ }^{17}$ Even though the level of taxation is the result of a political and societal choice, the capacity to tax seems to be positively correlated to the income per capita of a country. See Gupta (2007), and Pessino and Fenochietto (2010).

${ }^{18}$ Pessino and Fenochietto (2010) suggest that Portugal's tax effort is above average when compared to a larger set of countries.
}

${ }^{19}$ The implicit tax rate is the result of the tax revenues divided by its underlying economic base. 
in the 2013 budget. However, the high taxation of capital is an important issue to be addressed in order to boost the country's attractiveness to investment and to support job creation. For instance, a shift from capital to consumption taxation (e.g. exploring some space to further streamline tax expenditures), could go in the direction of a growth-enhancing tax reform.

\section{Growth-Oriented Reforms ${ }^{20}$}

\section{There is extensive use of tax expenditures with a view to promoting growth and} equity but the pay-off seems questionable. ${ }^{21}$ Without rules to cap their usage and in the absence of a periodic reassessment of their effectiveness, tax benefits were expanded and reached 9 percent of GDP in 2010. Traditionally, there has been a weak institutional framework to estimate and assess policy in this area. Following recent initiatives to reduce the scope of tax expenditures, these are projected to decline to around 6 percent of GDP in 2013 - a still high level. Portugal's tax expenditures are poorly targeted, which may generate significant, although unintended, economic distortions. There is scope to streamline non-productive tax expenditures, which could be supported by a general evaluation based on a cost-benefit analysis. For those tax expenditures that will remain in the system, their granting criteria could be made more objective, ideally under a rules-

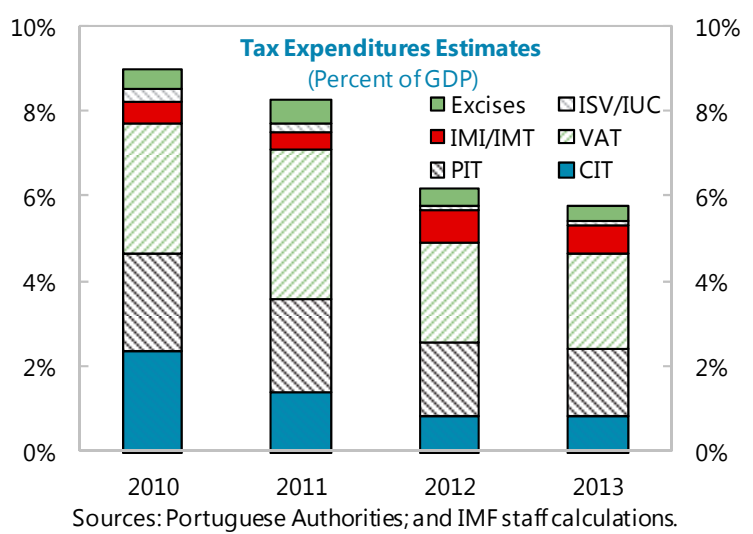
based approach. In specific cases, better targeting to increase the effectiveness of the tax incentives could be justified (e.g. in the tradable and high value-added sectors).

\section{Simplifying the tax system and modernizing the tax administration would help} to improve the business environment. Beyond reducing tax expenditures (which make tax

\footnotetext{
${ }^{20}$ A growth-oriented tax reform aims at minimizing the distortive nature of taxation. There are certain bases that are more sensitive to taxation due to their mobile nature. For instance, capital is highly volatile and, indeed, over the past years there has been a worldwide trend to reduce CIT rates. On the other hand, given its immobile nature, property taxes seem to have a minimal impact on economic behavior. However, the option for efficiency needs to be informed by an appropriate balance between certain trade-offs, for example on how to increase efficiency without hurting equity. Usually, equity considerations should be taken into account in the context of a broader set of fiscal policies, involving the effects of taxes and expenditures on income distribution. Some recent empirical studies have suggested that a shift from income (in particular, corporate income) to consumption and property taxation would be growth-enhancing (OECD, $2010 \mathrm{a}, \mathrm{OECD}, 2010 \mathrm{~b}$, and EC, 2011).

${ }^{21}$ Tax expenditures are government revenues foregone as a result of preferential tax treatment of specific sectors, activities, regions, or agents, namely: exemptions (exclusions from the tax base), allowances (deductions from the base), credits (deductions from liability), rate reliefs (reductions of the tax rate), and deferrals (postponement of payments).
} 
compliance more complex and less transparent), there is scope to: reduce the number of taxes and surcharges applied on similar bases (in particular, in corporate and personal income taxation); and streamline the VAT rates (see below). On the administrative front, Portugal has made significant advances in e-government, including electronic tax returns. The merger of three agencies into a unified revenue administration and the implementation of a Large Taxpayer Unit have been key recent accomplishments. But the allocation of resources in the revenue administration could still be improved, particularly by reducing the excessively large network of local offices and assigning resources according to a modern taxpayer compliance strategy. Improving third-party information access to effectively combat evasion is paramount to ensuring a level playing field for economic agents. ${ }^{22}$ Reforms to the judicial system are also important, given that an average tax resolution case of about 4 years is likely to discourage investments, especially large ones - which tend to be subject to more complex and longer disputes. Overall, a study on compliance costs could support a targeted proposal for simplifying the system. ${ }^{23}$

\section{Consumption Taxation}

28. There is also scope to improve the efficiency of the VAT. The VAT C-efficiency indicator (which reflects a compliance gap and a policy gap) stood at 46.8 in 2010, slightly below European average (about 50). The existence of two reduced rates may explain this lower-than-average C-efficiency indicator. Compliance may be another reason but there is no official estimate of the VAT compliance gap. The significant reduction in the number of the goods and services subject to the reduced and intermediate rates in 2012 was a positive policy to improve the VAT Cefficiency. However, there is still some scope for a further widening of the tax base.

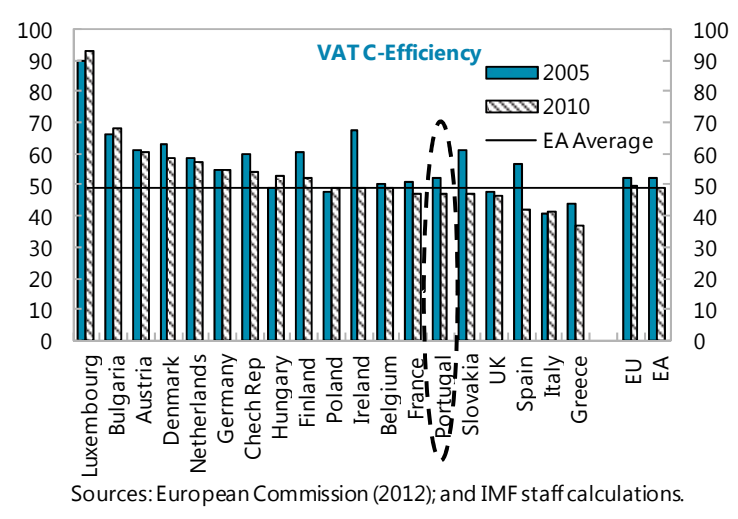

Alternatives include a revenue-neutral adoption of a two-rate VAT (the rationalization of the reduced rates could open space for a reduction in the standard rate), or a revenue-generating reform by increasing the VAT C-efficiency to offset, for example, a more competitive CIT rate (see below).

\footnotetext{
${ }^{22}$ Recent studies estimate the shadow economy in Portugal at around 19-23 percent of GDP (see Schneider 2011, and Murphy 2012).

${ }^{23}$ OECD (2011) estimates the administrative cost in Portugal at 1.4 percent of total net revenues, higher than the EU average (1 percent of total net revenues). Also, the number of hours devoted to tax compliance in Portugal is estimated at 275 hours, one of the highest in Europe, while EU average stands at 184 hours (PwC, 2012).
} 
29. Equity concerns are the main argument for maintaining the reduced VAT rates. However, in absolute terms, higher income earners end up benefiting much more from such tax expenditure. ${ }^{24}$ This reinforces the argument that reduced VAT rates are not a welltargeted instrument to deliver social support, which should be achieved through targeted social policy. ${ }^{25}$ Moreover, some of the goods and services currently subject to the reduced and intermediate rates do not seem to target basic necessities (e.g. wines, cultural events, processed food).

\section{Labor Taxation}

30. The labor tax wedge in Portugal is low relative to European peers but higher compared to a broader group of OECD countries. ${ }^{26}$ In terms of composition, employers' contribution in the total tax wedge is on average larger in Portugal than in other European countries. The sweeping changes in personal income taxation that will be adopted starting in 2013 will likely alter this profile. Looking forward, in order to encourage employment, policies could aim at (i) reducing the total tax wedge, (ii) focusing on a targeted reduction of the

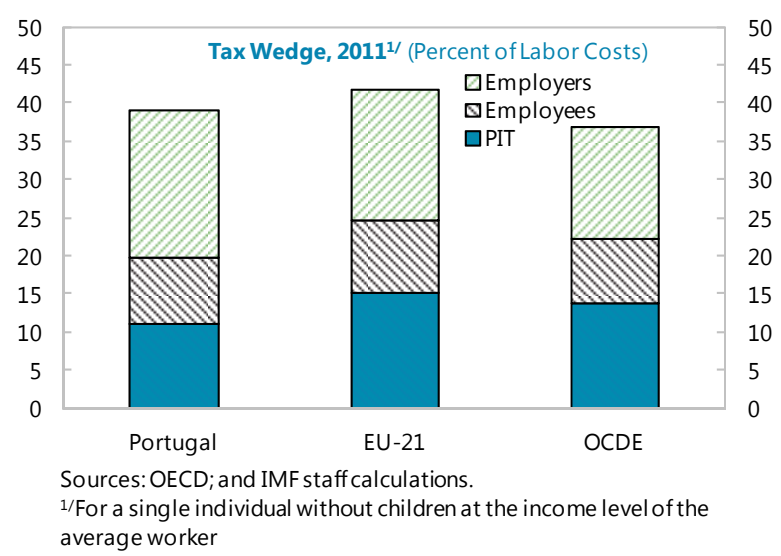
employers' social security contribution (SSC) for low-paid workers, as employment demand tends to be relatively elastic among low-wage earners; and (iii) assessing the scope to broaden the SSC.

\section{Over the medium term, it is possible to continue improving the PIT. Portugal is} one of the few countries that apply a mandatory family unit concept. ${ }^{27}$ This imposes a high marginal tax burden on secondary earners, especially when the spouse earns a high income. It may cause disincentives for labor-market participation or for increasing work activity, especially because secondary earners are found to be relatively elastic in their labor supply. Recognizing this, most countries apply the tax to individual incomes, rather than to family

\footnotetext{
${ }^{24}$ Different papers have shown the use of direct transfers to poorer families as a more effective way to promote equity (Atkinson and Stiglitz, 1976, Deaton and Stern, 1986, Mirrless Review). A study done for Mexico demonstrates that the bulk of the benefits of the VAT zero rate accrues to the better-off. OECD (2010a) mentions that "[D]istributional arguments in favor of VAT rate differentiation may be more persuasive where countries do not have the administrative capacity to provide more direct transfers to poorer households."

${ }^{25}$ A study on UK shows that, if the zero-rating were abolished, the country could raise 0.79 percent of GDP in revenues even after compensating the poor. See www.imf.org/external/np/fad/news/2011/docs/Keen2.pdf.

${ }^{26}$ OECD Taxing Wages (2012), OECD average does not include Chile and Mexico.

${ }^{27}$ In Europe, only Luxemburg and France adopt this principle of mandatory family unit, while Spain, Germany, and Ireland offer the option to declare jointly. All other countries adopt individual taxation.
} 
incomes. Other issues that could be addressed are: (i) reducing fragmentation and simplifying the tax by eliminating the existence of multiple schemes (the general PIT, the extraordinary surcharge, and the solidarity surcharge); (ii) continuing to enlarge the taxable income (for example, some social security incomes - such as maternity leave - are not in the scope of the tax, even if earned by richer taxpayers); (iii) further reducing tax expenditures, in particular on education, health, and housing (given that Portugal's education and health system are publicly provided and deliver universal coverage, tax expenditures in these areas are mainly a regressive policy enjoyed by the higher-income earners); and (iv) reassessing the statutory rate structure in the aftermath of the crisis (at 54 percent, the top rate will be one of the highest in Europe and may encourage tax evasion).
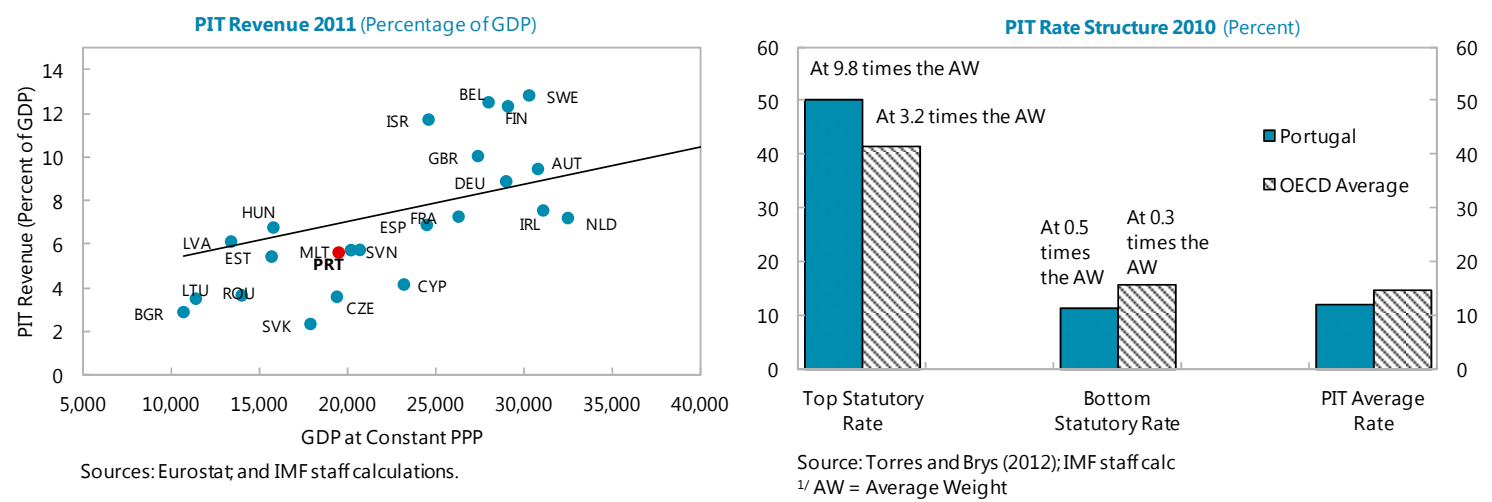

\section{Corporate Income Taxation}

\section{Portugal's corporate income tax rate (CIT) is high relative to its peers. The CIT} rate (31.5 percent) is higher than the European average ( 23.5 percent) and has moved in the opposite direction from peers in recent years. As a result, revenue collections as a share of GDP have been above the European average. Even though it is difficult to establish causality between high rates and a narrow capital base, Portugal has a smaller capital tax base $\mathrm{e}^{28}$ than the regional average (the European capital base range is from 18.7 percent of GDP in Slovenia and about 40 percent of GDP in Ireland and the Netherlands, while Portugal stands at 22.5 percent of GDP). Thus, it may be taxing too much a limited economic base, and likely discouraging its expansion. This policy may reduce incentives to attract FDI. In order to address this problem, rather than reducing the overall rate, there has been a greater tendency in recent years to grant tax incentives. The effect of this has been to reduce the effective rate for some activities, but the policy has been less effective at increasing the total volume of

\footnotetext{
${ }^{28}$ The capital tax base is the denominator of the ITR on capital, and is an approximation of the world-wide capital and business incomes of residents for domestic tax purposes. It comprises the net operating surplus, interests, insurance property income attributed to policy holders, rents on land and dividends for the sectors nonfinancial and financial corporations, households, self-employed, non-profit organizations, general government and rest of the world. For a detailed methodological description, see European Commission (2012), Taxation Trends in the EU.
} 
FDI. ${ }^{29}$ Reasons for the relative ineffectiveness of tax incentives in Portugal may include poor design as well as the temporary and uncertain nature of the benefit.

\section{In addition, the CIT structure is complex-comprising three different taxes that} are not levied on a unified base. These include: the standard CIT, the State surcharge (which has two different rates depending on the profit level), and the Municipal surcharge (which has rates that vary from zero to 1.5 percent across municipalities, and may include a special rate for SMEs). Portugal is one of a few EU countries that levy a CIT at a sub-national government level. Such a tax is not appropriate for local governments, in particular for countries with small

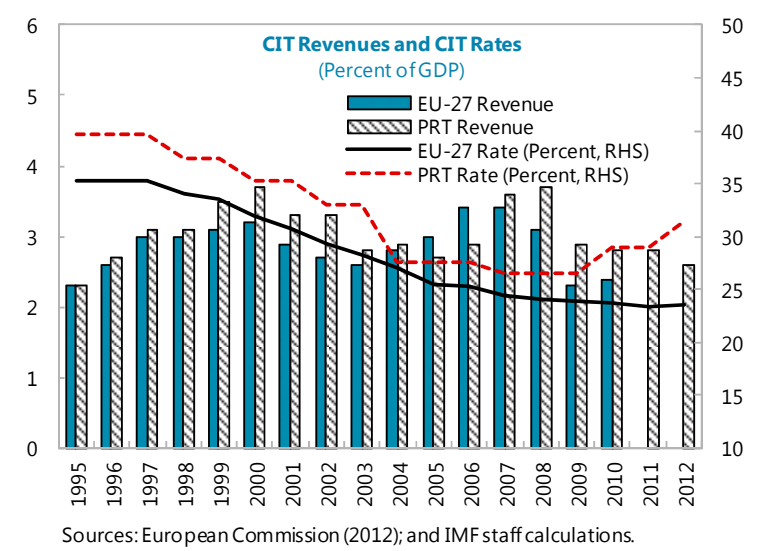
municipalities with high spillover effects. Its base is volatile and it is concentrated in rich jurisdictions. Lisbon alone accounts for 35 percent of total Municipal surcharge while poorer municipalities do not have scope to levy it. The two autonomous regions can also apply reduced CIT rates, a practice that may increase the risk of arbitration and avoidance schemes.

\section{A comprehensive CIT reform aiming at rate reduction, base broadening, and} simplification could support growth. Even though tax incentives could be used as a limited and targeted way of affecting resource allocation, the CIT system should build its advantages by attaining a lower ordinary rate, deep simplification, and stability. A leaner system could benefit from phasing out the Municipal and State surcharges. This would support reducing the overall CIT rate toward European average, while the rate differentiation between the mainland and the regions could be abolished, eliminating the problems posed by levying different rates within the same country on such a volatile base. A simplified regime for SMEs could also be analyzed, in order to facilitate compliance and control. Another important reform, which is already on the government's agenda, is to address the CIT debt bias. ${ }^{30}$ Finally, the international aspects of the CIT design (e.g. transfer pricing rules, the country's double taxation treaties, and holding regimes) could be revised with the view of encouraging investment and modernizing the Portuguese system. The government has recently announced that it will launch a reform along some of these lines, which is seen as a preferable option compared with sporadic interventions on base composition and applicable rates.

\footnotetext{
${ }^{29}$ An important consideration about tax incentives nonetheless is that they cannot make up for deeper constraints on investment such as competitiveness, especially if embedded in a tax structure that is misaligned with international practice.

${ }^{30}$ See Goretti and Souto (2012), SI Chapter III.
} 


\section{Property Taxation}

\section{The reform to be implemented in $\mathbf{2 0 1 3}$ will likely push the Portuguese property} taxation above the European average. Such policy is positive since property taxes seem to have a less adverse impact on the allocation of resources in the economy. It can also impose a higher burden on wealthier households owning more valuable real-estate property, which is a policy recently followed by the government. Moreover, this is a very stable tax base, well suited to local governments. Property tax revenues stood at 1.2 percent of GDP in 2010, already in line with the EU-27 average (1.3 percent of GDP). A medium-term challenge for Portugal could be: to shift the burden from the transaction property tax to the recurrent property tax; and to broaden the base for rural property taxation. Unwinding the distortive transaction tax would likely be feasible only after the ongoing reforms of the recurrent tax stabilize. On the other hand, the taxable value of rural properties has not been reassessed for a long period, resulting in a very low participation in the total recurrent property tax. Increasing rural property taxation could also help promote a more efficient use of land.

\section{Conclusions}

\section{All in all, Portugal faces the significant challenge of completing its fiscal} consolidation effort and enhancing the equity and efficiency of fiscal policy. To reduce public debt to the 80 percent of GDP mark by 2030 , primary spending needs to be reduced by around $33 / 4$ percent of GDP from its current level. Addressing this challenge requires a well-articulated design and successful implementation of specific policies. Crucial questions refer to choosing the appropriate level and composition of taxation and spending, clarifying the options regarding who will pay for and who will benefit from the public sector. The path of an expenditure-led adjustment seems more appropriate, given that the tax effort in Portugal is already aligned with the country's income level. Given the relative regressivity of the existing spending policies in Portugal, there may be scope to reduce spending in some areas while enhancing equity. On the revenue side, even though the space to increase taxes is limited, there are some areas of the tax system that could be reformed to facilitate higher investment. In particular, the existing high tax burden on capital could be recalibrated toward consumption taxes. The reduction of sizable untargeted tax expenditures could generate space for rate reductions in the corporate and personal income taxes. Finally, simplifying the system and improving tax compliance would ensure a level playing field for doing business in Portugal. 


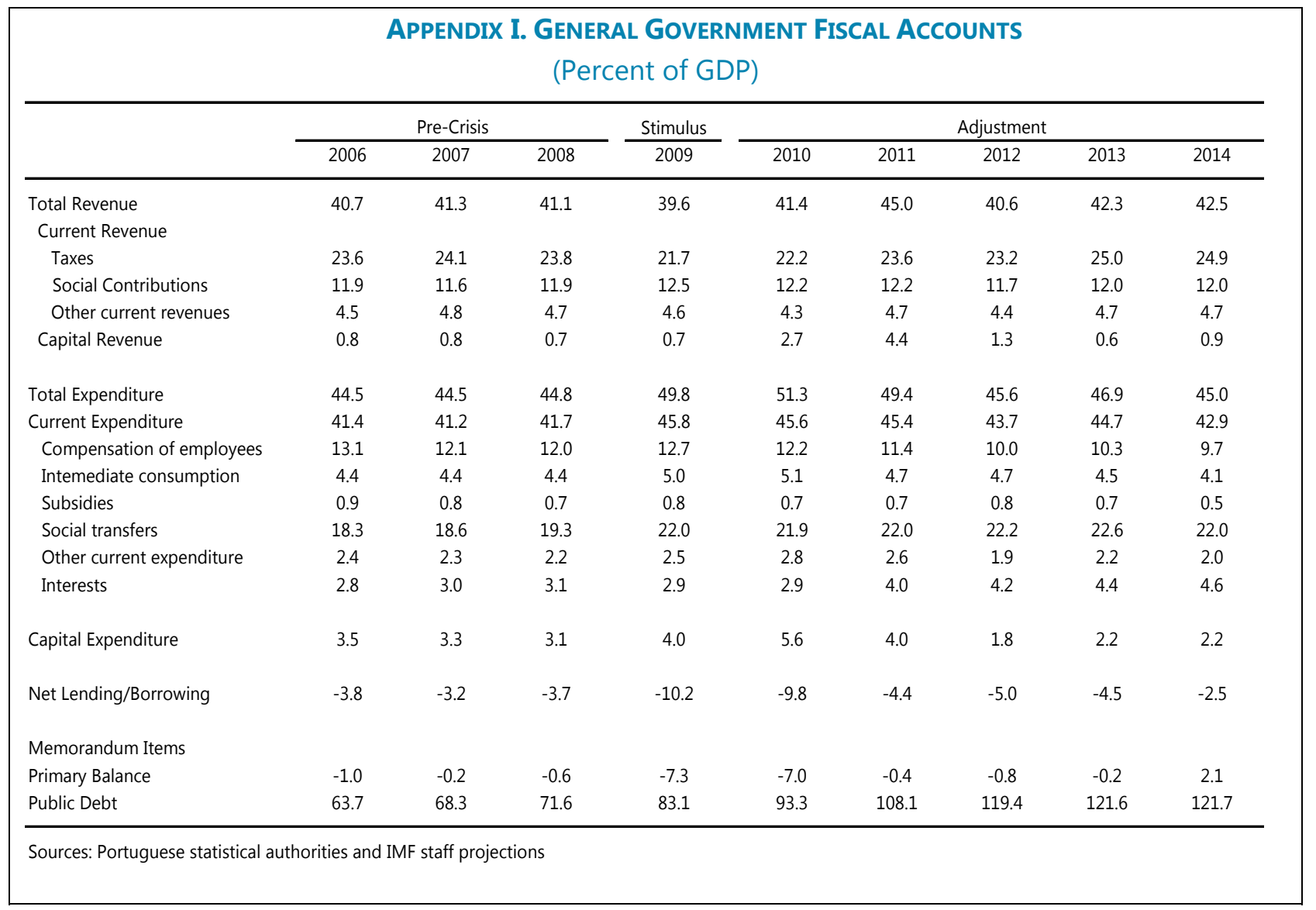


APPENDIX II. EXPENDITURE OUTCOMES
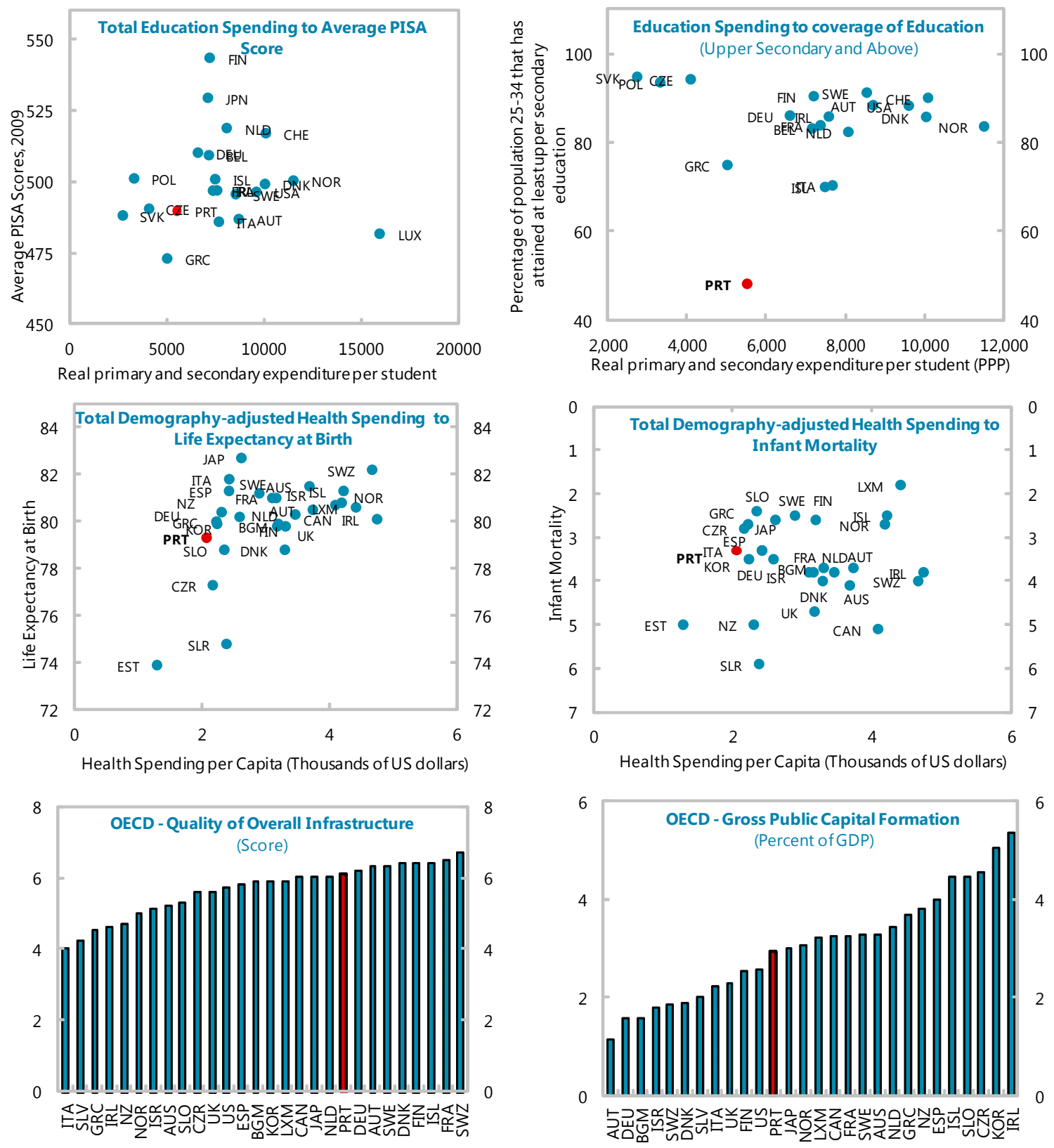

Sources: OECD; Eurostat; and IMF staff calculations. 


\section{REFERENCES}

Alesina, A. et al., 2012, "The Output Effect of Fiscal Consolidations", NBER Working Paper No. 18336, August 2012.

Atkinson, A. B. and J. Stiglitz, 1976, “The Design of Tax Structure: Direct versus Indirect Taxation", Journal of Public Economics 6, pp. 55-75.

Cunha, J. and C. Braz, 2009, "The Main Trends in Public Finance Developments in Portugal: 1986-2008”, Occasional Papers No. 1/2009, Bank of Portugal.

Deaton, A. and N. Stern, 1986, "Optimally Uniform Commodity Taxes, Taste Differences and Lump-Sum Grants”, Economics Letters, 20 (3), pp. 263-66.

European Commission (DG ECFIN) and the Economic Policy Committee (AWG), 2012, "The 2012 Ageing Report: Economic and budgetary projections for the EU27 Member States (2010-60)," European Economy 2.

European Commission, 2011, "Tax Reforms in EU Member States 2011 - Tax Policy Challenges for Economic Growth and Fiscal Sustainability", European Economy No. 5/2011.

European Commission, 2012, “Taxation Trends in the European Union”, 2012 Edition.

Giordano et al., 2011, The Public Sector Pay Gap in a Selection of Euro Area Countries, ECB Working Paper 1406/2011.

Goretti, M. and M. Souto, 2012, "Portugal's Corporate Deleveraging" in Portugal: Selected Issues, http://www.imf.org.

Gupta, A., 2007, "Determinants of Tax Revenue Efforts in Developing Countries", IMF Working Paper 07/184, July 2007.

International Monetary Fund, World Economic Outlook, "Recovery, Risk, and Rebalancing", October 2010, IMF, Washington, DC.

International Monetary Fund, 2010, "Macro-fiscal Implications of Health Care Reforms in Advanced and Emerging Economies," IMF Policy Paper (Washington).

International Monetary Fund, 2011, "The Challenge of Public Pension Reform in Advanced and Emerging Economies," IMF Policy Paper (Washington).

Mirrless Review, available online at: http://www.ifs.org.uk/mirrleesReview 
Murphy, R., 2012, "Closing the European Tax Gap", Report for Group of the Progressive Alliance of Socialists and Democrats in the European Parliament, Tax Research LLP, 2012.

OECD, 2008, "Growing Unequal? Income Distribution and Poverty in OECD Countries", October 2008, OECD Publishing.

OECD, 2010a, "Choosing a Broad Base - Low Rate Approach to Taxation", OECD Tax Policy Studies, No. 19, OECD Publishing.

OECD, 2010b, “Tax Policy Reform and Economic Growth”, OECD Tax Policy Studies, No. 20, OECD Publishing.

OECD, 2011, "Tax Administration in OECD and Selected Non-OECD Countries:

Comparative Information Series (2010)", Center for Tax Policy and Administration.

OECD, 2012, “Taxing Wages 2011”, OECD Publishing.

Pessino, C. and R. Fenochietto, 2010, “Determining countries' tax effort", Revista de Economia Publica, 195 (4/2010), Instituto de Estudios Fiscales.

PricewaterhouseCoopers and World Bank, 2012, "Paying Taxes 2013 - The Global Picture", available online at: http://www.pwc.com/payingtaxes

Schneider, F., 2011, "The Shadow Economy in Europe, 2011—using electronic payment systems to combat the shadow economy", A.T. Kearney, 2011.

Torres, C., K. Mellbye and B. Brys, 2012, “Trends in Personal Income Tax and Employee Social Security Contribution Schedules", OECD Taxation Working Papers, No. 12, OECD Publishing. 